\title{
DEVELOPMENT OF A MACHINE TOOL SYSTEM WHICH UTILIZES ULTRASONIC THICKNESS GAGING TO MACHINE THE WALL OF CYLINDERS TO CONSTANT THICKNESS
}

L. E. Carey

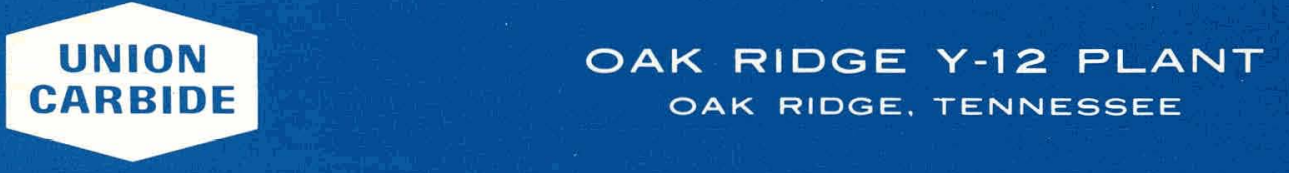




\section{DISCLAIMER}

This report was prepared as an account of work sponsored by an agency of the United States Government. Neither the United States Government nor any agency Thereof, nor any of their employees, makes any warranty, express or implied, or assumes any legal liability or responsibility for the accuracy, completeness, or usefulness of any information, apparatus, product, or process disclosed, or represents that its use would not infringe privately owned rights. Reference herein to any specific commercial product, process, or service by trade name, trademark, manufacturer, or otherwise does not necessarily constitute or imply its endorsement, recommendation, or favoring by the United States Government or any agency thereof. The views and opinions of authors expressed herein do not necessarily state or reflect those of the United States Government or any agency thereof. 


\section{DISCLAIMER}

Portions of this document may be illegible in electronic image products. Images are produced from the best available original document. 
Reference to a company or product name does not imply approval or recommendation of the product by Union Carbide Corporation or the U.S. Atomic Energy Commission to the exclusion of others that may meet specifications.

Printed in the United States of America. Available from National Technical Information Service

U.S. Department of Commerce

5285 Port Royal Road, Springfield, Virginia 22151

Price: Printed Copy \$4.00; Microfiche \$1.45

This report was prepared as an account of work sponsored by the United States Government. Neither the United States nor the United States Atomic Energy Commission, nor any of their employees, nor any of their contractors, subcontractors, or their employees, makes any warranty, express or implied, or assumes any legal liability or responsibility for the accuracy, completeness or usefulness of any information, apparatus, product or process disclosed, or represents that its use would not infringe privately owned rights. 


\title{
DEVELOPMENT OF A MACHINE TOOL SYSTEM WHICH UTILIZES ULTRASONIC THICKNESS \\ GAGING TO MACHINE THE WALL OF CYLINDERS TO CONSTANT THICKNESS
}

\author{
L. E. Carey
}

Fabrication Systems Development Department Y-12 Development Division

Adapted from a Thesis that was Presented for the Master of Science Degree at the University of Tennessee

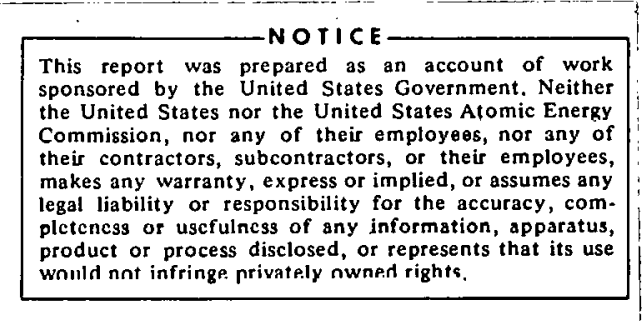

\section{Oak Ridge Y.12 Plant}

P.O. Box Y, Oak Ridge, Tennessee 37830

Prepared for the U.S. Atomic Energr Commission Under U.S. Government Contract W.7405eng.26 


\begin{abstract}
A machine-tool system has been developed which utilizes ultrasonic gaging to machine the walls of cylinders to a constant thickness. The machining system is used to machine the outside surface of a cylinder after the inner surface has been machined by conventional methods. One ultraonsic transducer and two thickness gages are used to continuously measure the distance to the inner surface of a cylinder. The pulsed-echo technique is used to measure thicknesses, and the output of the thickness gages continuously controls the position of the tool. A fast-response electrohydraulic servo swiftly moves the cutting tool in response to the movement of the back surface of the rotating cylinder. The cutting tool is continuously controlled to maintain constant distance from the inner surface of the cylinder as it rotates in a lathe. The front surface of the cylinder is machined identically to the back surface, and the cylinder thus has a wall of uniform thickness.
\end{abstract}




\section{CONTENTS}

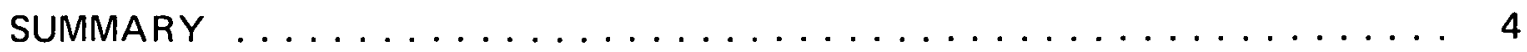

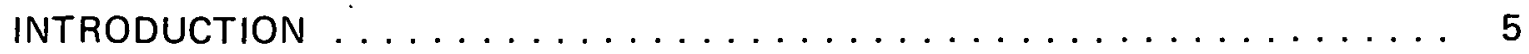

MACHINING SYSTEM TO PRODUCE CONSTANT-WALL CYLINDERS $\ldots \ldots \ldots$

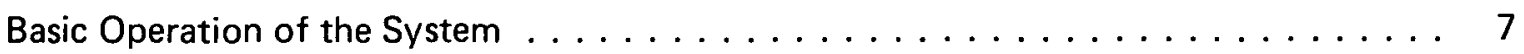

A Need for Cylinders Having a Uniform Wall Thickness . . . . . . . . . 7

Secondary Design Requirements . . . . . . . . . . . . . . 8

Operation of the Machining System $\ldots \ldots \ldots \ldots \ldots$

Methods to Ultrasonically Measure Thickness . . . . . . . . . . . . . . . 9

Characteristics of Ultrasonic Sound . . . . . . . . . . . . . . . . 11

Focused Ultrasonic Probes . . . . . . . . . . . . . . . . . 11

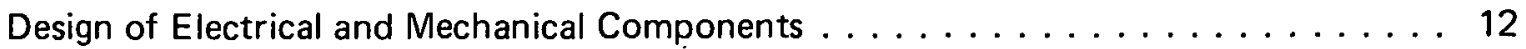

Modifications of the Thickness-Readout Modules . . . . . . . . . . . . 12

Addition of a Slave Receiver and a Second

Thickness- Readout Module . . . . . . . . . . . . . . . . . . . 15

Measurement of Distance to the Inner Surface of a Part . . . . . . . . . 16

Calibration of the Two Thickness-Readout Modules . . . . . . . . . . . 17

Hydraulic and Mechanical Components . . . . . . . . . . . . . . 20

System Frequency Response and Compensation . . . . . . . . . . . . . . . 24

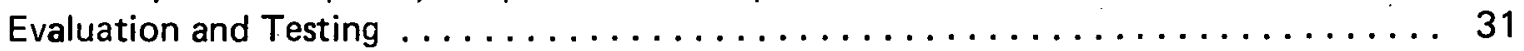

Accuracy of Ultrasonic-Thickness Measurements . . . . . . . . . . . . . . . . 31

Material Characteristics Affecting Ültrasonic-

Thickness Measurements . . . . . . . . . . . . . . . . . 32

Sources of Error Affecting the Machining Accuracy . . . . . . . . . . . . . . 39

Machining Tests to Evaluate the System Performance . . . . . . . . . . . . . 45

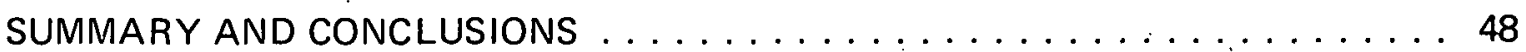

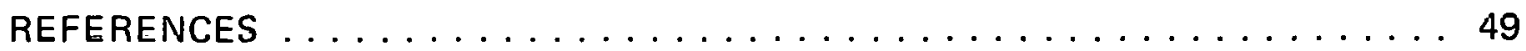

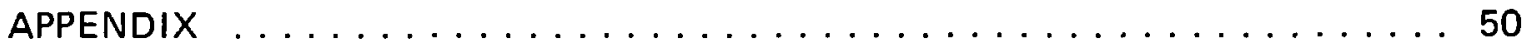

The Sperry Reflectoscope System . . . . . . . . . . . . . . . 50

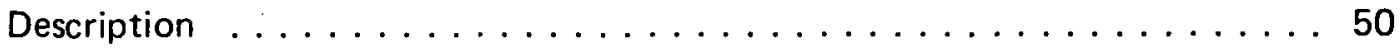

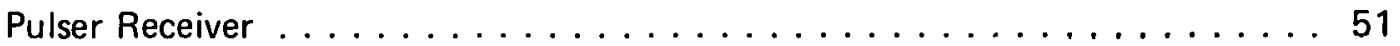

Thickness-Readout Module . . . . . . . . . . . . . . . 51

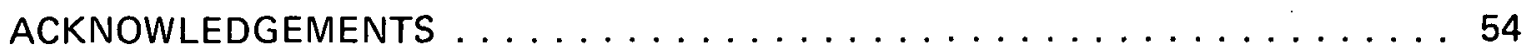




\section{SUMMARY}

A closed-loop feedback control system was developed at the Oak Ridge Y-12 Plant(a) to machine, the walls of cylinders to a constant thickness. The major elements of the system consist of an electrohydraulic servo, an ultrasonic transducer, and a reflectoscope with associated electronics. The reflectoscope system contains two thickness-readout modules which measure two different thicknesses concurrently and thereby provide a control signal to the servo.

Investigation revealed that the material structure of metals can seriously affect the accuracy of ultrasonic thickness: measurements. Metallurgical tests on samples of Type 6061 aluminum indicated that inclusions, segregations, and variations in grain size were present in the matrix of the metal. Comparison between conventional and ultrasonic wall-thickness measurements of Type 6061 aluminum cylinders having a nominal thickness of 0.2 inch revealed that the ultrasonic measurements had inaccuracies as large as 0.008 inch. Inaccuracies of varying magnitudes were also observed in other metals. A uranium alloy was found in which the ultrasonic thickness measurements were accurate to within 500 microinches. Cylinders made from this alloy were used to test and evaluate the machining capabilities of the system.

(a) Operated by the Union Carbide Corporation's Nuclear Division for the US Atomic Energy Commission. 


\section{INTRODUCTION}

Ultrasonic thickness gages have been generally used to measure thicknesses of different materials including metals (both magnetic and nonmagnetic), plastics, and glass. They are extremely useful when only one surface of a component is accessible. Large sheets of metal, closed metal storage tanks, ship hulls, and reactor process tubes are only a few of the applications where ultrasonic thickness gaging has been widely used. (1)

The machining industry has also utilized ultrasonic thickness gaging to measure cross-sectional dimensions of machined parts while they are still on the work table of a machine tool. If any dimensional errors are present, the part can be remachined to obtain the correct part dimensions. The Follard Aircraft Company (1) has used the Visigage with success to measure the thickness of skin panels for the wings of their Gnat trainer aircraft between machining operations on a heavy-duty routing machine. The lower side of the part was inaccessible, and the gage was used to measure thickness from the upper side of the part.

Another area of application for ultrasonic thickness gaging is the field of machine tool control. Goldman (2) developed the idea of controlling the cutter of a milling machine, as illustrated in Figure 1. In this case, the cutter is milling a slot in a block to specified size. The tool, the block, and the ultrasonic probe are submerged in a bath of oil or water. The ultrasonic-thickness gage continuously measures the critical dimension of the block, and the output of the gage controls the position of the machine table. If the block is thicker than a selected thickness, the gage causes the block to move into the cutting tool at a continuous

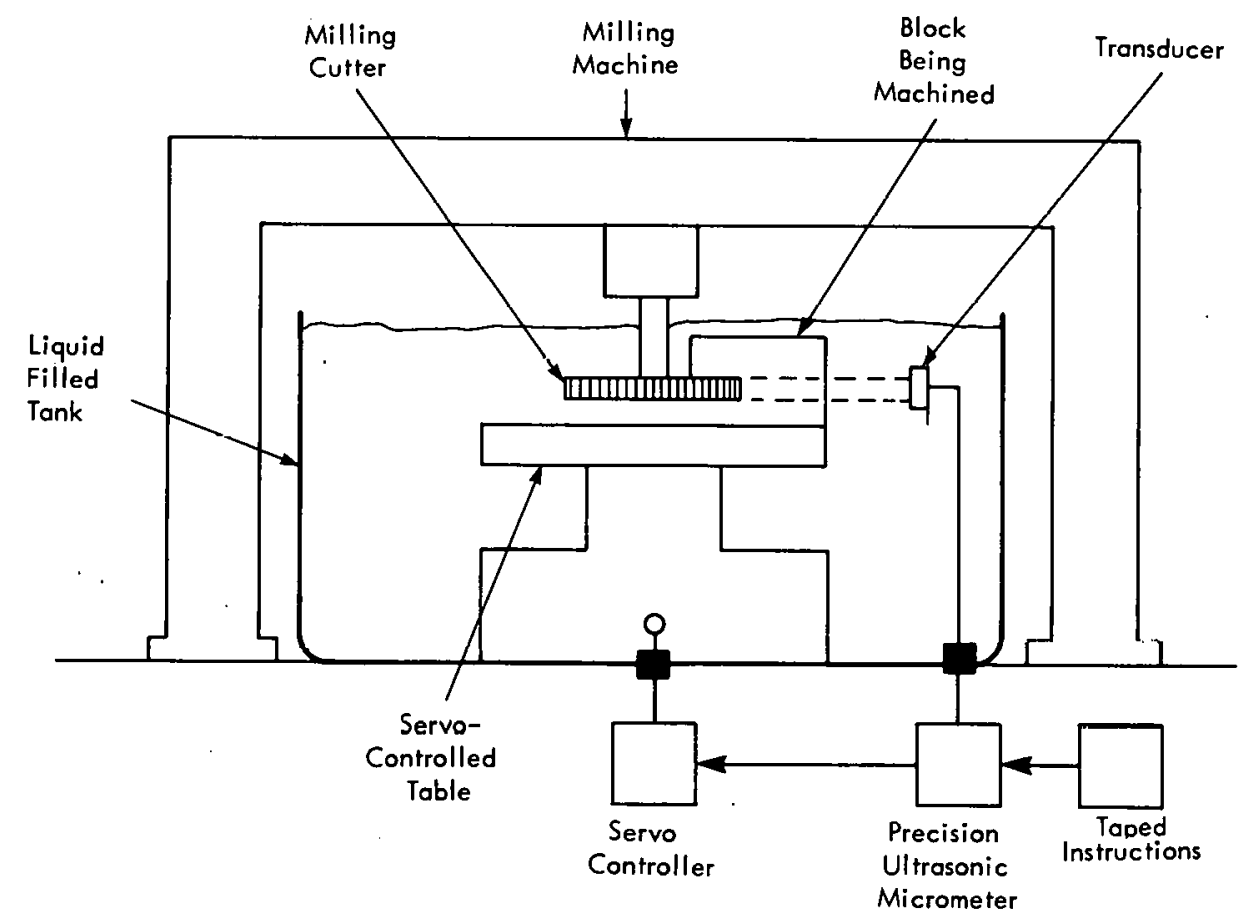

Figure 1. AN ULTRASONIC MICROMETER TO CONTROL A MILLING MACHINE. (From Goldinan (2) 
rate. When the measured thickness equals the desired thickness, the movement of the block is stopped.

The milling machine operating, as described, is a closed-loop servo system. The machining accuracy of such a system is dependent primarily on the accuracy of the thickness gage. If the cutting tool wears or if the machine adjustments are incorrect, the gage senses these errors and automatically repositions the part to correct for the errors. The milling machine is thus a positioning device and a power source. The ultrasonic thickness gage gives the milling machine the capability. of milling accurate parts. The milling machine just described is basically limited to milling slots in a part, but the concept of using ultrasonic thickness gaging can be extended to machines having several axes of controlled motion. Complex parts having very accuracte dimensions can thus be machined.

Battelle Memorial Institute(3) at the Pacific Northwest Laboratory has developed a prototype milling system to machine very flat and accurate plates. The milling system uses an ultrasonic micrometer to control an electrospark discharge machine (EDM). The micrometer uses the ultrasonic pulse-interference technique to measure thickness, and the output of the micrometer controls the EDM tool the correct distance from a plate being milled. If the thickness of the plate is larger than the desired thickness, the EDM is in a normal mode of operation and mills material from the plate. When the plate thickness equals or is less than the desired thickness, the EDM tool is retracted from the part. The system has been used to mill aluminum plates to within \pm 100 microinches of a constant thickness.

The wall-thickness machining system and the Battelle Institute milling system are two very significant accomplishments in closed-loop machine-tool control systems. Both systems use ultrasonic thickness gages to control a machining process to manufacture parts having tighter dimensional tolerances than were previously possible with conventional machining technology. Each system is significantly different in its fundamental operating characteristics. The Battelle machining system requires a slow speed of movement in response to the ultrasonic gage; the EDM tool mills material from one spot on the plate. When the desired thickness is obtained, the EDM moves to an adjacent spot and continues to mill material.

The constant-wall-thickness machining system presented in this report requires a fast speed of movement in response to the ultrasonic gage. The cylinder is mounted in a lathe and is machined with a single-point tool at several hundred revolutions per minute (rpm). The tool is required to move small distances (less than $0.010 \mathrm{inch}$ ) at very fast speeds in order to cut the outside surface of the cylinder identically to the inside surface. As the cylinder turns, the tool slowly travels the length of the cylinder, machining the outer surface of the cylinder. 


\section{MACHINING SYSTEM TO PRODUCE CONSTANT-WALL CYLINDERS}

\section{BASIC OPERATION OF THE SYSTEM}

\section{A Need for Cylinders Having a Uniform Wall Thickness}

No known industrial technique can machine a cylinder having a wall of uniform thickness where the wall-thickness tolerance is smaller than the sum of the tolerances for the inner and outer surfaces. Conventional machining of cylinders requires two distinct setup and machining operations in order to cut the inner and outer surfaces. The second setup and fixturing operation introduces slight misalignment between the part and the machine tool because of the difficulty in precisely realigning the part. In the process of centering the part, the chuck jaws may distort the part from its normal shape. The part also expands and contracts because of temperature variations during and between the two machining operations. The machine tool-path has inaccuracies which cause errors in the part surfaces.

On a precision lathe, these errors are minimized, but it is difficult to completely eliminate them. Parts may be machined having very small dimensional errors and meet the tolerances for the inner and outer surfaces. But, because the surface errors may constructively add in places, the parts may still fail to meet the wall-thickness tolerance.

Figure 2 pictorially illustrates how misalignment and distortion of the part in the lathe causes the wall thickness of a cylinder to be nonconstant. View a shows a cylinder whose inner and outer surfaces were machined to be true circular sırfaces, but the part was slightly out of alignment. As a result, the wall thickness is not constant around the circumference of the part. View b shows another cylinder which was distorted by the chuck jaws of the lathe as the outer surface of the part was being machined. Even though the outer surface was machined to be a true circular surface, the wall thickness of the part is definitely nonuniform.

To meet the need for machining cylinders to uniform wall thicknesses, the ultrasonically controlled

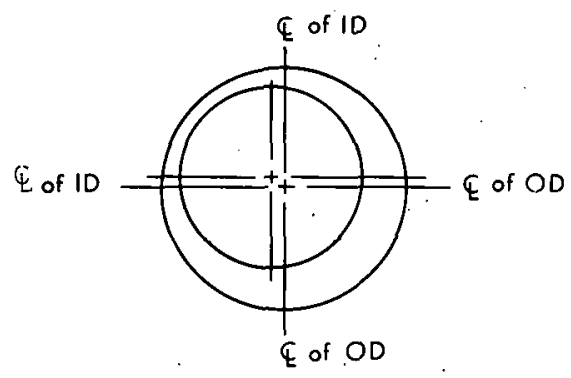

(a) Misaligned Cylinder Machined Conventionally.

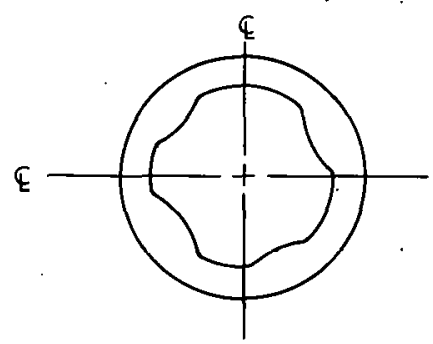

(b) Distorted Cylinder Machined Conventionally.

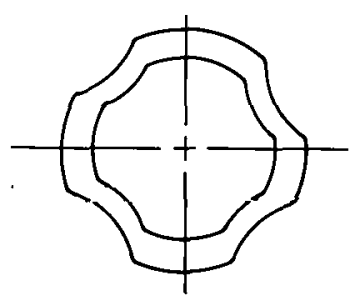

(c) Distorted Cylinder Machined with the WallThickness Machining System.

Figure 2. TYPICAL CYLINDERS MACHINED CONVENTIONALLY AND WITII TIIC WALL-TIIICICNESS MACHINING SYSTEM. 
wall-thickness machining system was developed. The inner surface of the cylinder is first machined on a lathe, and then the part is transferred to the wall-thickness machining system. This system uses the inner surface of the part as a datum surface from which to position the cutting tool to machine the outer surface. View c, Figure 2, shows a cylinder which was misaligned and distorted in the chuck jaws of the lathe. The system machined the outer surface identically to the inner surface of the cylinder. The inner and outer surfaces are not truly circular, but the wall thickness of the cylinder is constant around the circumference of the part.

\section{Secondary Design Requirements}

Secondary design requirements for the wall-thickness machining system require that the system be capable of machining both magnetic and nonmagnetic metals. This criterion excludes any magnetic probes such as a magentic-induction gage for measuring thickness. Also the probe must be a noncontacting probe and be easily utilized from the outside of the part. Ultrasonic-thickness gaging was chosen as the measuring system because it satisfies the design criteria. It can easily measure the thickness of a part from the outside surface. It can also measure a wide variety of materials, both magnetic and nonmagnetic.

The machining system is to be mounted on a small $12 \times 30$-inch Hendley lathe. Cylinders having diameters from 6 to 12 inches and wall thicknesses from 0.05 to 0.5 inch are to be machined at rotational speeds up to $500 \mathrm{rpm}$. In order to machine cylinders rotating at such speeds, the control system must swiftly and accurately move the cutting tool. The control systemthus is required to have a large DC gain and an upper bandwidth of several hundred hertz.

\section{Operation of the Machining System}

Figure 3 is a block diagram of the ultrasonically controlled wall-thickness machining system. It is a tast-response electrohydraulic servo containing an ultrasonic transducer and a Sperry Reflectoscope system in the feedback loop. A frequency-compensation network, a high-gain amplifier, a servo amplifier, a servo valve, and a hydraulic cylinder are the major elements in the forward loop of the the system.

The function of the frequency compensation network is to broaden the bandwidth and give the system the frequency response needed to respond to fast-revolving parts. The developed control system has a bandwidth of $200 \mathrm{~Hz}$. and is able to machine cylinders turning at speeds up to $500 \mathrm{rpm}$.

The high-gain amplifier allows the operator to adjust the system gain so that the system has a rapid speed of response and achieves the desired amount of overshoot. The servo amplifier provides power to drive the servo valve, and the hydraulic cylinder moves the cutting tool and ultrasonic probe as a single unit.

The control system operates in the following manner. The reflectoscope system containing two thickness-readout modules (TRMs) measures the distance to the back surface of the cylinder being machined. The hydraulic cylinder positions the cutting tool and ultrasonic probe the desired distance from the back surface of the part. Any changes in the position of 


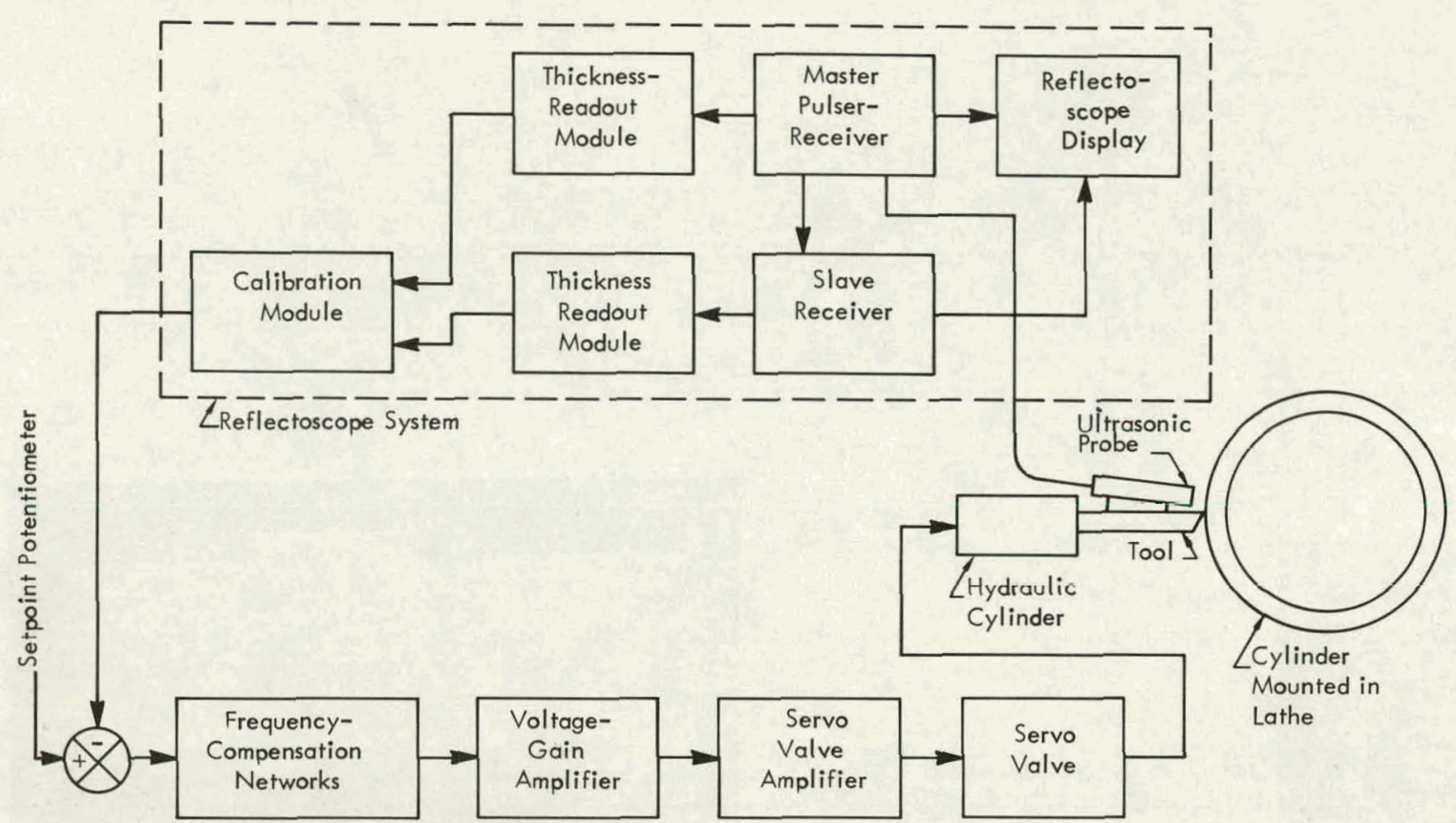

Figure 3. PRINCIPAL COMPONENTS OF THE WALL-THICKNESS MACHINING SYSTEM.

the back surface are sensed by the TRMs as the cylinder rotates and thus provide an error voltage which is applied to the servo valve. As the part is being machined, the system continually positions the tool the desired distance from the back surface. The front surface of the part is thus machined identically to the back surface, and the cylinder has a uniform wall thickness.

Figure 4 provides a view of the developed wall-thickness machining system mounted on the Hendley lathe. Also shown are the servo valve, hydraulic cylinder, tool and tool holder, the ultrasonic probe and probe housing, and the coolant line. The Sperry Reflectoscopesystem, seen in Figure 5, contains two pulser receivers, two thickness-readout modules, and two other associated modules. A view of the frequency-compensation networks, the high-gain amplifier, and the scrvo amplifier is given in Figure 6.

\section{Methods to Ultrasonically Measure Thickness}

Several methods are frequently used to ultrasonically measure the thickness of materials. One technique $(1)$ is to detect a mechanical resonance in a material of unknown thickness. By varying the frequency of ultrasonic energy entering the material, the resonant condition is detected by a sharp increase in power going to the ultrasonic crystal oscillator.

A second method for measuring thickness, the pulsed-interterence technique, $(3)$ depends upon the interference patterns created when bursts of ultrasonic sound waves interfere with each other. Basically, a burst of ultrasonic waves reflected from the front surface of a part will interfere with the waves which enter the part and are reflected from the back surface. When the part is an integral number of half-wavelengths thick, the waves will interfere destructively, and a characteristic null pattern may be observed on an oscilloscope. By varying the frequency of the ultrasonic signal oscillator until the null pattern is achieved, the thickness of a material can be measured. 


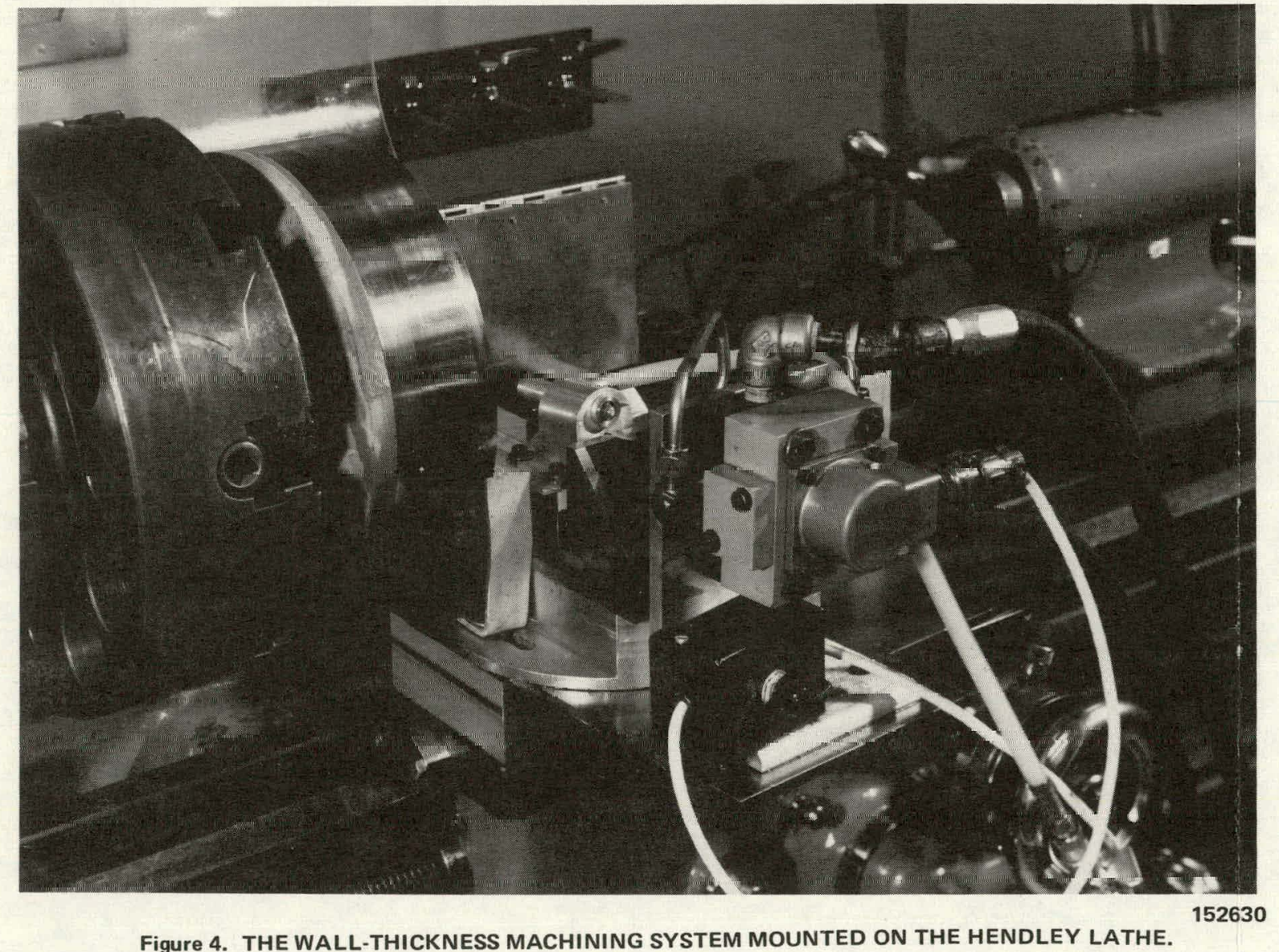

Figure 4. THE WALL-THICKNESS MACHINING SYSTTEM MOUNTED ON THE HENDLEY LATHE.

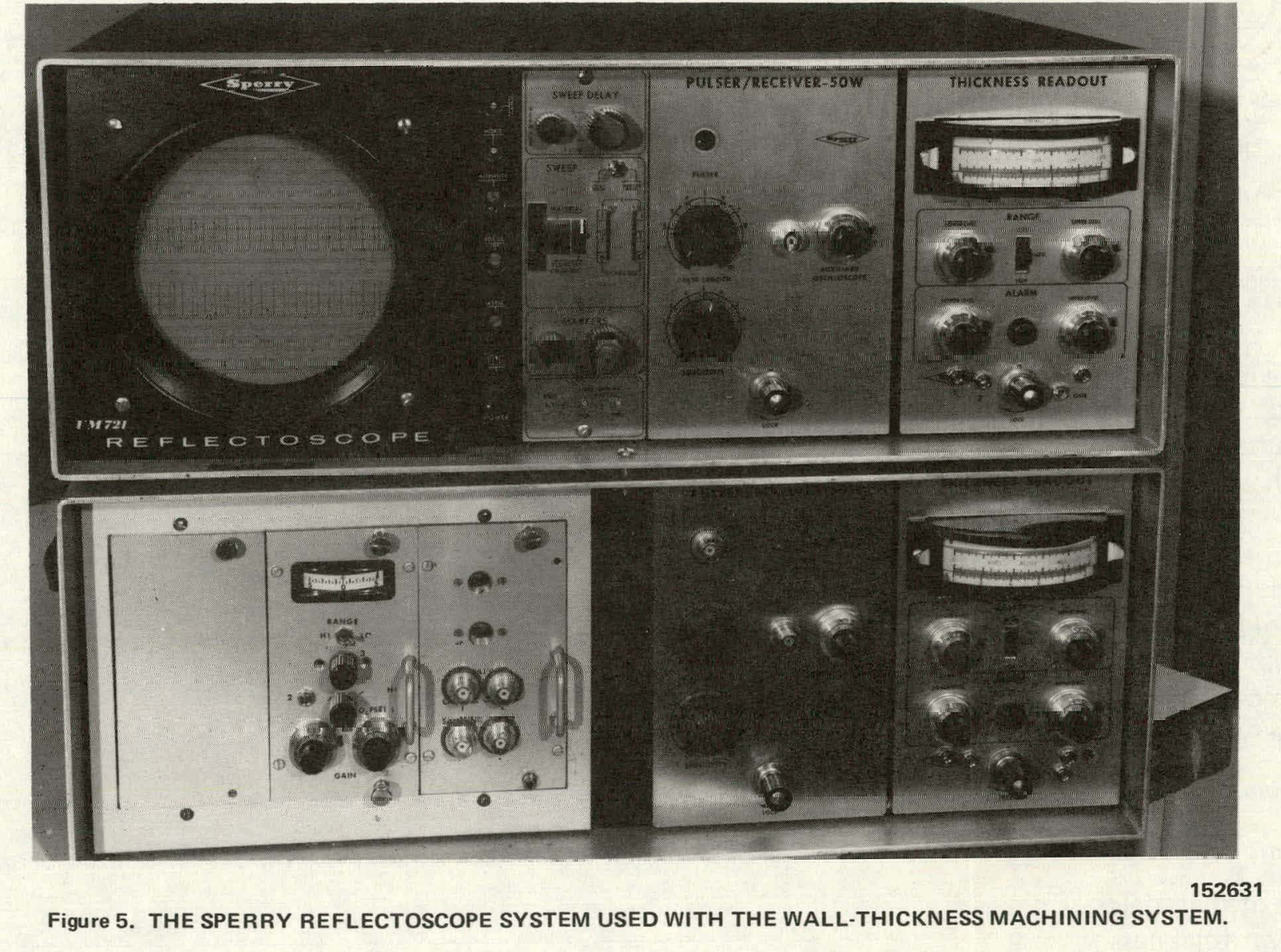

Figure 5. THE SPERRY REFLECTOSCOPE SYSTEM USED WITH THE WALL-THICKNESS MACHIIING SYSTE2.

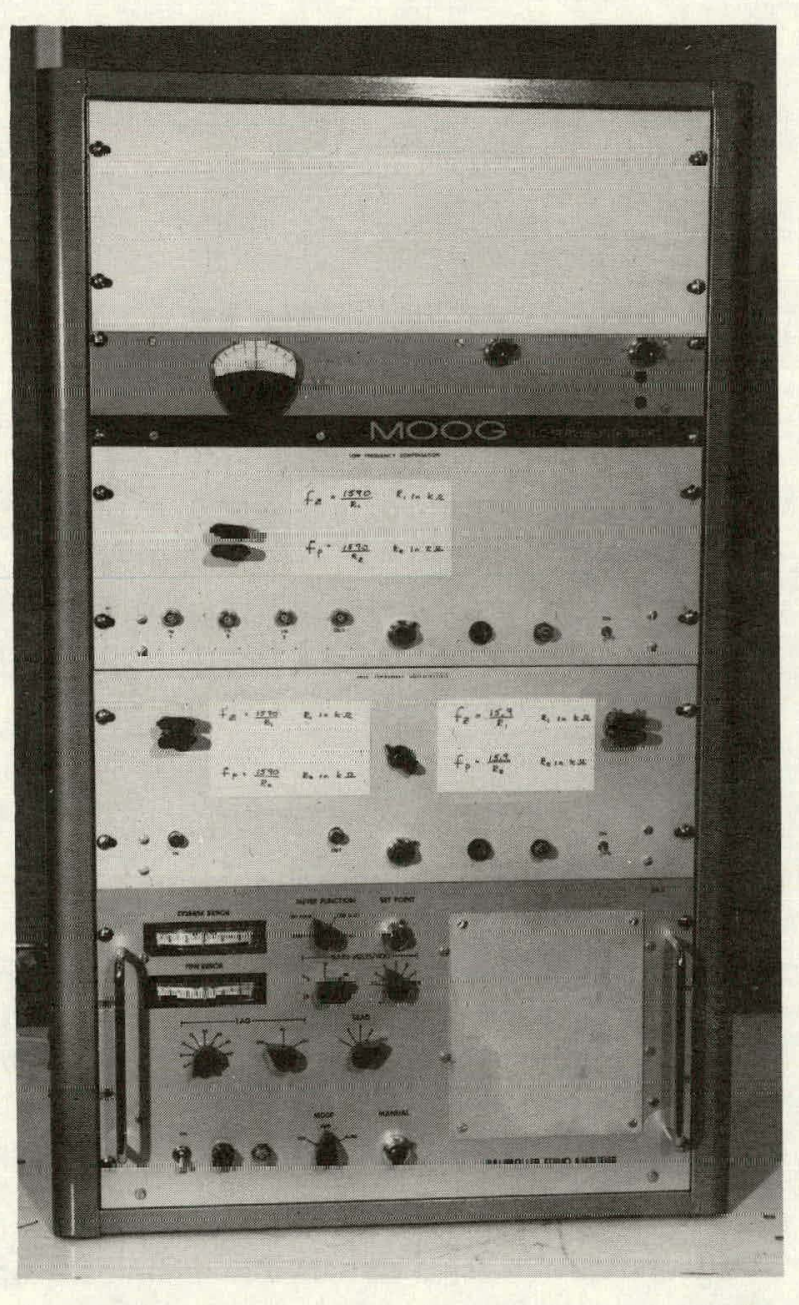

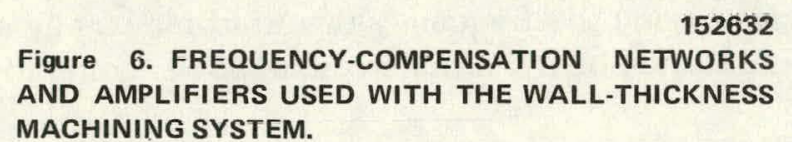


The third method of measuring thickness is the pulse-echo technique. (4) A pulse of ultrasonic sound is transmitted toward a part of unknown thickness. Reflections of the ultrasonic pulse occur at the front and back surfaces of the part. Reflected ultrasonic pulses are detected by the ultrasonic probe. The thickness is determined by measuring the time period between ultrasonic pulses reflected from the front and back surfaces of the part.

High-frequency ultrasonic sound is coupled through a liquid medium to a part being ultrasonically tested because it is severely attenuated in air transmission. (4) When a contact probe is used, a film of oil is placed on the part and the probe is tightly pressed against the part to form a good coupling seal. When an immerision probe is used, both the probe and part are submerged in a liquid, usually water or a specially prepared oil.

Techniques for immersion testing of parts have been developed which do not require the part to be submerged in a liquid tank. One basic technique ${ }^{(2)}$ is to mount the ultrasonic probe in a tube or housing through which the coupling liquid is flowing. The liquid flows out the end of the tube onto the part, coupling the ultrasonic sound to the part. The liquid may be caught in a drip pan to avoid a messy operation. This technique has been successfully used on large parts and structures, but it is applicable to many other situations where it is not practical to submerge the part in a liquid tank.

\section{Characteristics of Ultrasonic Sound}

The characteristic pattern of ultrasonic sound radiated from a driven ultrasonic probe is composed to two zones of energy. (5) The Fresnel zone, or near field, exists close to the probe and contains many areas of high and low energy as the ultrasonic sound beam is in the process of forming a wave front. The Fraunhofer zone, or far field, exists farther away from the probe and contains a homogeneous and well-defined sound beam. In immersion testing, the sound energy used is primarily that of the far field.

Where it is possible, it is desirable to perform ultrasonic-thickness measurements with the part positioned in the far field. In this region, the beam is well defined and the thickness measurement is not influenced by the undulations of the near field. However, when using an unfocused ultrasonic probe, it is not always possible or convenient to position the part in the far field. For example, when using a 3/8-inch-diameter, $15-\mathrm{MHz}$, nonfocused ultrasonic probe, the far field is 9 inches from the probe. In order to measure a 1/4-inch-thick aluminum part and use the far zone, the water path is excessive, and the measurement is made at a shorter and more convenient distance by using the undesirable near field of the ultrasonic sound beam.

\section{Focused Ultrasonic Probes}

The focused ultrasonic probe offers a solution to the problem of long water paths. (5) Through the use of an acoustic lens, the ultrasonic-beam pattern can be manipulated to provide definite advantages. With these lenses, the near and far fields of the ultrasonic beam are shifted toward the ultrasonic probe. The far field is now at the focus point of the acoustic lens. For example, when using a 3/8-inch-diameter, $15-\mathrm{MHz}$, medium-focus ultrasonic probe, the far field is 2.2 inches from the probe. When measuring a $1 / 4$-inch 
aluminum part, the water path should be 1.2 inches in order to keep the part positioned in the far zone of the ultrasonic sound beam. Different lenses may be used to vary the focal length of an ultrasonic probe. Through the use of focused ultrasonic probes, the sensitivity, resolution, and directivity of the ultrasonic testing system are enhanced.

Ultrasonic probes are composed of materials which convert electrical energy into sound energy and conversely. Some materials having this property are lithium sulfate, lead metaniobate, lead zirconate, and quartz crystal. Two different materials may be used in an ultrasonic probe to give it the characteristics or properties of both materials for a special application.

Ultrasonic probes are available in a wide range of frequencies from 0.5 to $25 \mathrm{MHz}$. Some applications require a low-frequency, large-diameter ultrasonic beam for deep penetration into metal. For other applications, a high-frequency, small-diameter beam is necessary for detecting minute defersts.

\section{DESIGN OF ELECTRICAL AND MECHANICAL COMPONENTS}

\section{Modifications of the Thickness-Readout Modules}

Design innovations and modifications to existing equipment were required in the development of the ultrasonically controlled wall-thickness machining system. Three major circuit modifications are incorporated into the thickness-readout modules (TRMs) used in the reflectoscope system. The first modification is a video-signal-conditioner printed-circuit board, the second modification is a low-and-high-thickness generator board and a mode-selector switch, and the third modification is the addition of a sample-and-hold module. Figure 7 is a block diagram of a thickness-readout module containing the modifications. Figure 8 shows the typical voltage waveforms of the modified TRM during normal operation of the unit. Typically, an ultrasonic signal seen on the cathode-ray tube (CRT) display of the reflectoscope is a collection of pulses containing a large-amplitude primary pulse and several smaller, secondary pulses. As the sensitivity of the pulser receiver (PR) is increased, the secondary pulses increase in amplitude until they equal the amplitude of the primary pulse. As the sensitivity is decreased, the secondary pulses decrease in amplitude and disappear, and only the large-amplitude primary pulse remains. The sensitivity is optimally adjusted so that the ultrasonic signals consist of the large-amplitude primary pulses, and the secondary pulses are small in amplitude or nonexistent.

The thickness-readout module measures the time period between two ultrasonic signals in making a thickness measurement. Occasionally, the module incorrectly measures the time period between the primary and a large secondary pulse of the same ultrasonic signal. This phenomenon is called "misgating" and is evident on the CRT display as the gate signal terminates on the first rather than on the second ultrasonic signal. This condition may be corrected by adjusting the pulser-receiver sensitivity to reduce the amplitude of the secondary pulse.

Another phenomenon causing misgating is when the thickness measurement does not terminate on the second ultrasonic signal because its amplitude is too small. This condition is evident on the CRT display as the gate signal continues to the extreme right side of the 
display. Adjustment of the sensitivity potentiometer may correct this condition by increasing the amplitude of the ultrasonic signals. At times, it is very difficult to adjust the sensitivity of the PR without having the TRM misgate either one way or the other.

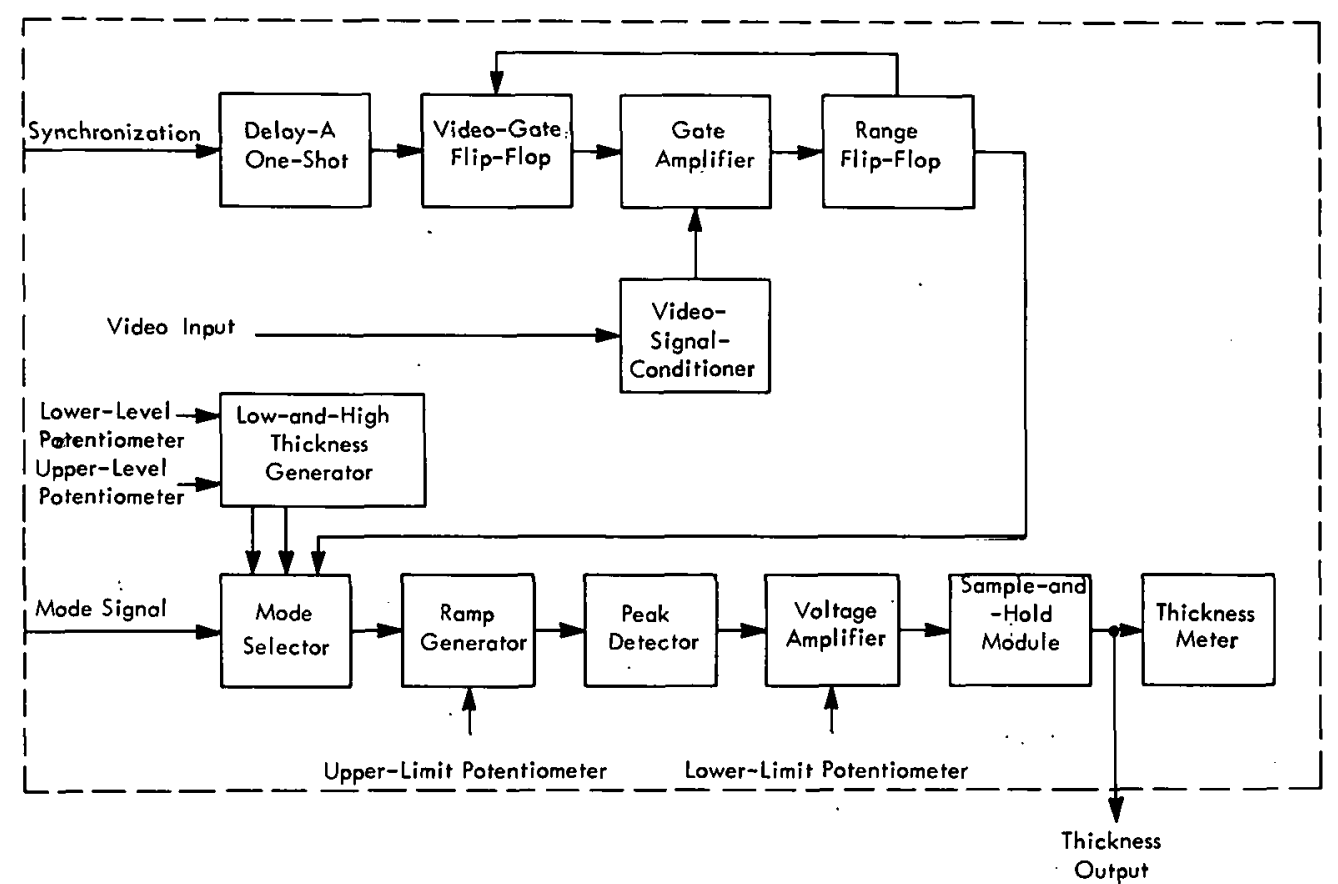

FigIre 7. PRINCIPAL COMPONENTS OF .THE MODIFIED THICKNESS-READOUT MODULE.

In developing the wall-thickness machining system, the TRM was required to reliably measure thicknesses without misgating. If a TRM misgated, its output voltage would suddenly change in value, and the machining system would erratically try to respond to a large change in the control signal. Usually, the system will drive the cutting tool into the part being machined and score the part.

The function of the video-signal-conditioning board is to prevent the TRM from misgating. The board consists of a Schmitt trigger and a monostable multivibrator. Each ultrasonic signal whose amplitude is larger than the voltage setpoint fires the Schmitt trigger. The trigger pulses the monostable multivibrator which outputs a pulse whose time period is slightly longer than any reflected ultrasonic signal. Thus, only one pulse is generated for each ultrasonic signal received. The one-shot pulses are the signal input to the gate amplifier. The TRM is now capable of reliably measuring the time period between two consecutive ultrasonic signals without misgating.

Thie functiun of the thickness-generator board is to generate two pulses-the low and high-thickness calibration pulses. The time period of the two pulses is adjustable by the respective low-level and upper-level potentiometers. The two pulses are equivalent to the pulse generated by the range flip-flop during measurement of the time period between two ultrasonic signals.

Each modified TRM has llıre mudes of operation. The operate mode selects the range flip-flop pulse as the input to the ramp generator. In this mode, the TRM operates normally 
in measuring the thickness of a metal shim. In the calibrate-low mode, the low-thickness pulse is the input to the ramp generator. A voltage proportional to a preselected value of low thickness is the output of the TRM. Similarly, in the calibrate-high mode, a voltage proportional to a preselected value of high thickness is the output of the TRM. The modes of operation of the TRM are switch-selectable on the calibration module of the reflectoscope system. The calibrate-low and calibrate-high modes of operation are designed to provide an easy method of equalizing the calibration constants of the two TRMs.

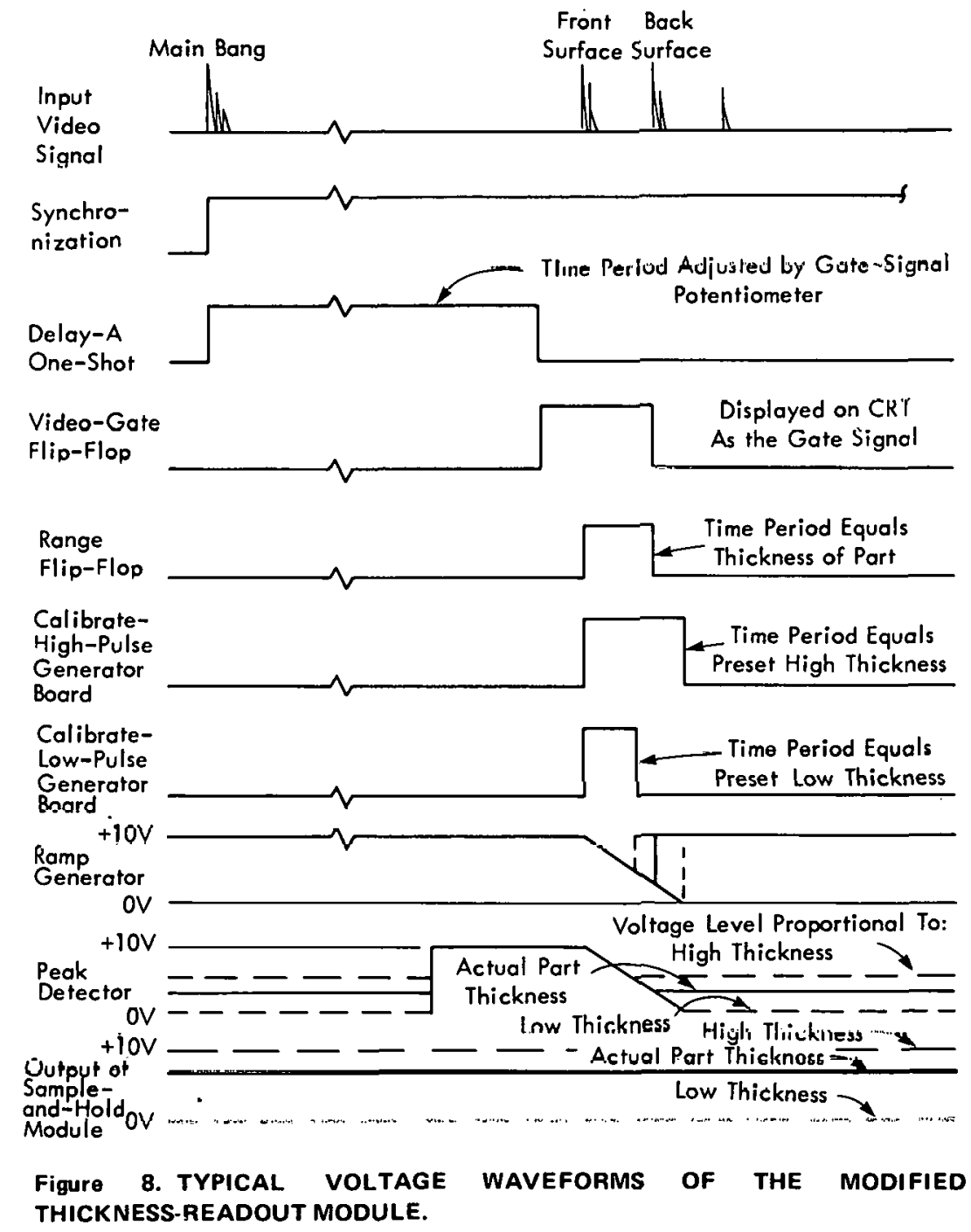

The function of the sample-and-hold module is to remove the square wave from the voltage output of the TRMs. This square wave drives the amplifiers in the forward loop of the servo system into saturation. The square wave is superimposed on the peak-detector output voltage each time the TRM makes a new thickness measurement. The peak detector is reset to +10 volts prior to the arrival of the voltage ramp. The output of the peak detector then falls in amplitude as it measures the peak of the voltage ramp. The value of thickness measured is proportional to the DC value of the peak-detector output voltage after the measurement is terminated.

In the sample mode of operation, the output of the sample-and-hold module is equal to the output voltage of the TRM. At a predetermined time prior to the occurrence of the next 
thickness measurement, the module switches to the hold mode and the output voltage remains constant. After the thickness measurement has occurred, the module switches back to the sample mode. The output of the module changes to the new output voltage of the TRM. Thus, the sample-and-hold module blocks out the square wave and does not allow it to be present in the output voltage of the modified TRMs.

\section{Addition of a Slave Receiver and a Second Thickness-Readout Module}

A slave receiver (SR) and a second TRM were added to the reflectoscope system which enables the system to make two different thickness measurements simultaneously. These two modules are mounted in the auxiliary cabinet on the bottom of the main reflectoscope cabinet.

Each TRM is capable of making thickness measurements independently of the other TRM. The meter scales of each module are adjusted for the different ranges of thicknesses being measured. Also, each module is individually calibrated to accurately record the measurements on a strip-chart recorder. The two TRMs are electronically identical and operate exactly the same way in making thickness measurements.

The slave receiver is a pulser receiver whose electronic circuits have been modified. The block diagram of the slave receiver is given in Figure 9. Operation of the slave receiver is dependent upon the master pulser receiver (MPR) which transmits the main bang to the ultrasonic probe, receives the reflected ultrasonic signals, and sends them to the slave receiver. The MPR was modified to provide the transmitted and reflected ultrasonic signals to the input of the SR. The SR operates identically to the MPR in detecting and amplifying the ultrasonic pulses. The video signal from the SR goes to the input of the second TRM mounted in the bottom chassis of the reflectoscope. The video signal from the MPR goes to the input of the first TRM mounted in the top chassis of the reflectoscope. The video display signals from both the MPR and the SR are switch selectable to be displayed on the reflectoscope CRT display.

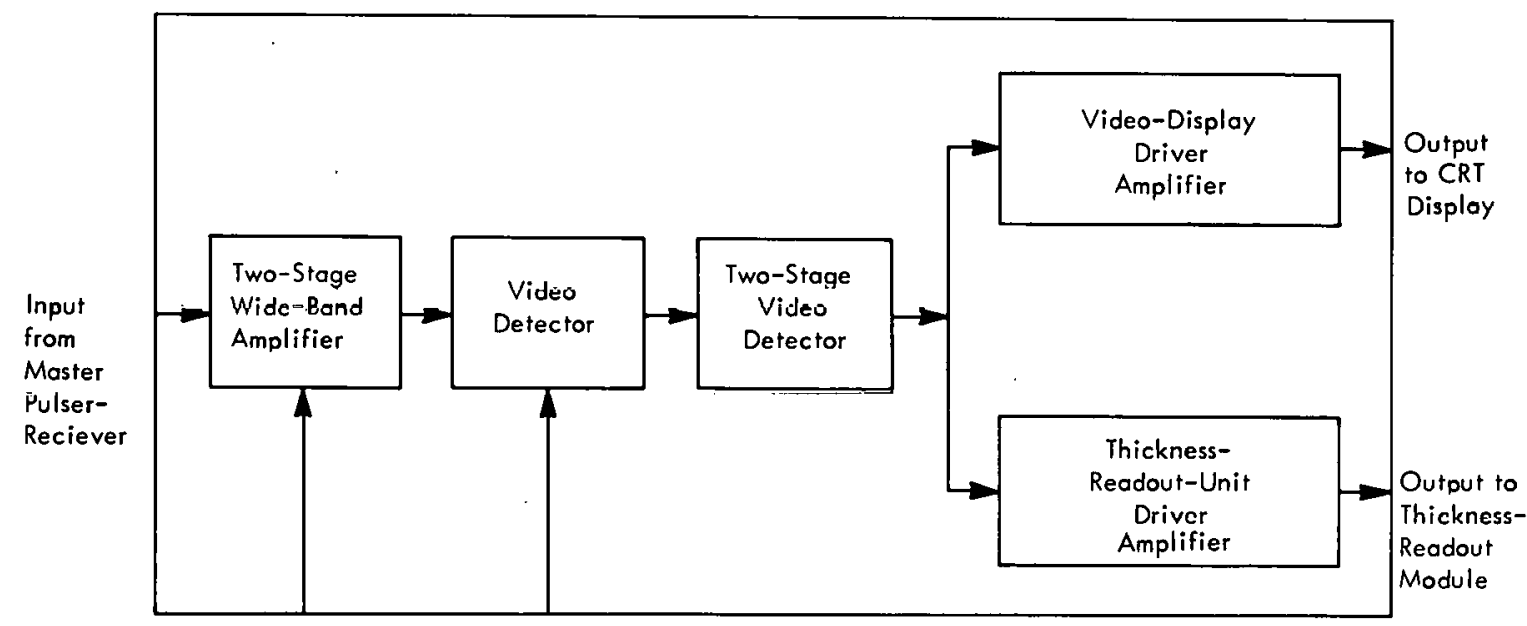

Figure 9. PRINCIPAL COMPONENTS OF THE SLAVE RECEIVER. 
The master and slave receivers independently amplify the ultrasonic pulses that they receive. Amplification is adjusted by the sensitivity potentiometer on each module. Also, both the MPR and SR were modified to provide potentiometer adjustment of the video detection level. The video detector eliminates noise and other unwanted small-amplitude signals by clipping off the bottom of the ultrasonic signals.

Use of two receivers simplifies the setup and operation of the TRMs. Each TRM requires that the amplitude of the ultrasonic pulses it receives be optimally adjusted. in order to make accurate and reliable thickness measurements. The two receivers provide the independent detection and amplification of the ultrasonic pulses needed in order to optimally adjust the two TRMs.

\section{Measurement of Distance to the Inner Surface of a Part}

Development of the wall-thickness machining system requires a method of measuring the distance to the inner surtace of a cylinder using a sensor mounted external to the part. This distance is composed of two components. The first component is the liquid transmission path from a reference surface to the outer surface of the cylinder; the second component is the wall thickness of the part. By measuring the liquid path and the wall thickness and adding the two components, the distance to the inner surface of the cylinder can be measured.

With the addition of the SR and the second.TRM, the reflectoscope system now has the capability of simultaneously measuring both the wall thickness of a part and the liquid path. Figure 10 is a drawing of a typical test facility containing an ultrasonic probe, a reference surface, and a metal shim. Typical CRT displays of the MPR and the SR video signals show the ultrasonic signals reflected from the reference surface and the outer and inner surfaces of the metal shim. The first TRM measures the thickness of the metal shim by measuring the

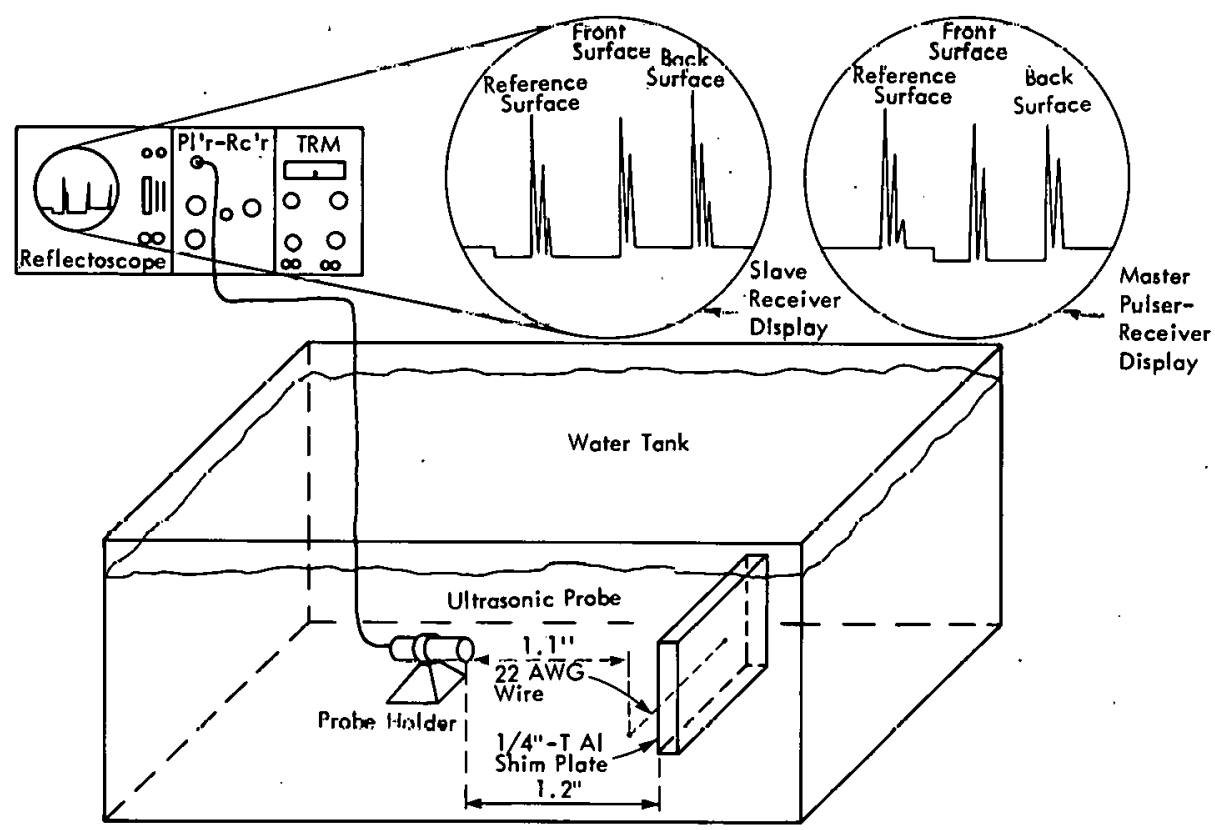

Figure 10. TYPICAL TEST FACILITY FOR MEASURING THE DISTANCE TO THE INNER SURFACE OF A METAL SHIM. 
time period between the inner and outer-surface ultrasonic signals, the second TRM measures the water path by measuring the time period between the reference-surface and front-surface ultrasonic signals. To set up the second TRM to measure the liquid path, the gate signal is adjusted until it appears in front of the reference-surface ultrasonic signal which initiates the liquid-path measurement.

The reference surface, shown in Figure 10, is a small piece of 22 AWG wire positioned 0.1 inch from the metal shim and directly in the sound path of the ultrasonic probe. It produces a reflected ultrasonic signal approximately equal in amplitude to the ultrasonic front-surface signal. The distance from the reference surface to the front surface of the part is called the liquid path and is approximately 0.1 inch. Placement of the reference surface close to the metal shim effectively reduces the magnitude of the liquid path that is to be measured from 1.2 inches to approximately 0.1 inch.

In developing the scheme to measure the distance to the inner surface of a cylinder, it is desirable to have the liquid-path distance approximately equal to the wall thickness. The wall thickness of the cylinders to be machined is from 0.05 to 0.2 inch. The liquid path and the wall thickness are thus approximately the same magnitude. The accuracy of adding two quantities of similar magnitude is better than the accuracy of adding one large and one small quantity.

In comparison, an alternative method is to measure the liquid path from the ultrasonic probe to the front surface of the part. The probe is positioned 1.2 inches from the part, and the water path and the wall thickness differ by a magnitude of 10 or more. The accuracy of adding a large water path to a small wall thickness is poor. The poor accuracy of adding the two quantities would be reflected in the poor performance of the machining system to machine parts having a constant wall thickness.

\section{Calibration of the. Two Thickness-Readout Modules}

Addition of the calibration module to the reflectoscope system provides the capability for accurately adding the outputs of the two TRMs. The function of the module is to equalize the calibration constants of the two TRMs prior to the addition of the TRMs output voltages. The output of the calibration module is a voltage proportional to the distance from the reference surface to the back surface of a metal shim. This distance is equal to the sum of the water path and the thickness of the metal shim.

Figure 11 provides a block diagram of the calibration module. The two inputs are the output voltages of the two TRMs. The module contains two voltage-level shifters, two variable-gain amplifiers, a sum amplifier, a difference amplifier, and a voltage meter. The module also contains the master mode-selector switch which operates the mode-selector switches in the TRMs.

Correct setup and calibration procedures of the two TRMs is a prerequisite for accurately measuring the distance from a reference surface to the back surface of a metal shim. Assume that the ultrasonic probe has a $15-\mathrm{MHz}$ resonance frequency and a focal length in water of 2.0 inches, and the metal shim to be measured is approximately 0.2 inch thick, First, the ultrasonic probe and the shim are submerged in a water tank and the shim is positioned 1.2 


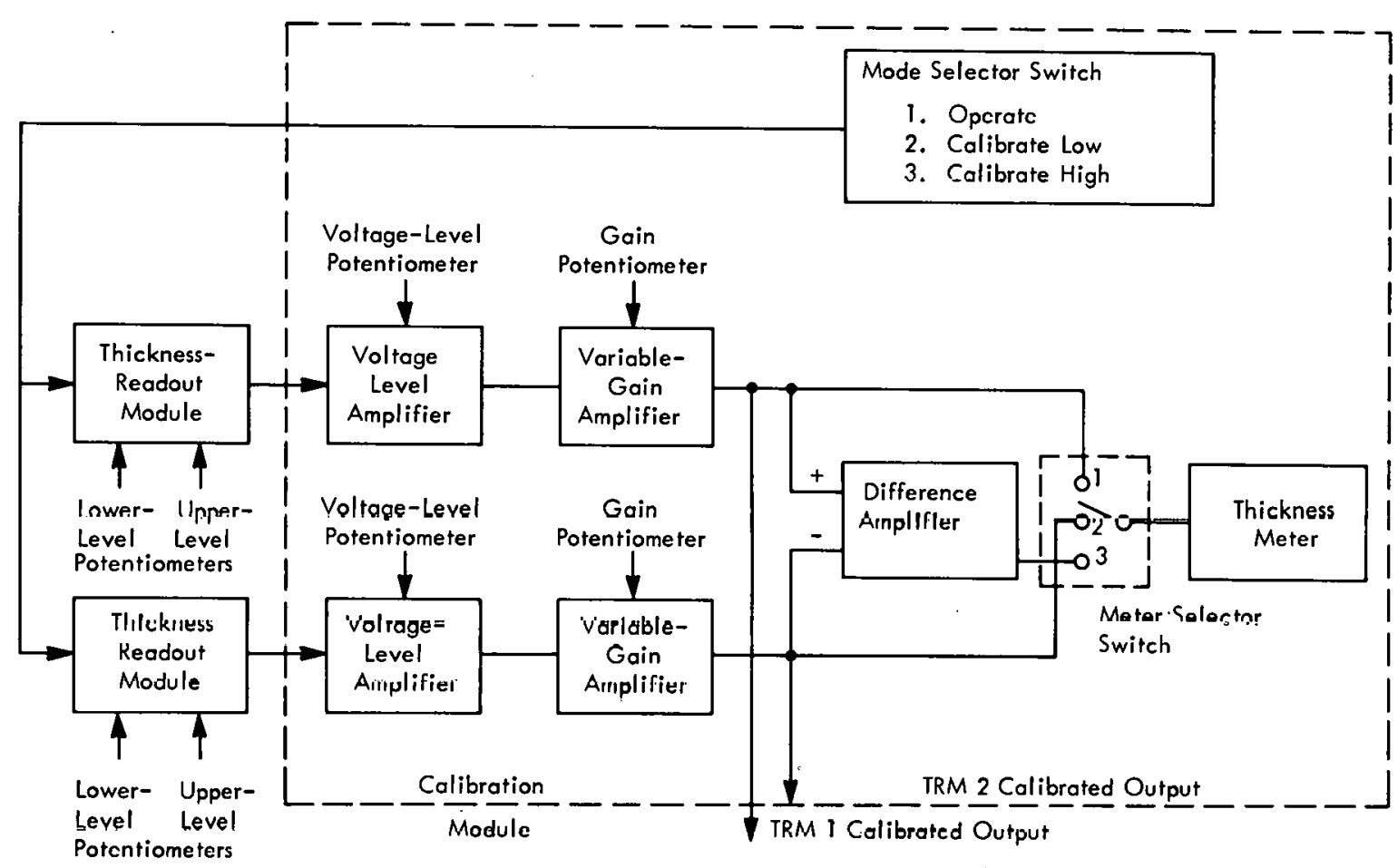

Pigure 11. PRINCIPAL COMPONENTS OF the CALIBRATION MUUOULE.

inches in front of and normal to the face of the probe. The potentiometer controls on both the master pulser receiver and the slave receiver are adjusted until the amplitude and width of the ultrasonic signals displayed on the CRT are optimal. The video-display output of each receiver is switch selectable to be displayed on the CRT.

Next, the gate-signal potentiometer of each I RMV is adjusted untıl the gate signal on the display appears in front of the ultrasonic signal that is to initiate the respective thickness measurement. The gate signal of the first TRM now appears in front of the front-surface ultrasonic signal in order to measure wall thickness. Respectively, the gate signal of the second TRM appears in front of the reference-surface signal in order to measure water path.

The thickness meter ranges on each TRM must be adjusted. For example, the scale range of the first TRM is to read wall thickness from 0.100 inch, zero scale to 0.200 inch, full scale. The scale range of the second TRM is to read water path from 0.050 inch, zero scale to 0.150 inch, full scale.

The mode switch on the calibrate module is switched to the operate position. The meter range of the first TRM is adjusted by repetitively measuring two metal shims of 0.100 and 0.200 -inch thickness, respectively. The meter range of the second TRM is similarly adjusted by repetitively measuring water path distances of 0.50 and 0.150 inch, respectively.

A fixture designed to aid in adjusting the meter ranges of the two TRMs is illustrated in Figure 12. The fixture contains an ultrasonic probe holder, a reference surface, a shim holder, and a micrometer. The shim holder is attached to the movable shaft of the micrometer. The unit is submerged in water with the micrometer barrel above the water 


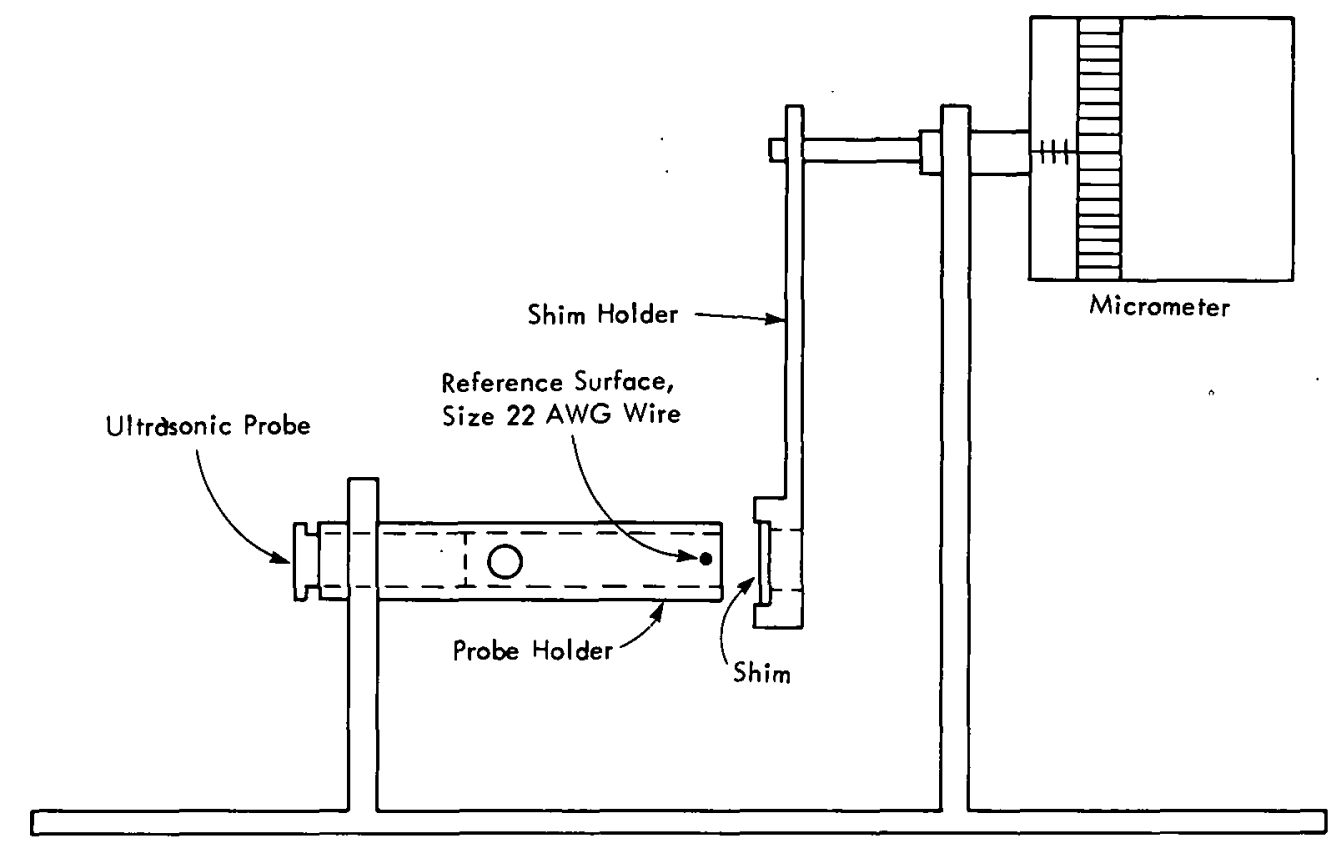

Figure 12. FIXTURE USED TO AID IN THE SET UP AND CALIBRATION OF THE TWO THICKNESS-READOUT MODULES.

surface. A metal shim mounted in the holder may be moved toward and away from the ultrasonic probe and the reference surface. Thus, the water path is accurately changed from 0.050 to 0.150 inch by adjusting the micrometer. This fixture is used to accurately adjust the meter range of the second TRM. Also, metal shims of different thicknesises can be easily placed in the holder to aid in adjusting the meter range of the first TRM.

Prior to equalizing the calibration constants of the two modules, the width of the calibrate-low and the calibrate-high pulses in each TRM are adjusted. The calibrate-low pulse widths are adjusted by selecting the calibrate-low mode and then adjusting the lower-level potentiometers on both TRMs until the meters read zero scale. The calibrate-high pulse widths are similarly adjusted by selecting the calibrate-high mode and then adjusting the upper-level potentiometers on both TRMs until the meters read full scale. Now, the meters of the TRMs will read zero and full scale, and the voltage outputs of each TRM will be proportional to the meter readings each time the calibrate-low or the calibrate-high mode is, respectively, selected.

Operation of the calibration module is dependent upon the accurate adjustment of the calibrate-low and calibrate-high pulse widths of the thickness generator in each TRM. Figure 13 shows typical TRM output voltages (Points $A, B, C$, and D) after the pulse widths of the thickness generator have been accurately adjusted to the correct values.

Adjustment of the calibration module is as follows: When the calibrate-low mode is selected, the output voltages of the two TRMs are proportional to preselected values of 0.050 inch of water path (Point $A$ ) and of 0.100 inch of metal thickness (Point $C$ ). These two voltages are adjusted to zero volts by the potentiometer adjustment of the two voltage-level amplifiers, (Points $A_{1}$ and $C_{1}$ ). The calibrate-high mode is selected, and the 


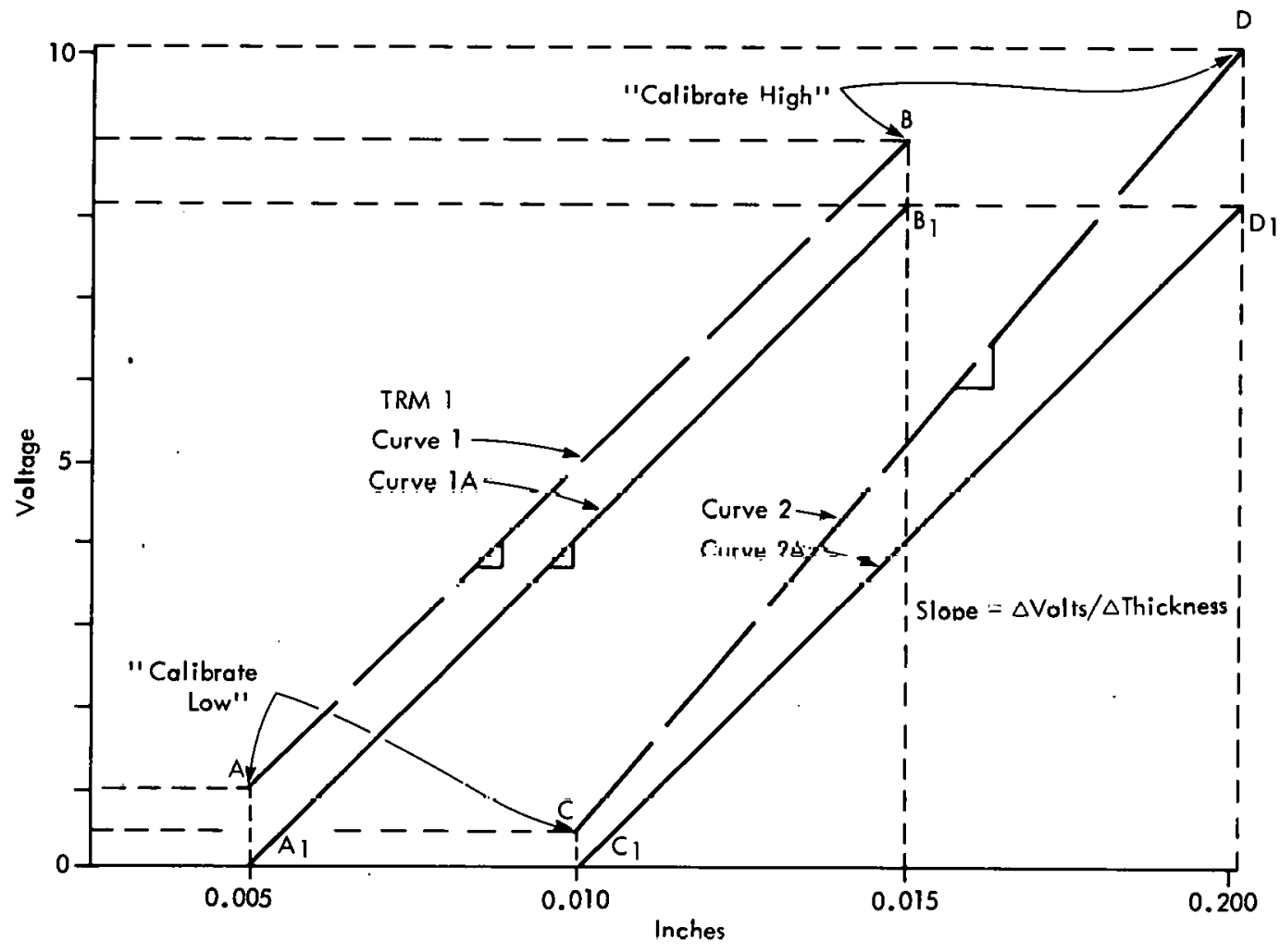

Figure 13. TYPICAL VOLTAGE VALUES OF THE THICKNESS-READOUT MODULES BEFORE AND AFTER CALIBRATION.

two TRMs output voltages are proportional to preselected values of 0.150 inch of water path and of 0.200 inch of metal thickness, (Points $B_{1}$ and $D_{1}$ ). The voltmeter measures the output of the difference amplifier, and the gain potentiometer of either the first or second variable-gain amplifier is adjusted until the meter reading is zero volt. Change in voltage from Point $A_{1}$ to Point $B_{1}$ is equal to the change in voltage from Point $C_{1}$ to Point $D_{1}$. Slopes of the two voltage lines (Lines $A_{1} B_{1}$ and $C_{1} D_{1}$ ) are equal. Thus, the calibration constants of the two TRMs are equal, and their value is equal to the slope of Lines $A_{1} B_{1}$ and $C_{1} D_{1}$. The reflectoscope system is now placed in the operate mode for normal operation. Output of the sum amplifier of the calibration module is proportional to the distance from the reference strip to the back surface of the metal shim. This signal is used to control the movement of the cutting tool of the wall-thickness machining system.

\section{Hydraulic and Mechanical Components}

The hydraulic system components selected for use with the wall-thickness machining system are a Moog Type 30 servo valve and a one-inch-diameter hydraulic cylinder. An existing hydraulic oil pump operating at a supply pressure of 1500 pounds per square inch (psi) was used as the source of hydraulic power. Selection of the supply pressure was based upon the knowledge that operating the pump at a higher pressure would seriously degrade the life expectancy of the pump. The frequency response of the Moog servo valve is higher at a supply pressure of 3000 psi. The longer life expectancy of the pump operating at 1500 psi outweighed the small gain in the system frequency response. 
The primary consideration in the selection of the Moog Type 30 servo valve is its high-frequency response. This valve has the highest frequency response of any standard valve. The natural frequency of the servo valve at a supply pressure of $3000 \mathrm{psi}$ is $240 \mathrm{~Hz}$.

The Moog Type 30 servo valve is a two-stage, mechanical-feedback, flow-control valve which controls the flow of oil to the hydraulic cylinder. The no-load-rated oil flow of the servo valve is 1.4 gallons per minute (gpm) at a supply pressure of 1500 psi.

Selection of the hydraulic cylinder was based upon the rated oil flow of the servo valve and the load forces required at the tool during machining of the cylinders. The tool load forces are small due to the small depths of cuts taken. No more than 0.005 inch of metal is machined from a cylinder during the final cut with the wall-thickness machining system. Also, the maximum tool movement is generally less than 0.01 inch because of the small inner surface runout that the servo system is required to follow. A small, one-inch-diameter cylinder having a piston movement of 0.1 inch was chosen to be used with the machining' system.

The peak oil flow requirement is determined as follows: Assume that the bandwidth of the system is $200 \mathrm{~Hz}$, the maximum tool movement is 0.1 inch, and the tool load force is 400 pounds (lbs):

$$
\mathrm{Q}_{\mathrm{m}}=\mathrm{V}_{\mathrm{m}} \mathrm{A}
$$

where:

$Q_{m}$ represents the peak oil flow, in in $3 / \mathrm{sec}$,

A the area of the cylinder piston, in in 2 , and

$V_{m}$ the maximum velocity of the tool, in in/sec.

In addition:

$$
D-k \sin 2 \pi f t
$$

where:

D represents the tool displacement, in inches

$f$ the bandwidth of the system, in $\mathrm{H}$, and

t the time, in ser.

Also:

$$
V=2 \pi f K \cos 2 \pi f t
$$

where $V$ is tool velocity, in in/sec. 
Furthermore:

$$
\begin{gathered}
V_{m}=2 \pi \mathrm{fK}, \text { and } \\
Q_{m}=2 \pi \mathrm{fKA}, \text { or } \\
Q_{m}=2 \pi(200 \mathrm{~Hz})(0.005 \mathrm{in})(\pi / 4)(1.0 \mathrm{in})^{2}, \text { or } \\
Q_{m}=4.9 \mathrm{in} 3 / \mathrm{sec} \text {, or } \\
Q_{m}=1.28 \mathrm{gal} / \mathrm{min}
\end{gathered}
$$

The no-load-rated oil flow of the servo valve at a supply pressure of $1500 \mathrm{psi}$ is $1.4 \mathrm{gpm}$. At a rated load of $400 \mathrm{lbs}$, the oil flow is $1.12 \mathrm{gpm}$. Comparing the two values for oil flow, one sees that the required oil flow is larger than the actual oil flow at $200 \mathrm{~Hz}$ and a tool load of $400 \mathrm{lbs}$. Actually, the control system will never operate at this high a frequency; and, thus, the required oil flow will be less. However, these calculations show that the frequency response of the servo system is limited at high frequencies due to the oil-flow limitation of the servo valve.

Pressure drop across the hydraulic cylinder is directly proportional to the rated load. Assuming a load of $400 \mathrm{lbs}$ and a cylinder piston of 1.0 inch in diameter, the cylinder pressure drop is as follows:

$$
P=F / A
$$

where:

P represents the pressure drop, in Ibs/in2,

F the load force, in lbs, and

A the area of the piston, in in ${ }^{2}$.

Therelure:

$$
\begin{gathered}
P=(400 \mathrm{lbs}) / \pi(1 \mathrm{in})^{2} / 1, \text { or } \\
P=509 \mathrm{lhs} / \mathrm{in}^{2} .
\end{gathered}
$$

At a load pressure drop of $500 \mathrm{lbs} / \mathrm{in}^{2}$, the rated oil flow is approximately $80 \%$ of the no-load rated flow. This value was used in the previous calculations to determine the oil flow under load.

Figure 14 shows the design of the assembly containing the tool and tool holder, the ultrasonic probe and probe housing, the slide, and the hydraulic cylinder. The probe housing and the tool holder are directly attached to the cross member of a ball-bearing slide. The 


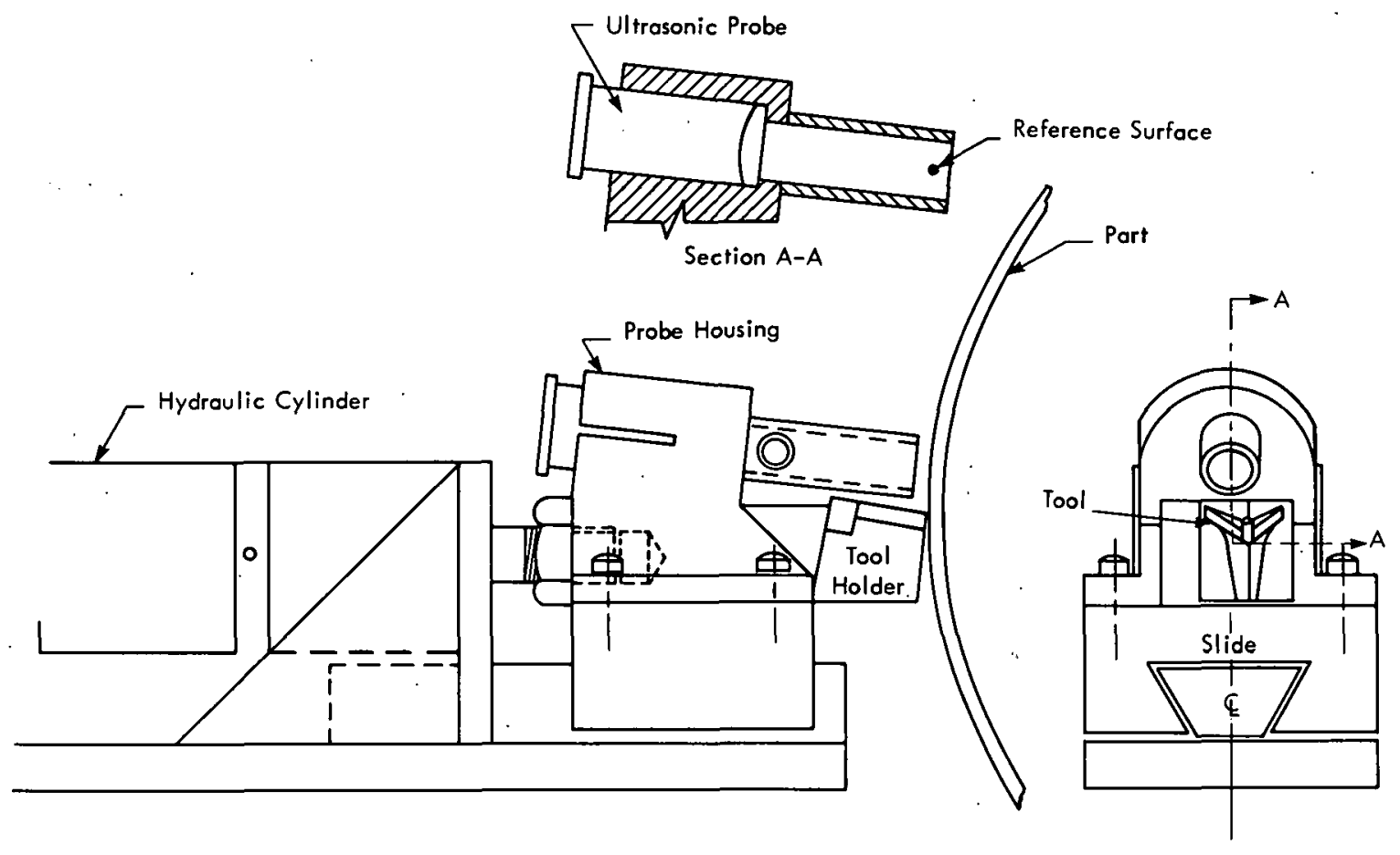

Figure 14. TOOL-PROBE-SLIDE ASSEMBLY.

hydraulic cylinder moves the tool and the probe in a horizontal direction toward the cylinder being machined. The ultrasonic probe is mounted in the probe housing above the tool and at a $6^{\circ}$ angle to the horizontal plane.

The position of the ultrasonic probe with respect to the tool was determined by two design requirements. One requirement is that the ultrasonic probe must be normal to the surface of the part at all times; the second requirement is that the probe must be positioned ahead of the tool. After considering that the closed-loop electrohydraulic system has $6^{\circ}$ of phase lag at $5 \mathrm{~Hz}$, the ultrasonic probe was positioned $6^{\circ}$ above the horizontal plane of the tool. The centerline of the ultrasonic probe and of the tool intersects the axis of the cylinder being machined. For larger or smaller parts, the ultrasonic probe holder is shimmed up or down so that the centerline of the probe always intersects the axis of the part. Also, the centerline of the ultrasonic probe is offset to one side of the centerline of the tool to maintain the probe normal to the surface of the cylinder. The surface where the cylinder is being machined is not normal to the ultrasonic probe and will not reflect the ultrasonic pulses back to the probe.

A cross-sectional view of the probe housing is also shown in Figure 14. It was designed to facilitate the ease of removal of the ultrasonic probe. Also, a continuous stream of liquid flows through it and couples the ultrasonic sound to the part. The reference surface is centered in the end of the housing to generate the reference ultrasonic signal. Several different gages of wire were used as the reference surface, but the 22 AWG wire generated the best reflected ultrasonic signal without seriously interfering with the other reflected pulses. 
A coolant is required when machining a part to lubricate the metal-cutting surfaces of the tool and the part. In the wall-thickness machining system, the coolant served a double function. It is also used to couple ultrasonic sound to the part. The coolant is pumped from a reservoir through the ultrasonic-probe housing. It then flows out the end of the housing and onto the part and the tip of the tool. Two different coolants were satisfactorily used in the wall-thickness machining system. One coolant was water containing a rust inhibitor, the second was a commercially prepared water-soluble oil.

A method was developed to prevent the chips from obstructing the path of the ultrasonic probe. During the first attempts at machining, long, stringy chips would become lodged in front of the ultrasonic probe holder. This action caused the machining system to behave erratically and plunge the tool into the part causing scars and deep grooves. A short piece of clear, flexible rubber tubing was slipped over the end of the ultrasonic-probe housing. The rubber tubing makes contact with the part and acts as a wiper. Any chips which tend to lodge under the probe holder are brushed aside by the rubber tubing. Any accumulation of chips around the rubber tubing is removed by the machininst with a chip puller.

\section{System Frequency Response and Compensation}

The frequency-domain specifications of the servo system are as follows: The system is to have a bandwidth of $200 \mathrm{~Hz}$, the magnitude of the transfer function is to be $0 \pm 1 / 2$ decibel (db) from 0 to $30 \mathrm{~Hz}$, and the phase of the transfer function is to be minimized in the same frequency range. The value of the resonant peak $\mathrm{Mm}$, the maximum value of the magnitude of the transfer function, is to be equal to or less than 1.4. The time-domain specifications equivalent to the frequency specifications are as follows: The peak overshoot to a step response is to be equal to or less than $30 \%$; the rise time of the step response is to be equal to or less than 2 milliseconds.

To determine if the servo system met the design criteria, the closed-loop frequency response was obtained. Figure 15 shows the uncompensated closed-loop frequency response of the system. The bandwidth is $110 \mathrm{~Hz}$ and the resonant peak value $\mathrm{Mm}$ is equal to $9 \mathrm{db}$. The magnitude of the transfer function is larger than $+1 / 2 \mathrm{db}$ in the frequency range from 0 to $30 \mathrm{~Hz}$. The frequency response of the system definitely does not meet specifications.

Figure 16 shows the Spectral Dynamics Mechanical Impedance Analyzer used to obtain the closed-loop frequency response of the system. It contains a frequency generator which forces the system with a sinusoidal signal. The generator slowly sweeps the frequency range of the servo system from 5 to $500 \mathrm{~Hz}$. The output response of the system is fed back to the analyzer which calculates the transfer function. The magnitude and phase components of the function are plotted on an $x-y$ plotter as a function of frequency. The analyzer proved to be an efficient method of accurately and quickly obtaining the actual frequency response of the servo system. It saved many hours of measuring the system response at specific frequencies and plotting by hand the values to obtain a frequency response.

To design a compensation network for improving the system performance, the open-loop frequency response, Figure 17, is obtained with the aid of the Nichol's chart. The Nichol's chart $(6,7)$ performs the calculation: 


$$
T(s)=G(s) /[1+G(s)],
$$

where:

$\mathrm{T}(\mathrm{s})$ is the closed-loop transfer function, and

$\mathrm{G}(\mathrm{s})$ is the forward-loop transfer function.

The Nichol's chart is easily used to graphically plot the open-loop transfer function from the closed-loop function, and conversely.

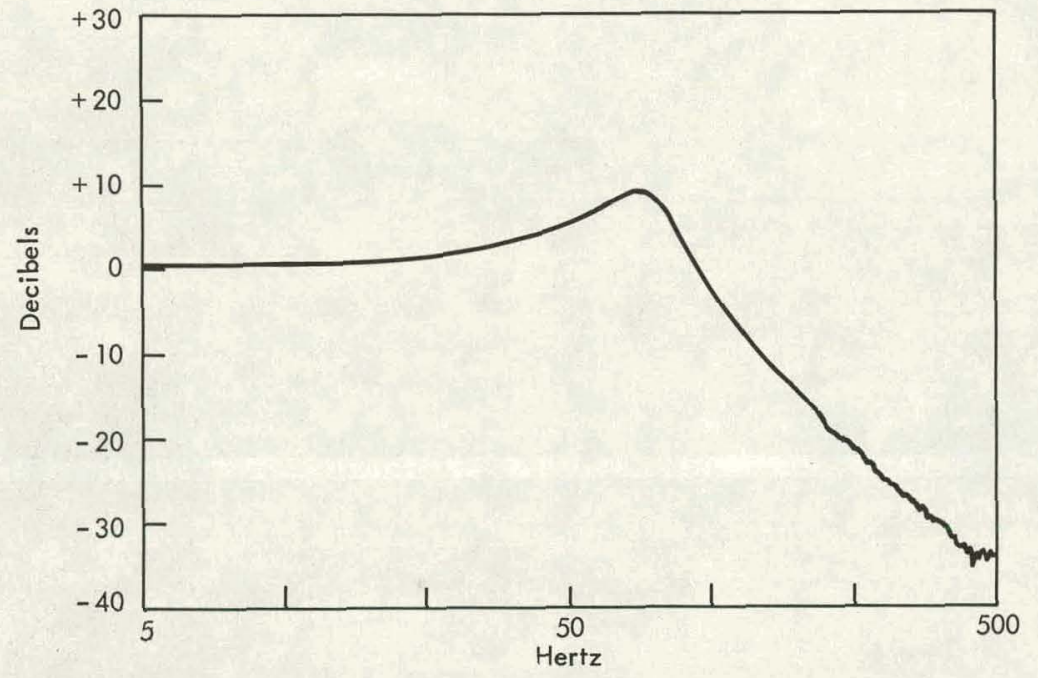

(a) Magnitude.

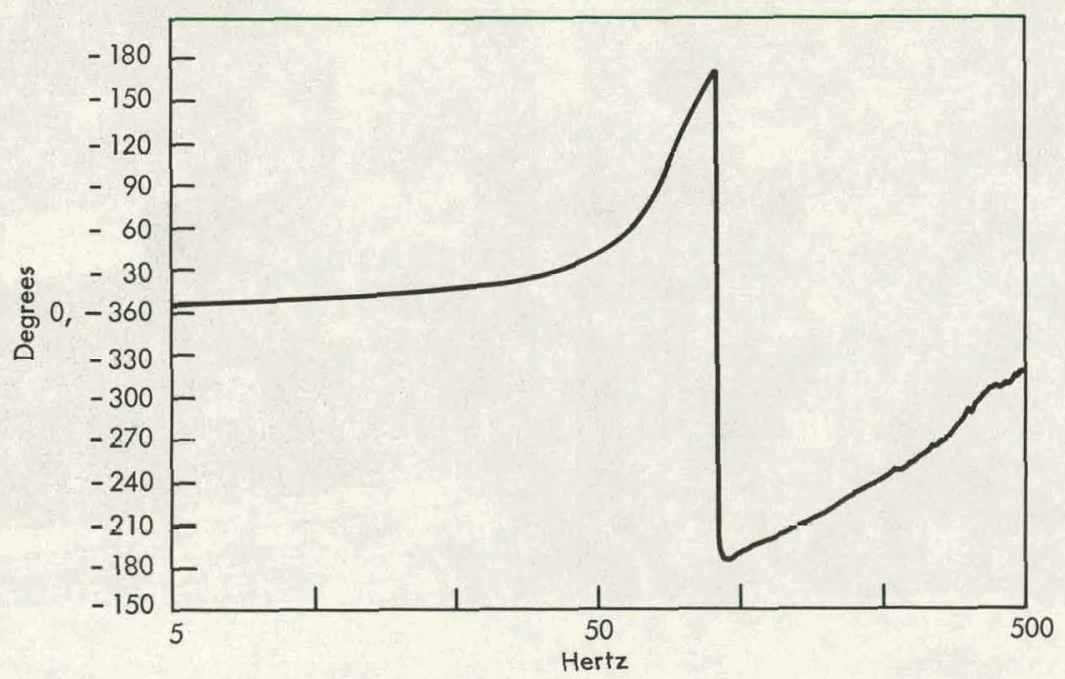

(b) Phase.

Figure 15. CLOSED-LOOP UNCOMPENSATED FREQUENCY RESPONSE OF THE WALL-THICKNESS MACHINING SYSTEM. (Gain Setting $=4 \times 0.5$ ) 


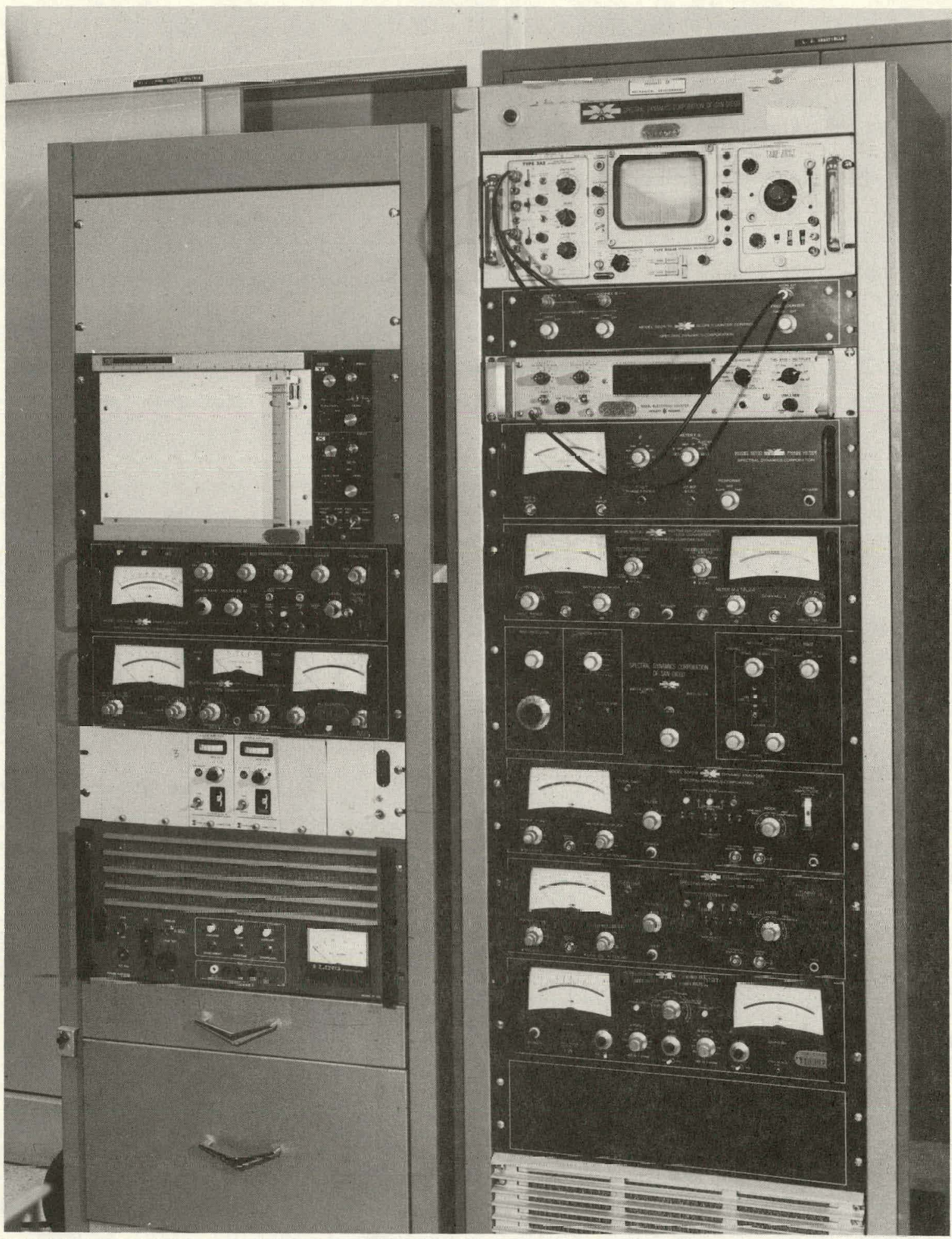

Figure 16. SPECTRAL DYNAMICS MECHANICAL IMPEDANCE ANALYZER. 
The open-loop frequency response was modified by using lag-lead and lead-lag networks to add phase and to change the magnitude of the gain as a function of frequency. The final compensation network added to the forward loop of the servo system is as follows:

$$
G_{c}(s)=\frac{(s+2 \pi \times 1.59)(s+2 \pi \times 0.589)(s+2 \pi \times 47)}{(s+2 \pi \times 0.016)(s+2 \pi \times 5.3)(s+2 \pi \times 230)}
$$

The lag-lead network is to increase the gain at low frequencies; the lead-lag network at high frequencies is to add phase and to extend the bandwidth of the system. $(6,7)$

Figure 18 shows the compensated open-loop frequency obtained by adding the compensation network to the frequency response obtained in Figure 15. The compensated

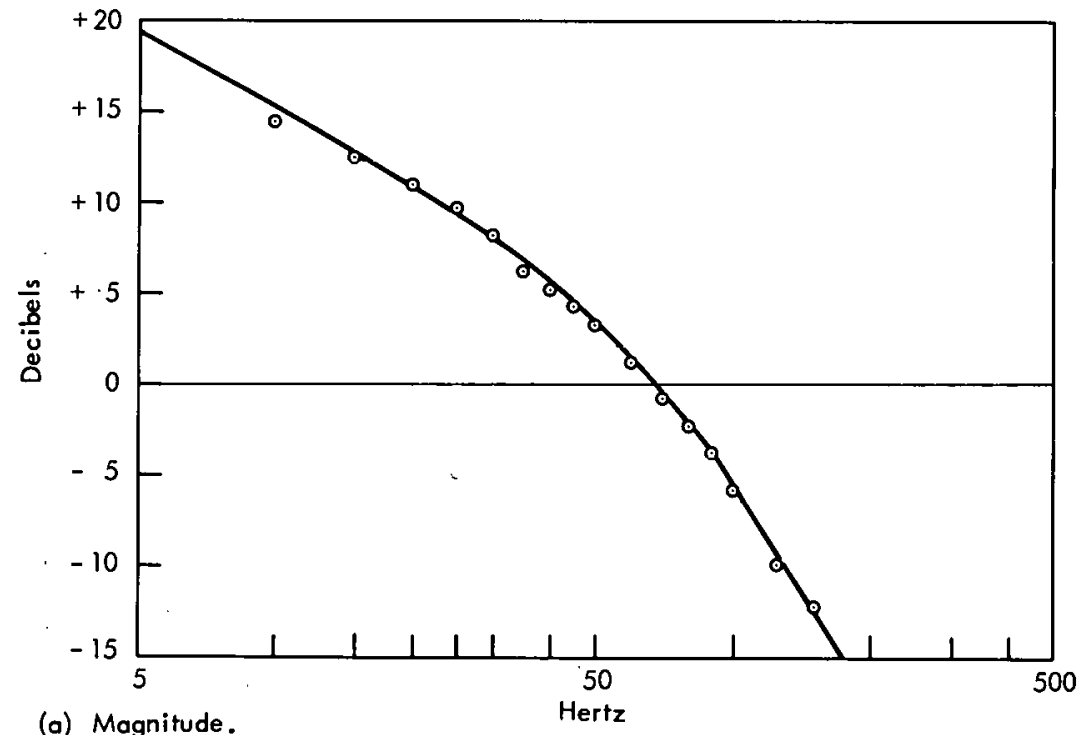

(a) Magnitude.

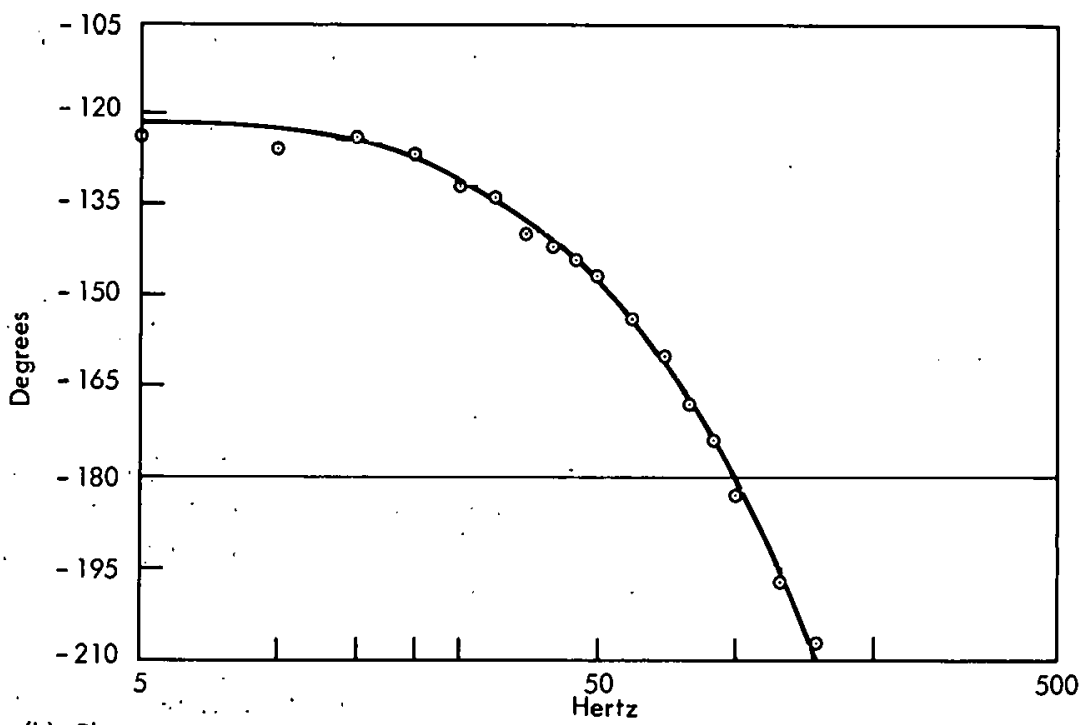

(b) Phase.

Figure 17. OPEN-LOOP UNCOMPENSATED FREQUENCY RESPONSE OF THE WALL.THICKNESS MACHINING SYYSTEM. 


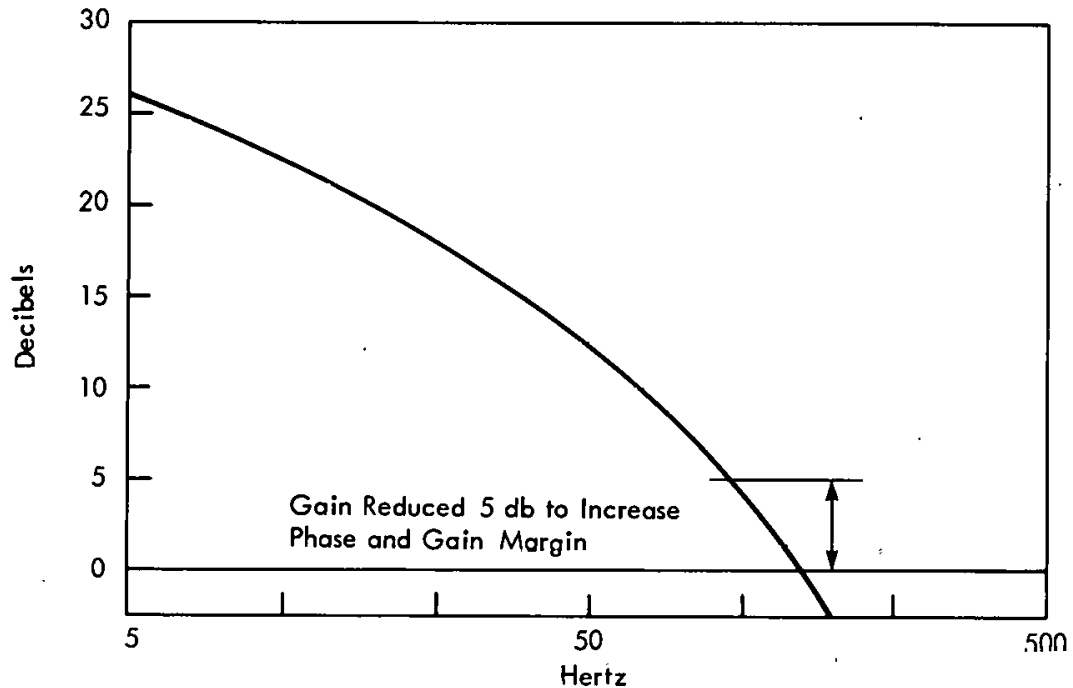

(a) Magnitude.

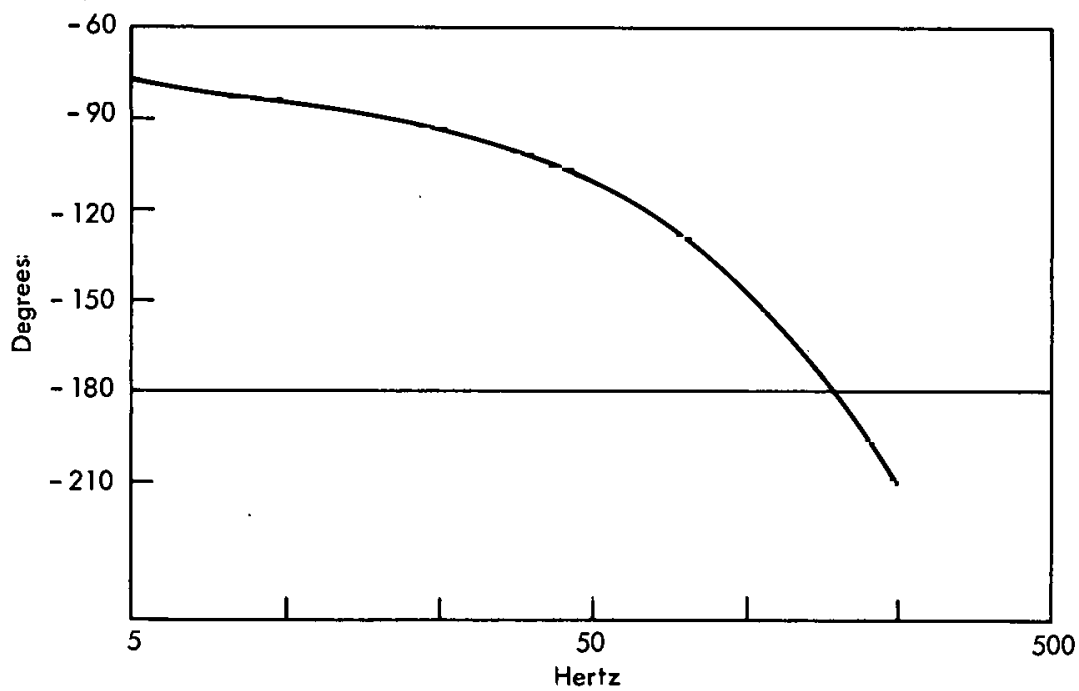

(b) Phase.

Figure 18. OPEN-LOOP COMPENSATED FREQUENCY RESPONSE OF THE WALL-THICKNESS MACHINING SYSTEM.

upen-loop frequency response shows a phase margin of 37 , a gain margin of $7.5 \mathrm{db}$, and a bandwidth of $130 \mathrm{~Hz}$.

Figure 19 shows the electroric circuit used to implement the compensation network. Three operational amplifiers interconnected, as shown, can be used to implement either a lead-lag or a lag-lead network. The poles and zeros on the negative real axis are dependent only upon the values of the two input resistors of the first operational amplifier.

The transfer function of the electronic compensation network is obtained as follows: The transfer function of the first operational amplifier is: 


$$
-X(s)=W(s) / s R_{1} C+Z(s) / s R_{2} C ;
$$

the transfer function for the second operational amplifier is:

$$
-Y(s) / X(s)=R_{3} / R_{4}
$$

the transfer function for the third operational amplifier is:

$$
\begin{gathered}
-Z(s)=R_{5} W(s) / R_{6}+R_{5} Y(s) / R_{7}, \\
-Z(s)=R_{5} W(s) / R_{6}-R_{5} R_{3} X(s) / R_{7} R_{4} \text {, and } \\
-Z(s)=R_{5} W(s) / R_{6}-\left(R_{5} R_{3} / R_{7} R_{4}\right)\left(W(s) / s R_{1} C+Z(s) / s R_{2} C\right) .
\end{gathered}
$$

Let $R_{5}=R_{6}, R_{5}=R_{7}$, and $R_{3}=R_{4}$, then:

$$
\begin{gathered}
-Z(s) / W(s)=\left(1+1 / s R_{1} C\right)\left(1+1 / s R_{2} C\right), \text { and } \\
-Z(s) / W(s)=\left(s+1 / R_{1} C\right)\left(s+1 / R_{2} C\right) .
\end{gathered}
$$

Let $a=1 / R_{1} C$ and $b=1 / R_{2} C$, then:

$$
\begin{gathered}
-Z(s) / W(s)=(s+a) /(s+b), \text { and } \\
-Z(s) / W(s)=\left(s+2 \pi f_{1}\right) /\left(s+2 \pi f_{2}\right)
\end{gathered}
$$

where $f_{1}=0.159 / R_{1} C$ and $f_{2}=0.159 / R_{2} C$.

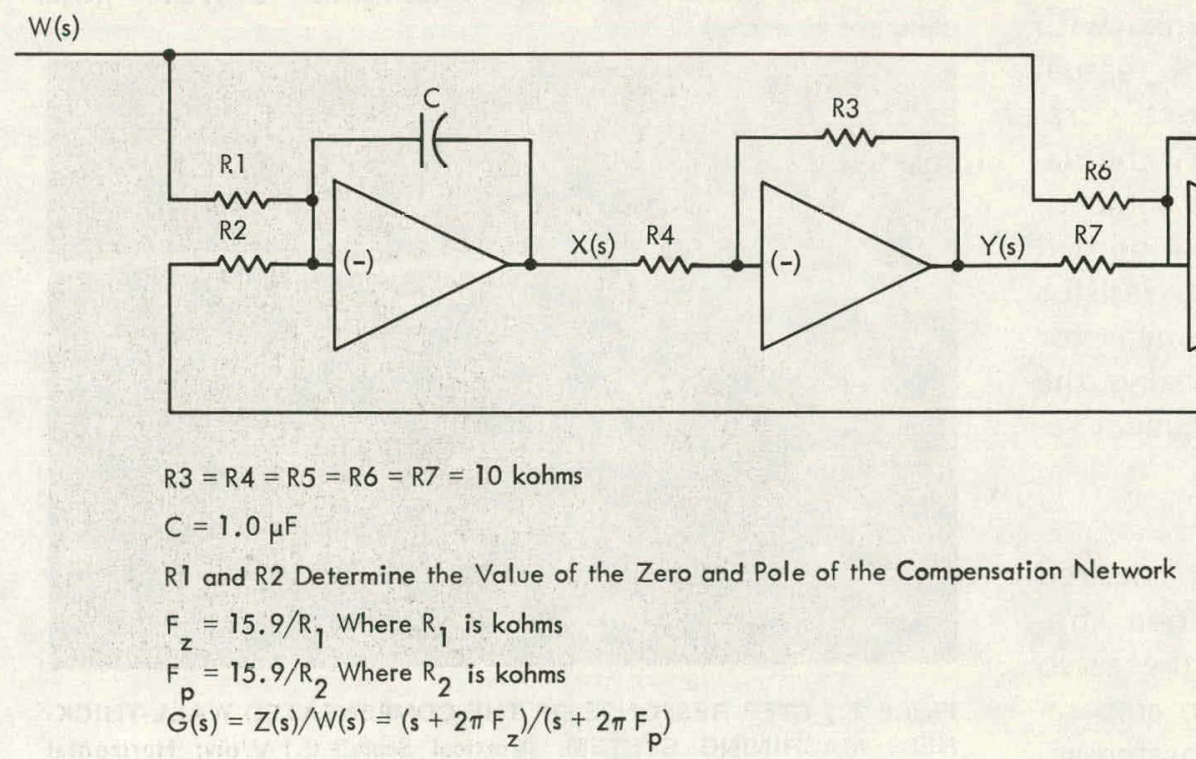

Figure 19. ELECTRONIC FREQUENCY-COMPENSATION NETWORK. 
This electronic network was chosen to implement the compensation network because of the ease with which the poles and zeros can be moved on the negative real axis. Other electronic networks were designed to implement complex poles and zeros, but the movement of a complex pole or zero required changing several different resistor values in the electronic-circuit network. Also, the servo system can be compensated with a network containing only real poles and zeros; therefore, complex poles and zeros were not required. Initial efforts to compensate the system consisted of changing the poles and zeros until the desired closed-loop frequency response was obtained. The final compensation network consisted of three electronic networks in series.

Once the desired compensation is added to the forward loop of the servo system, the actual closed-loop compensated response is easily obtained with the analyzer. If the actual closed-loop-compensated response does not satisfy the design requirements, the compensation network may be modified slightly by changing resistor valves, or a new compensator can be designed by using the original open-loop trequency response.

Figure 20 points out the desired compensated closed-loop frequency response of the servo system; Figure 21 the step response of the compensated system. This system satisfies the original design requirements.

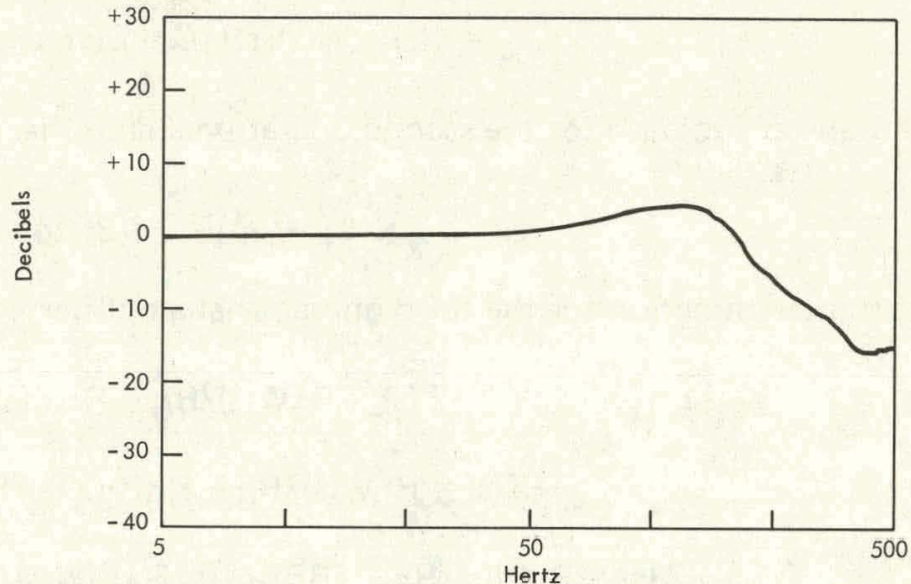

(a) Magnitude.

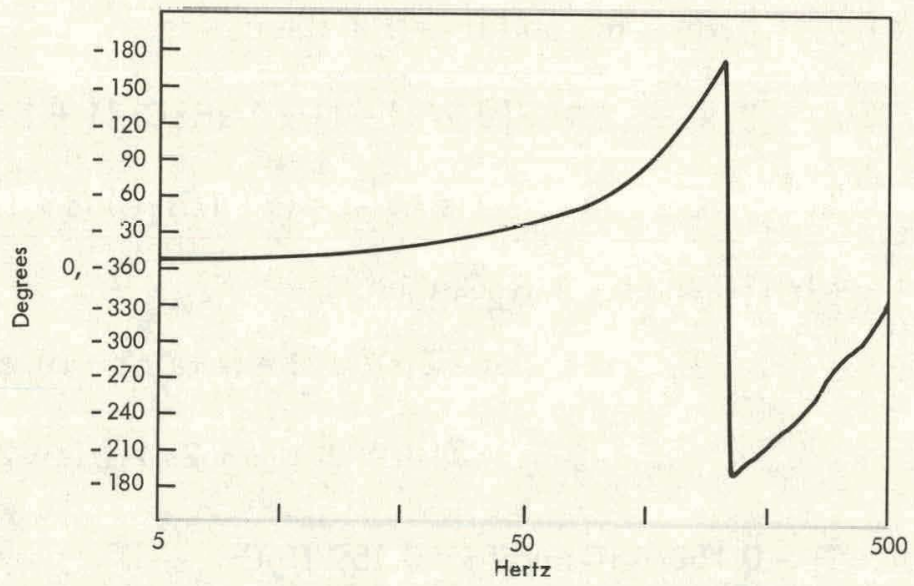

(b) Phase.

Figuro 20. CLOSED LOOP COMPENSATED FREQUENCY RESPONSE SF THE WALL.THICKNESS MACHINING SYSTEM. (Gain Setting $=40 \times 0.25$ )

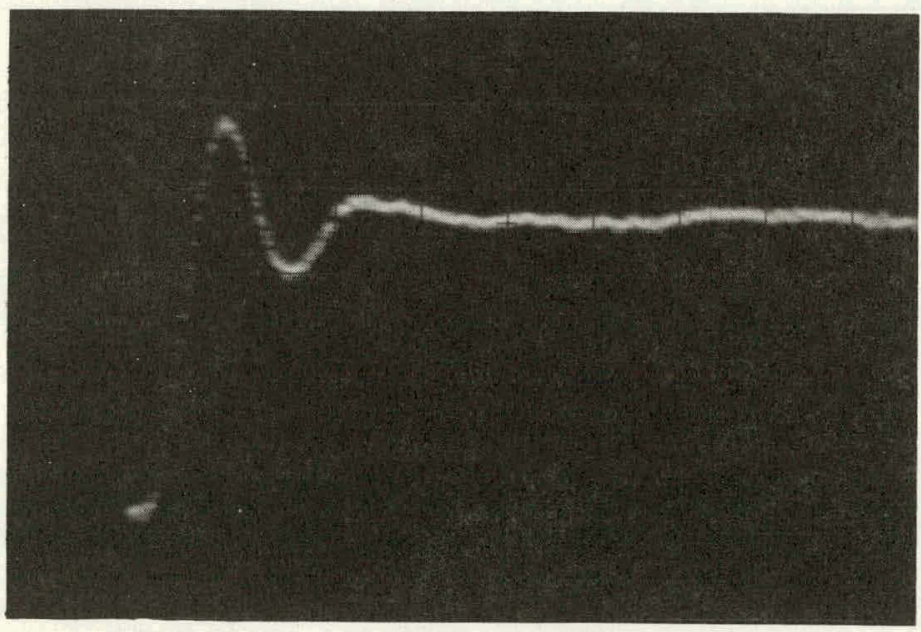

Figure 21. STEP RESPONSE OF THE COMPENSATED WALL-THICKNESS MACHINING SYSTEM. (Vertical Scale $=0.1 \mathrm{~V} /$ div; Horizontal Scale $=0.005 \mathrm{~s} / \mathrm{div}$; Forcing Function $=0.3-\mathrm{V}$ Square Wave Equivalent to 0.0075 inch; Gain Setting $=40 \times 0.25$ ) 


\section{EVALUATION AND TESTING}

\section{Accuracy of Ultrasonic-Thickness Measurements}

An investigation was conducted to determine the accuracy of the reflectoscope system to measure the wall thickness of aluminum cylinders. Eight-inch-outside-diameter (OD) cylinders having a nominal wall thickness of 0.2 inch were machined from Type 6061 aluminum bar stock. The Sperry Reflectoscope system and a dual linear-variable-differential-transformer (LVDT) probe system were used to inspect the wall thickness of the cylinders. Variations of wall thickness from both measuring systems were recorded using an $x-y$ plotter, and the results were compared.

Figure 22 portrays the LVDT probe system used to measure the wall thickness of the cylinders. Two LVDT probes are positioned opposite each other to measure the movement of the front and back surfaces of the cylinder. Measurements of the probes are electronically added to obtain a measure of the wall-thickness variations: The voltage outputs of the two amplifiers must be calibrated equally in order to obtain accurate measurements. Using the LVDTs is a conventional method of measuring thickness in precision gage laboratories. Ultrasonic and LVDT wall-thickness profiles were constructed for the aluminum cylinders by incrementing the transducers along the length of the part, making a circumferential measurement at each location, and recording the data with an $x-y$ recorder.

Figure 23 presents the LVDT and the ultrasonic wall-thickness profiles for an aluminum cylinder. The wall-thickness profiles of the remaining cylinders were very similar to the profiles shown. Comparing the profiles, discrepancies in the ultrasonic and LVDT wall-thickness measurements are readily seen. Peaks in the ultrasonic measurements are not present in the LVDT measurements. The LVDT measurements revealed wall-thickness variations from 500 to 800 microinches, peak to peak, around the circumferences of the cylinders. The ultrasonic measurements showed wall-thickness variations ranging from 2000 to 6000 microinches, peak to peak, around the circumferences of the same cylinders. The

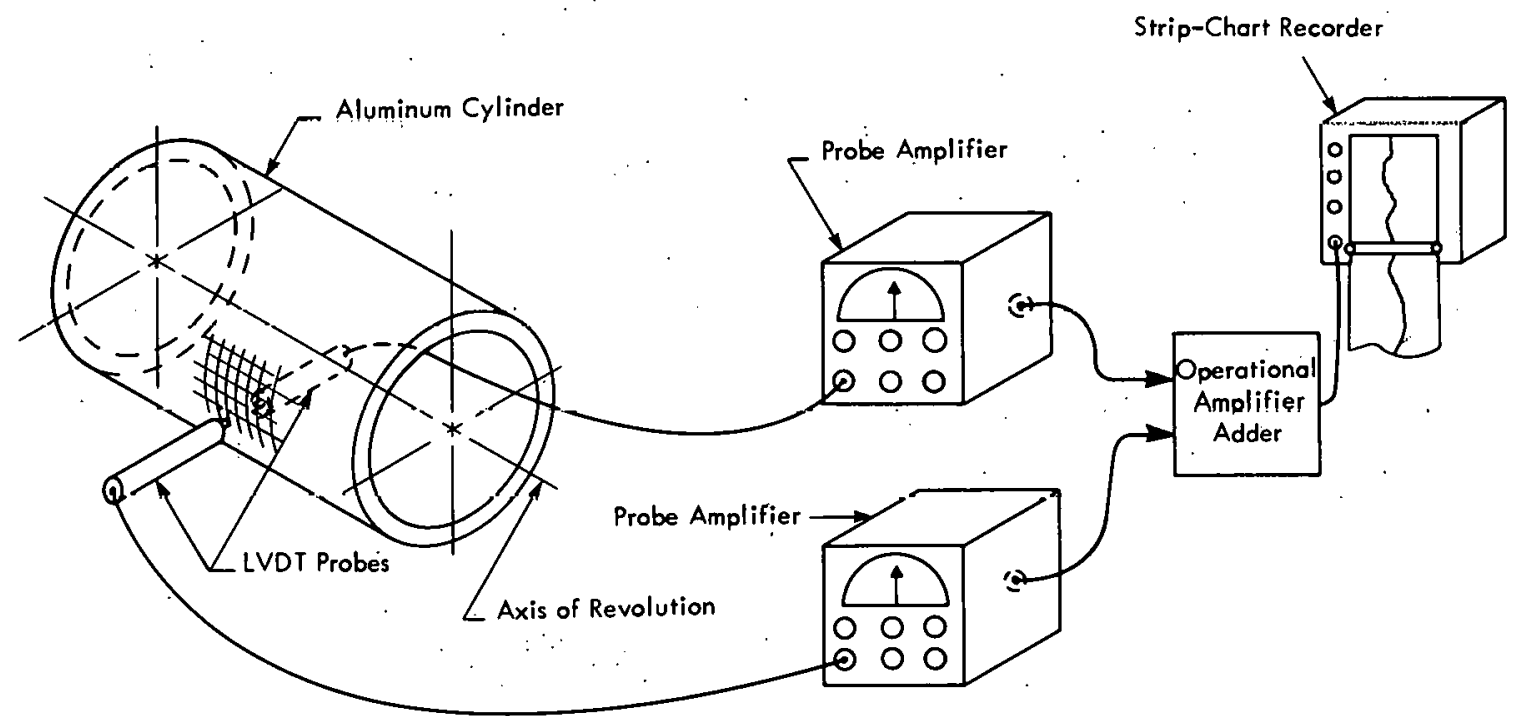

Figure 22. LINEAR VARIABLE DIFFERENTIAL TRANSFORMIER WALL-THICKNESS MEASURING SYSTEM. 


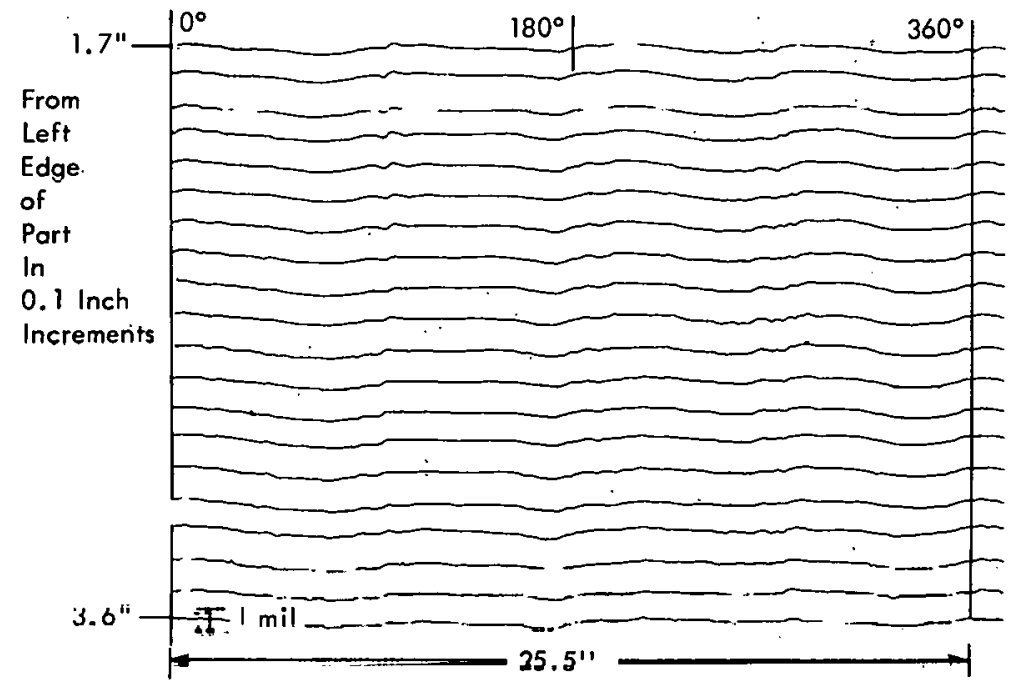

(a) Mechanical Profile.

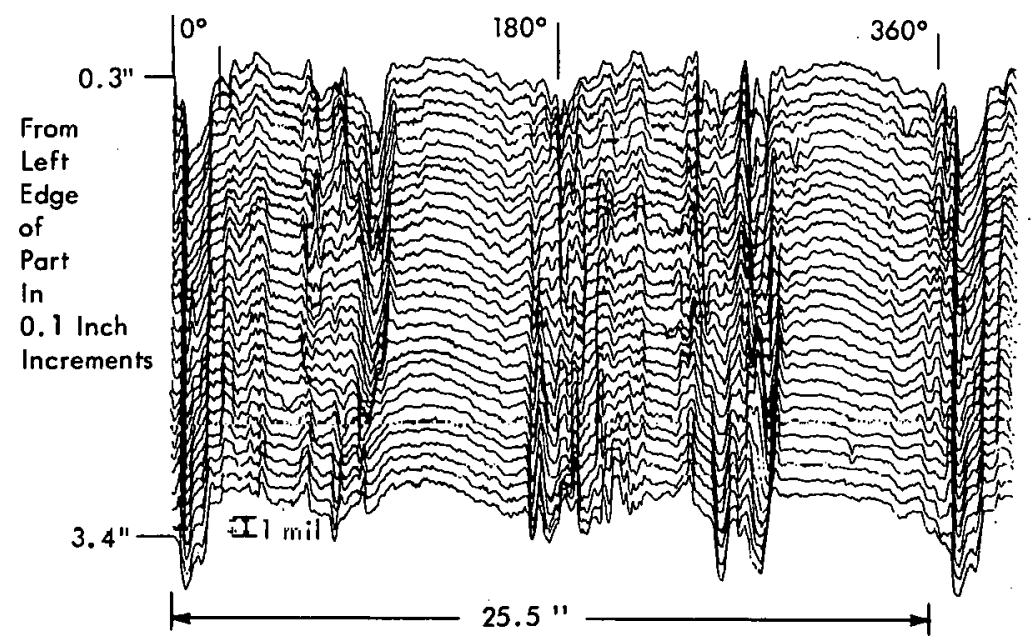

(b) Ultrasonic Profile.

Figure 23. WALL-THIÇKNESS PROFILES FOR AN ALUMINUM CYLINDER. (Part 13; Material, Typo 6061-T6 Aluminum; OD, 8 inches; Length, 5 inches; Wall Thickness, 0.2 inch; Chart Calibration. 3 units/0.001 inch)

apparent peaks in the thickness occurred in lines parallel to the axis of rotation of the cylinders. These peaks are unrelated to the actual wall-thickness variations because no similar peaks were measured in the LVDT wall-thickness profiles. $A$ tabulated summary of LVDT and ultrasonic wall-thickness measurements for six cylinders is presented in Table 1 :

\section{Material Characteristics Affecting Ultrasonic-Thickness Measurements}

Poor agreement between the ultrasonic and LVDT thickness measurements has raised the fundamental question of material characteristics masking the ultrasonic measurements. To explore the possibilities of inclusions, segregations, and grain-size variations in the aluminum material causing errors, several samples from one cylinder were tested by metallurgical and 
Table 1

INSPECTION RESULTS FOR ALUMINUM CYLINDERS

\begin{tabular}{ccccc}
\hline $\begin{array}{c}\text { Cylinder } \\
\text { Part }\end{array}$ & $\begin{array}{c}\text { Material } \\
\text { Type }\end{array}$ & $\begin{array}{c}\text { Mechanical } \\
\text { Thickness } \\
\text { Variations } \\
\text { (0.001 inch } \\
\text { peak to peak) }\end{array}$ & $\begin{array}{c}\text { Ultrasonic } \\
\text { Thickness } \\
\text { Variations } \\
(0.001 \text { inch } \\
\text { peak to peak) }\end{array}$ & Comments \\
\hline 12 & Al 6061-T6 & 0.7 & 2.1 & Six small peaks. \\
13 & Al 6061-T6 & 0.7 & 5.0 & Four definite peaks. \\
14 & Al 6061-T4 & 0.5 & 4.6 & Twenty-five peaks, large \\
15 & Al 6061-T4 & 0.8 & 3.6 & and small. \\
16 & Al 6061-T4 & No Data & 3.6 & Five prominent peaks. \\
17 & Al 6061-T4 & 0.5 & 6.1 & Eleven prominent peaks.
\end{tabular}

(1) Nominal OD of cylinders, 8 inches; nominal wall thickness of cylinders, 0.2 inch.

microprobe analysis. Also, another cylinder was tested by DXT (density times thickness) measurements to determine if any density variations existed in the aluminum metal.

Five samples areas from Part 16 were machined from the part, polished, and chemically etched for metallurgical test evaluation, Figure 24. Samples 1T, 3T, and 5T were machined from areas in which the ultrasonic thickness measurements indicated an increase in wall thickness; Sample $2 \mathrm{H}$ was machined from an area indicating a decrease in thickness. Areas of

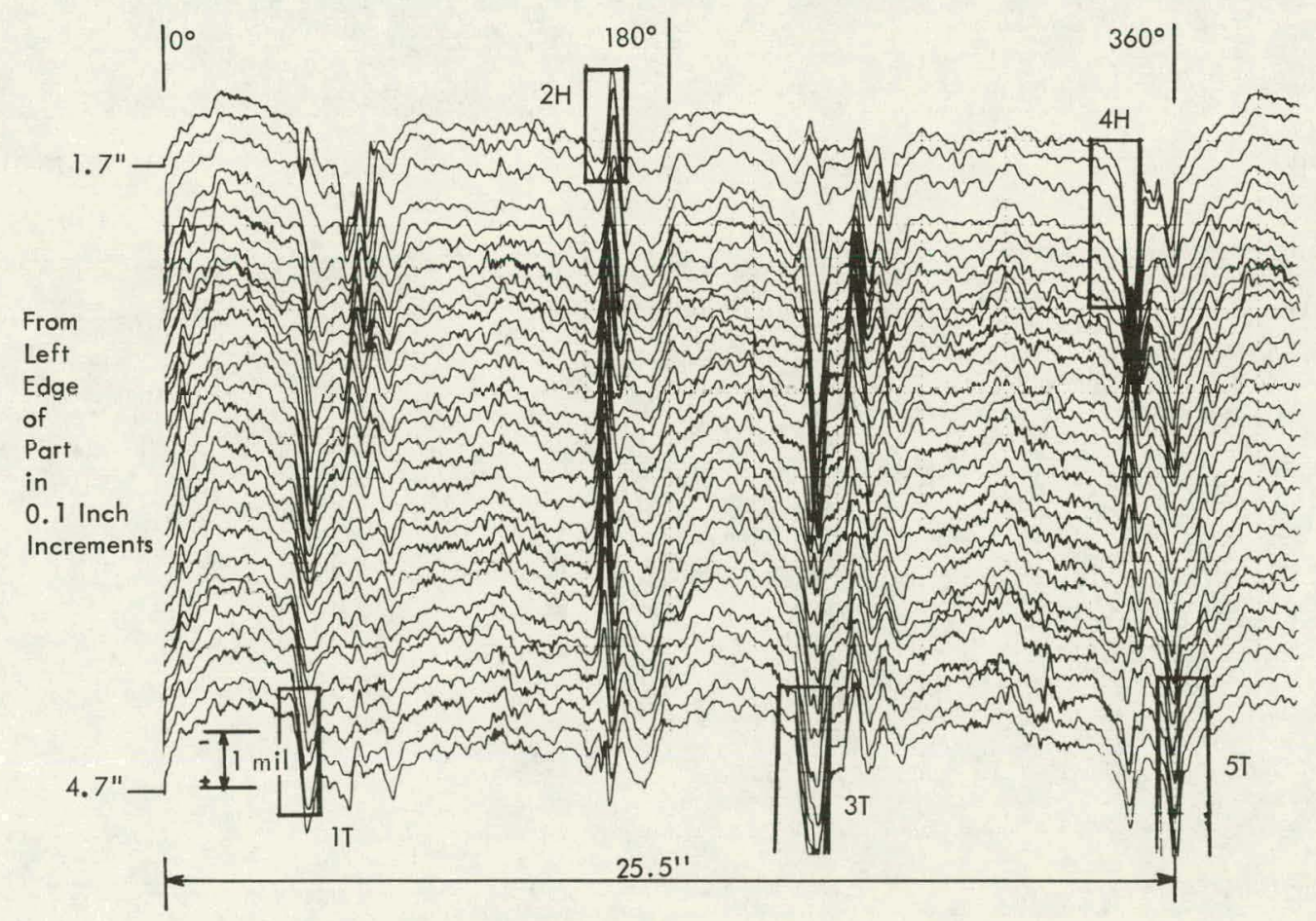

Figure 24. SAMPLE AREAS FOR METALLURGICAL EVALUATION. (Part 13; Material, Type 6061-T6 Aluminum; OD, 8 inches; Length, 5 inches; Wall Thickness, 0.2 inch; Chart Calibration, 3 units/ 0.001 inch) 
the sample causing an increase or a decrease in the ultrasonic measurements were marked with an " $x$ ". Metallurgical examination of these samples revealed that grain sizes varied from approximately 0.5 to 15 mils. The metal structure at the " $x$ " end of the samples had few small-grained structures and had large areas with no apparent grain boundaries; the metal structure at the opposite end of the samples had many small-grained structures and had few large-grained structures. Figure 25 provides views of the metal structure for Sample 3T; Figure 26 the grain structure of Sample $2 \mathrm{H}$ after a vacuum cathodic etch. The same type of grain structure as described previously is apparent. The dark, fern-shape markings in Figure 25 are inclusions and segregation; whereas the round, black areas in Figure 26 are over-etched areas of the sample.

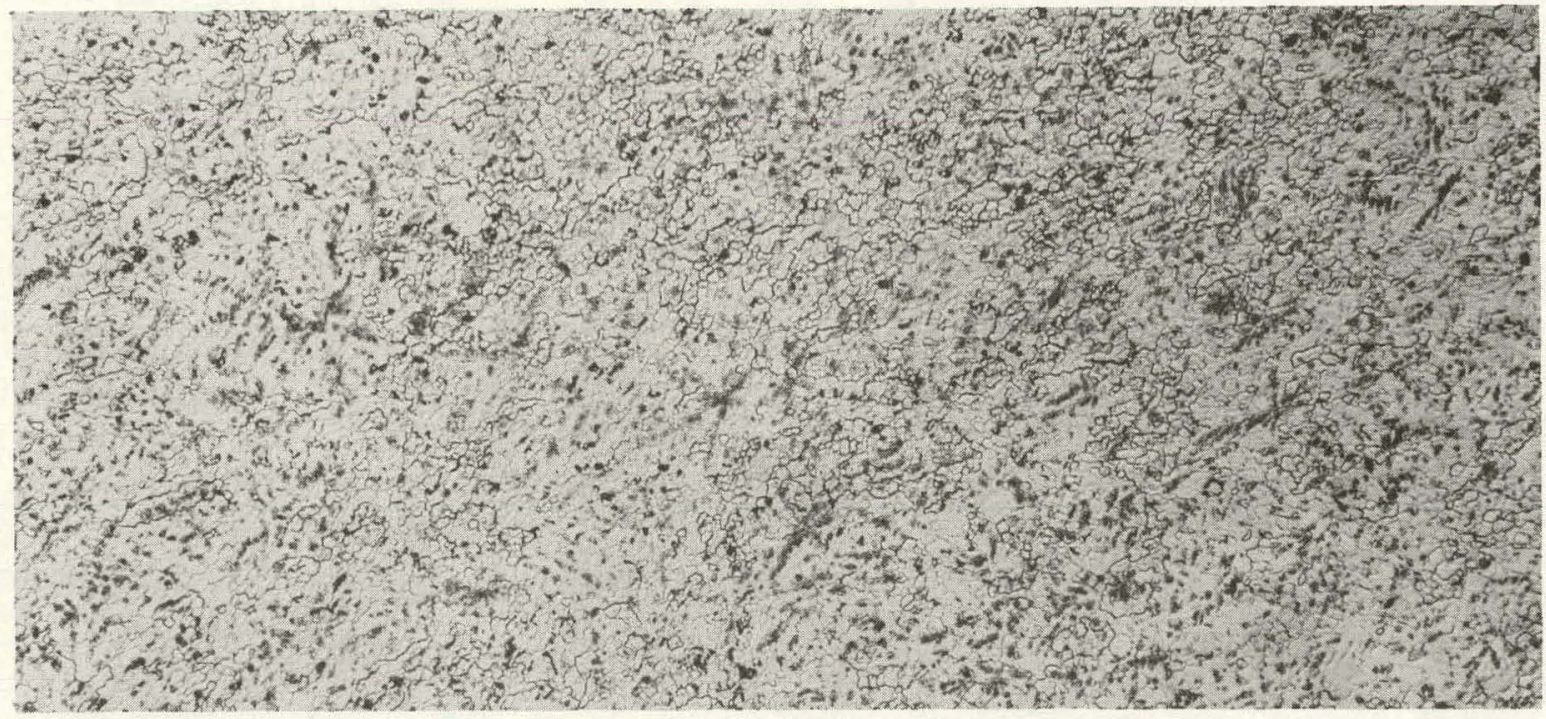

(a) $X$ End.

MS-13-0150-5

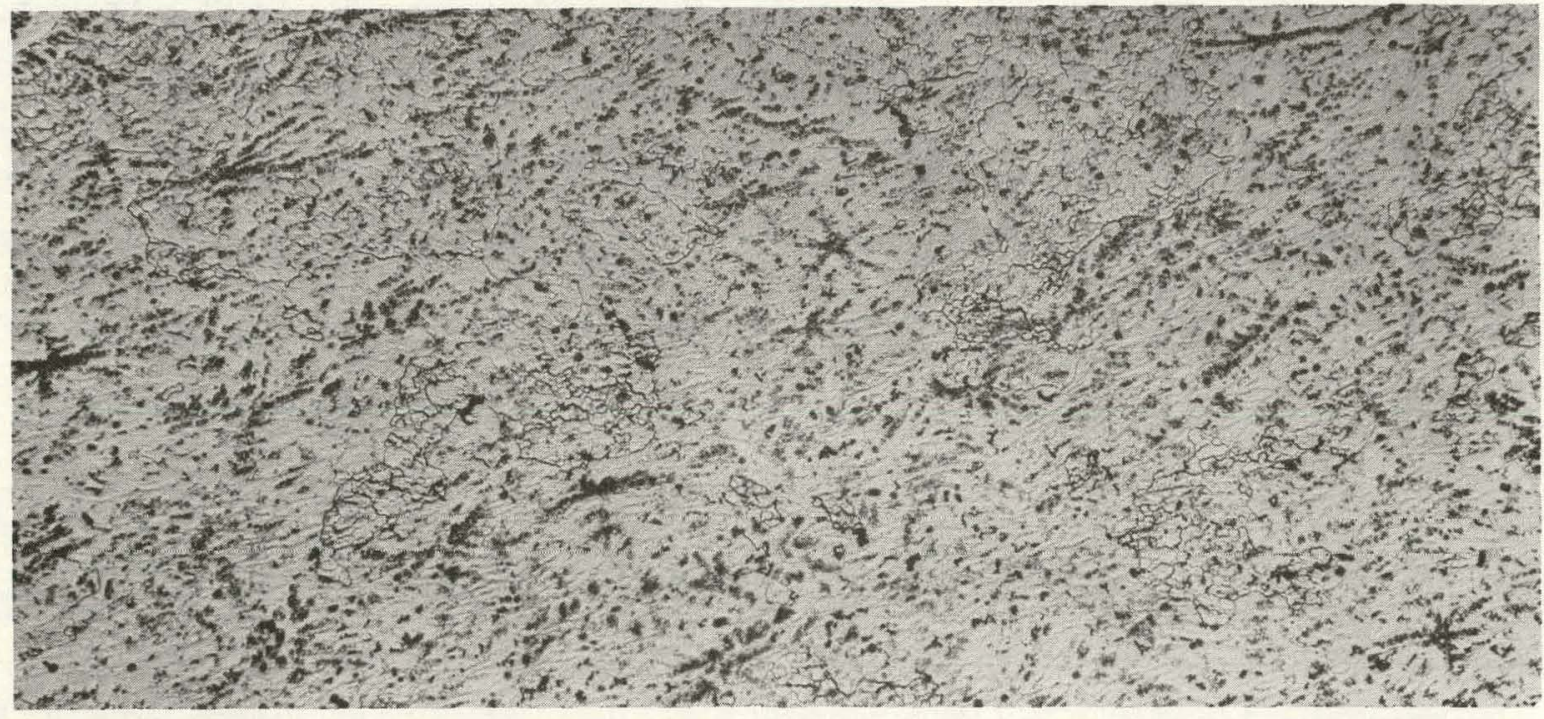

(b) Opposite End.

MS-73-0150-5

Figure 25. METALLURGicAL STRUCTURE OF SAMPLE 3T. (Part 16; Chemical Etch; 100X) 


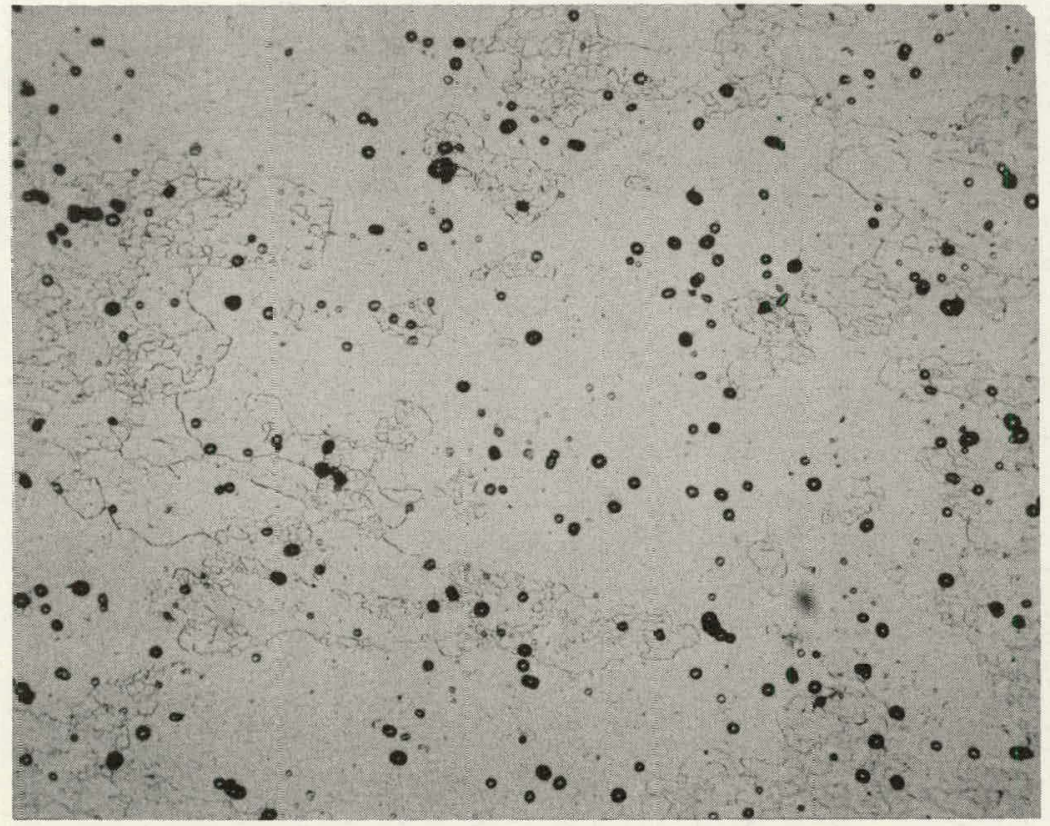

(a) $X$ End.

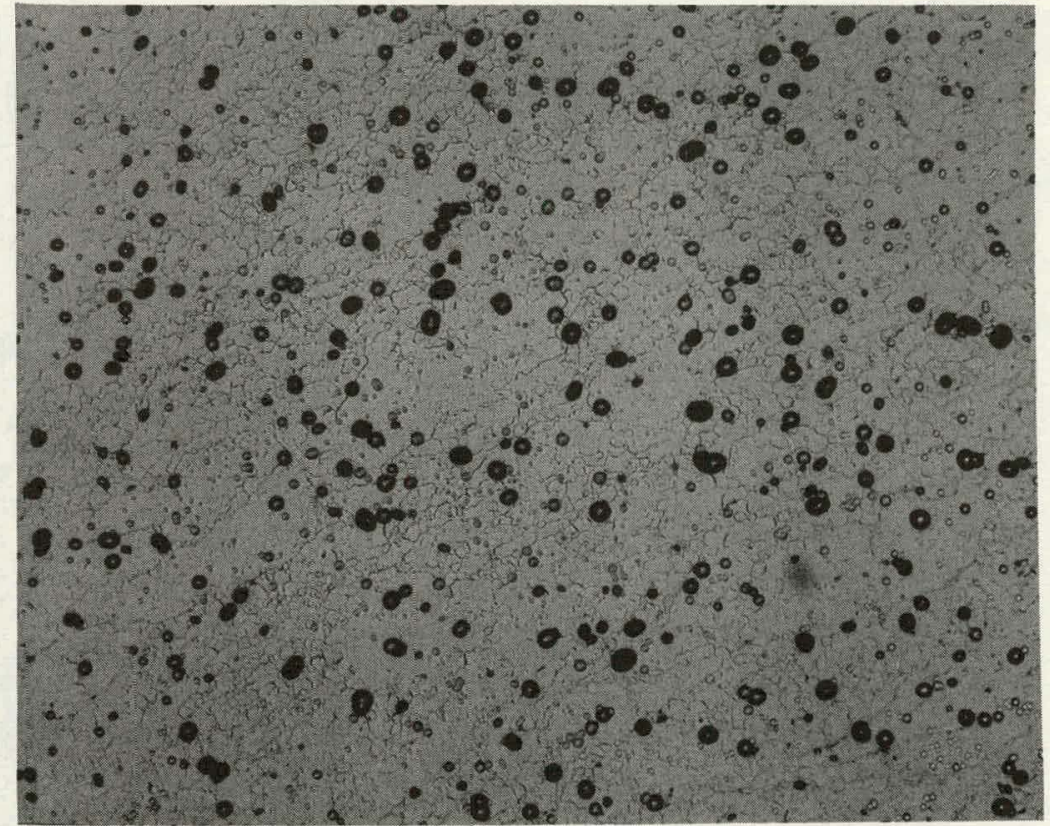

(b) Opposite End.

Figure 26. METALLURGical StRucture OF SAMPLE 2H. (Part 16; Cathodic Etch; 100X) 
To determine the amounts of various alloying metals in the inclusion areas, a microprobe analysis of Sample $2 \mathrm{H}$ was conducted. The approximate weight percent concentration levels of the alloying metals found in Sample $2 \mathrm{H}$ are given in Table 2. Figure 27 also shows the secondary electron images of the two ends of the Sample $2 \mathrm{H}$. The white spots are inclusions; the black spots are voids caused by the etching processes. Aluminum, silicon, iron, and chromium characteristic $X$-ray images of the areas shown in Figure 27, View c, are presented in Figure 28.

Table 2

MICROPROBE ANALYSIS RESULTS OF SAMPLE $2 \mathrm{H}$

\begin{tabular}{lccc}
\hline $\begin{array}{c}\text { Alloying Metals } \\
\text { in Sample 2H }\end{array}$ & $\begin{array}{c}\text { Average Weight } \\
\text { Percent Concentration } \\
\text { in Matrix } \\
(\%)\end{array}$ & $\begin{array}{c}\text { Average Weight } \\
\text { Porcent Concentration } \\
\text { in Inclusions } \\
(\%)\end{array}$ & $\begin{array}{c}\text { Range of Weight } \\
\text { Persent Concentration } \\
\text { in Inclusions } \\
\text { (\%) }\end{array}$ \\
\hline Silicon & 0.12 & 1.3 & 0.8 to 1.8 \\
Chromium & 0.16 & 1.4 & 0.9 to 1.8 \\
Iron & 0.18 & 10.7 & 7.1 to 13.8 \\
Copper & 0.16 & 0.6 & 0.3 to 0.8 \\
Magnesium & 1.4 & 0.8 & \\
\hline
\end{tabular}

Magnesium was fluoresced by the aluminum characteristic $X$ rays; therefore, the $1.4 \%$ average-weight-percent value in Table 2 is probably biased high and the magnesium concentration is probably lower than reported. Concentrations of silicon, chromium, and iron are approximately 11, 9, and 60 times, respectively, larger in the inclusion areas than in the aluminum matrix. These high concentrations of alloying metals in small areas could very possibly have a direct effect on the inaccuracies of the ultrasonic wall-thickness measurements.

DXT measurements on Part 13 whose wall thickness varied by only 0.0007 inch, peak to peak, revealed a DXT variation as large as 0.0042 inch around the cırcumference of the part. However, a high-energy $\mathrm{X}$-ray examination suggested that variations in grain size were influencing the DXT measurements.

To further determine if the metal structure of the Type 6061 aluminum cylinders was influencing the wall thickness measurements, a 0.2 -inch-thick pure aluminum plate (99.999\%) was measured. Ultrasonic and LVDT thickness measurements of the pure aluminum plate agreed within \pm 400 microinches; and, also, no peaks similar to those observed in the aluminum cylinders were ultrasonically detected.

Based upon the preceding laboratory analyses, it is concluded that the physical properties of Type 6061 aluminum caused the inaccuracies in the ultrasonic wall-thickness measurements. Apparently, wide variations in grain size, changes in the structure of the basic aluminum matrix, and a high concentration of alloying metals in inclusion areas significantly influenced the velocity of ultrasonic sound through Type 6061 aluminum.

To determine what materials can be accurately measured ultrasonically, the wall thickness of seven cylinders of different materials was measured conventionally and ultrasonically. 


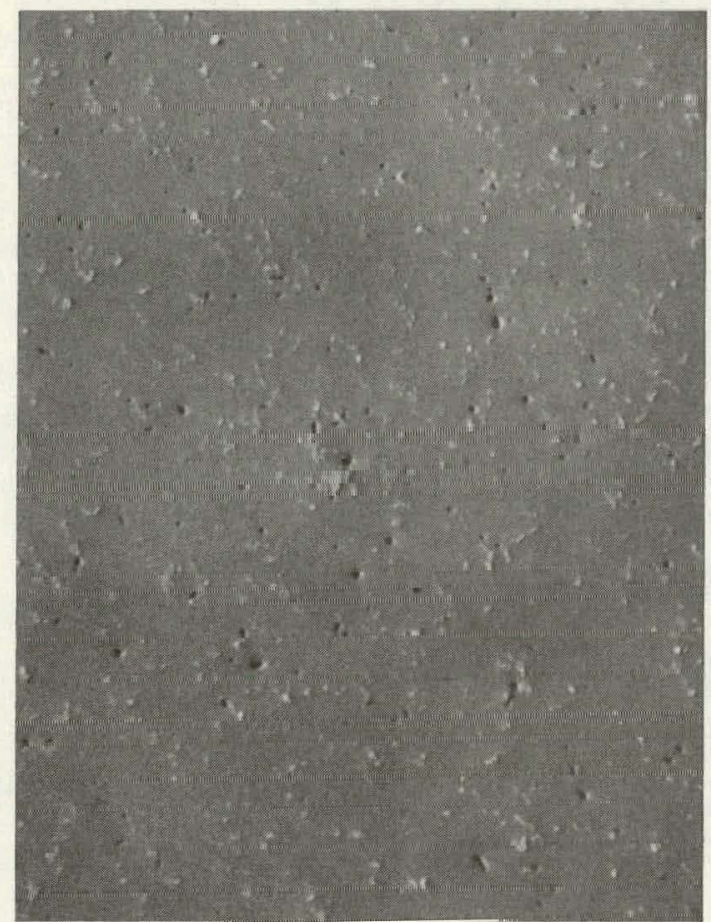

(a) $X$ End. (100X)

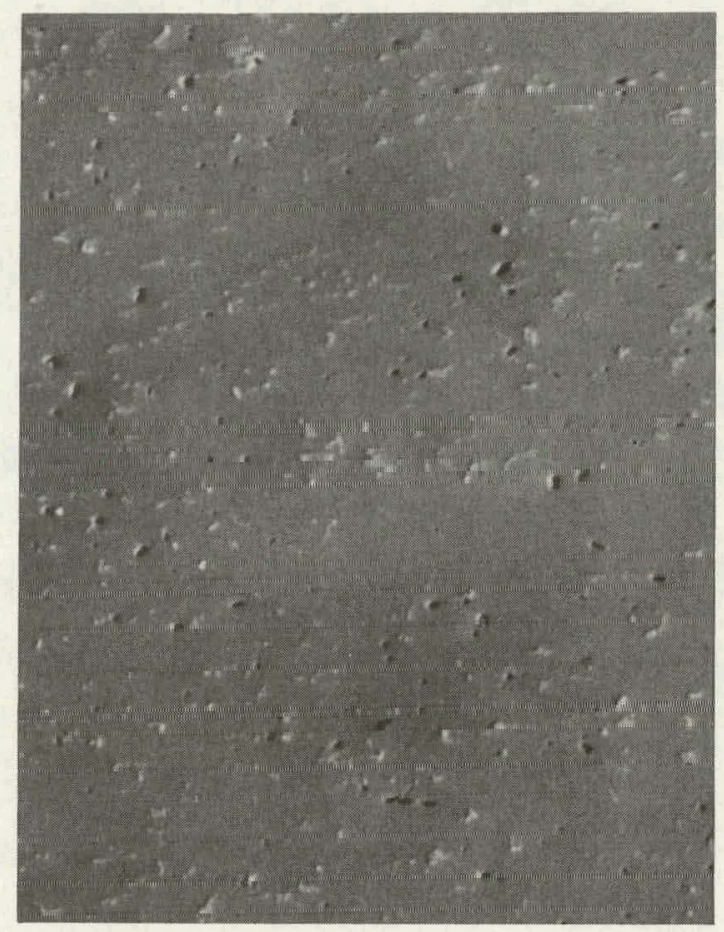

(b) Opposite End. (100X)

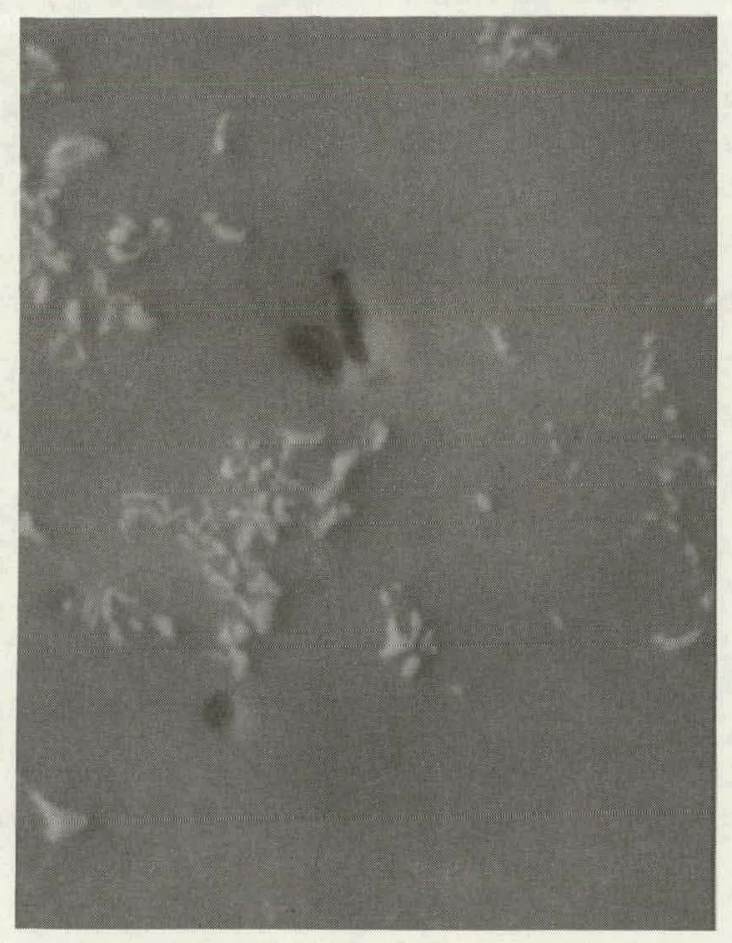

(c) $X$ End. $(1000 X)$

Figure 27. SECONDARY ELECTRON IMAGES OF SAMPLE $2 \mathrm{H}$. 


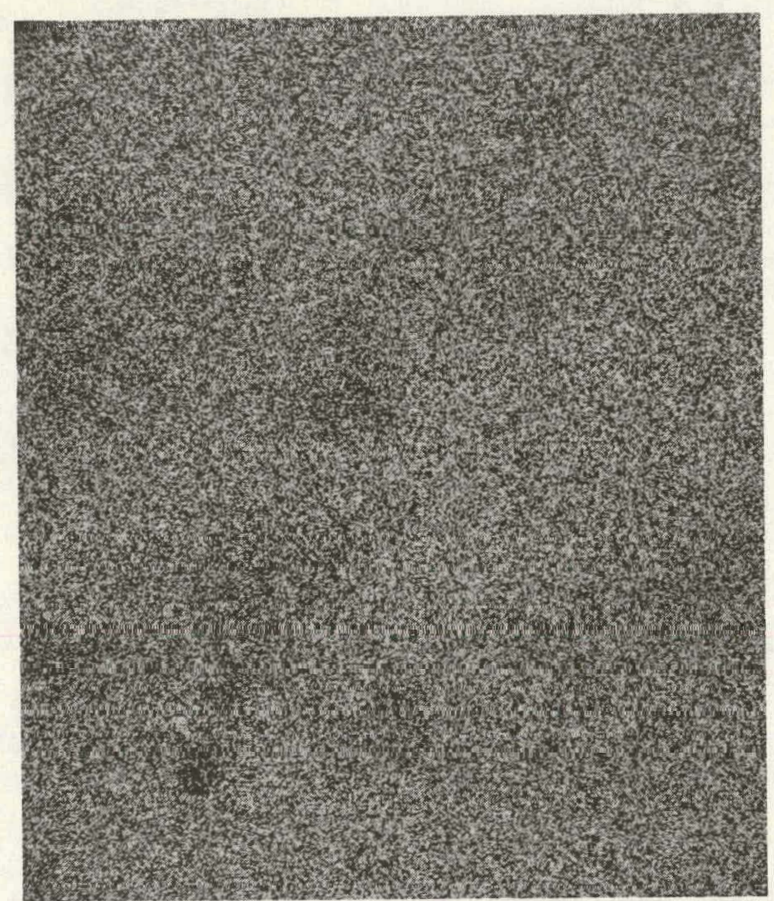

(a) Aluminum.

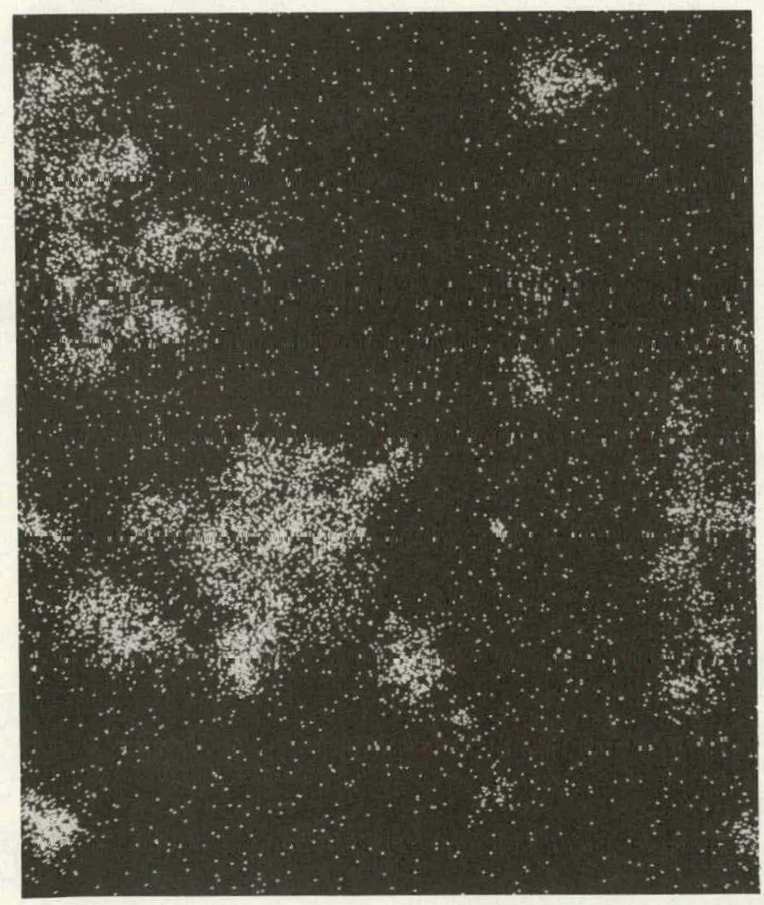

(c) Iron.

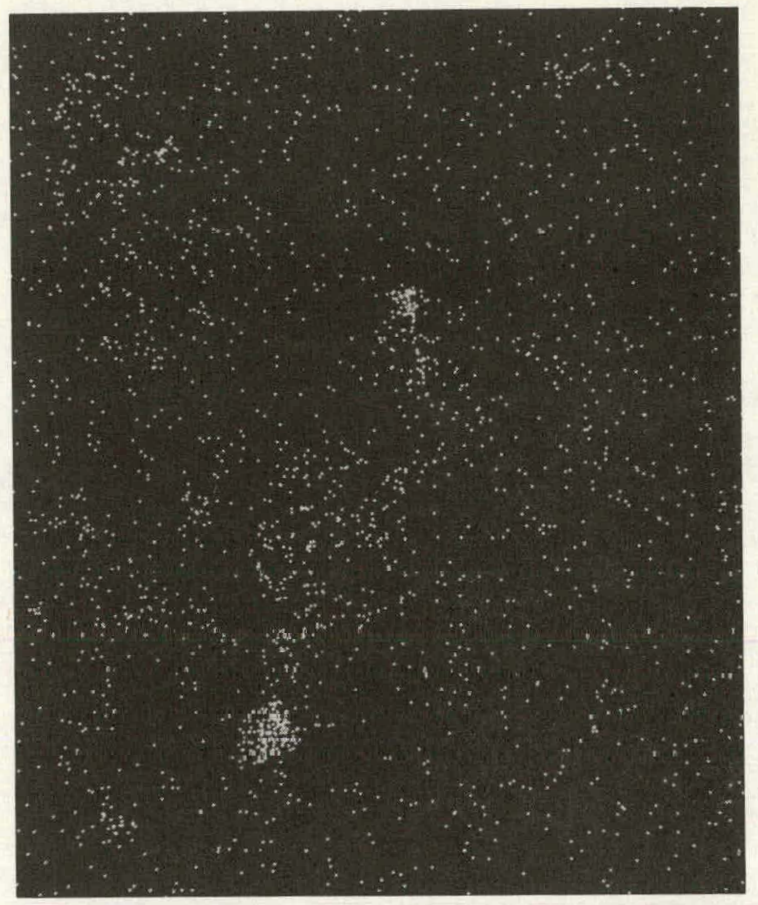

(b) Silicon.

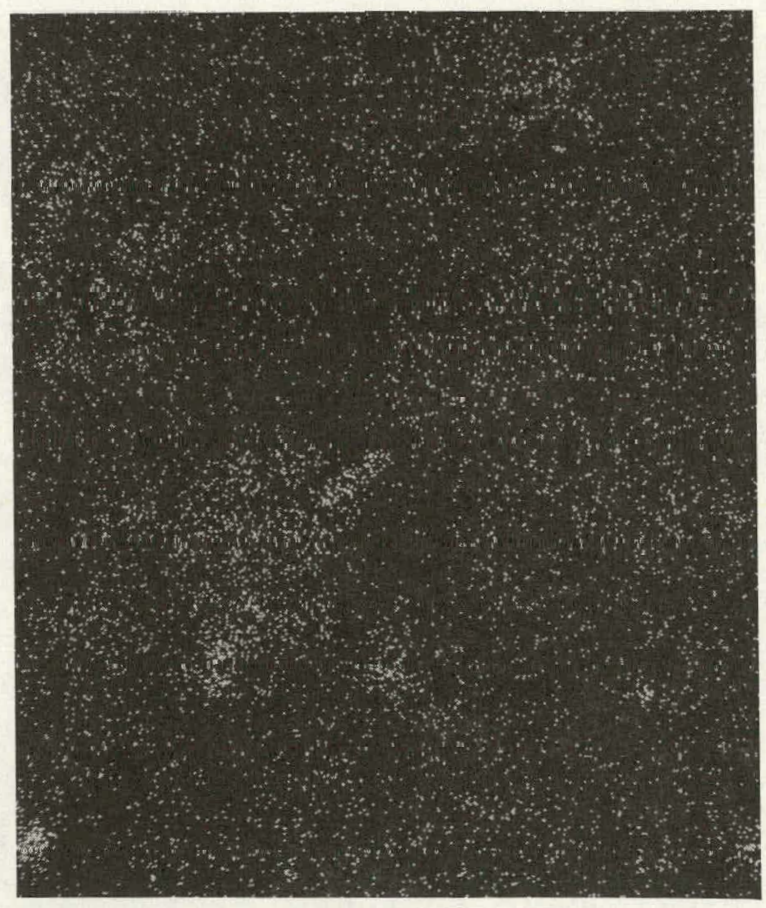

(d) Chromium.

Figure 28. X-RAY IMAGE CHARACTERISTICS OF SAMPLE 2H. (1000X) 
The ultrasonic and LVDT thickness measurements of two uranium alloy cylinders agreed with each other to within 0.0005 inch, Table 3. Ultrasonic and LVDT wall-thickness measurements of the second uranium alloy part are seen in Figure 29. The other cylinders showed larger magnitudes of disagreement between the ultrasonic and conventional measurements. Of all the cylinders inspected, none displayed the large peaks observed in the Type 6061 aluminum parts, but all did display thickness variations of different magnitudes which were not measured in the conventional thickness measurements. These apparent thickness variations of the different materials were a function of the position on the circumference of the cylinders. Therefore, material characteristics of the different metals are the probable cause of the differences between the ultrasonic and conventional thickness measurements.

Table 3

INSPECTION DATA FOR URANIUM ALLOY CYLINDERS

\begin{tabular}{|c|c|c|c|c|c|}
\hline Cylinder Type & $\begin{array}{c}\text { Nominal } \\
\text { OD } \\
\text { (in) } \\
\end{array}$ & $\begin{array}{c}\text { Nominal } \\
\text { Wall } \\
\text { Thickness. } \\
\text { (in) }\end{array}$ & $\begin{array}{c}\text { Ultrasonic } \\
\text { Wall Thickness } \\
\text { Variation } \\
\text { (mils, } \\
\text { peak to peak) }\end{array}$ & $\begin{array}{l}\text { Ultrasonic } \\
\text { Ripple } \\
\text { Deviations } \\
\text { (mils) }\end{array}$ & $\begin{array}{c}\text { Mechanical } \\
\text { Wall Thickness } \\
\text { Variations } \\
\text { (mils, } \\
\text { peak to peak) }\end{array}$ \\
\hline Uranium Alloy & 9.9 & 0.167 & 1.0 & 0.12 & No Data \\
\hline Uranium Alloy & 9.9 & 0.167 & 1.2 & 0.12 & 1.2 \\
\hline
\end{tabular}

\section{Sources of Error Affecting the Machining Accuracy}

Analysis of the wall-thickness machining system revealed several sources of error inherent within the system. Each source of error is described in this section, and its relative effect upon the accuracy of the machining system is evaluated.

The first source of error which has the most significant influence upon the machining accuracy of the system is the following error or phase lag of the servo system. The forcing function of the servo system under actual operating conditions is the movement of the back surface of the revolving cylinder. This movement is not a true sinusoidal function, but it is a smoothly varying periodic function whose fundamental frequency component is equal to the frequency of rotation of the cylinder. The bandwidth of the servo system was increased so that the system can accurately follow the fundamental and the first several harmonic frequency components of the forcing function accurately and thus machine a cylinder whose wall thickness will be of constant thickness to within a small tolerance. To analyze the magnitude of the following error of the servo system, assume that the forcing function and the system response are sinusoidal signals:

$$
\begin{gathered}
\text { Error }=\text { Input }- \text { Output, or } \\
\text { Error }=A \sin w t-B \sin (w t-\phi),
\end{gathered}
$$

where $A$ and $B$ are the magnitudes of the input and output sinusoidal signals and $\phi$ is the phase lag between the two signals. For simplicity, assume that the rotational speed of the 


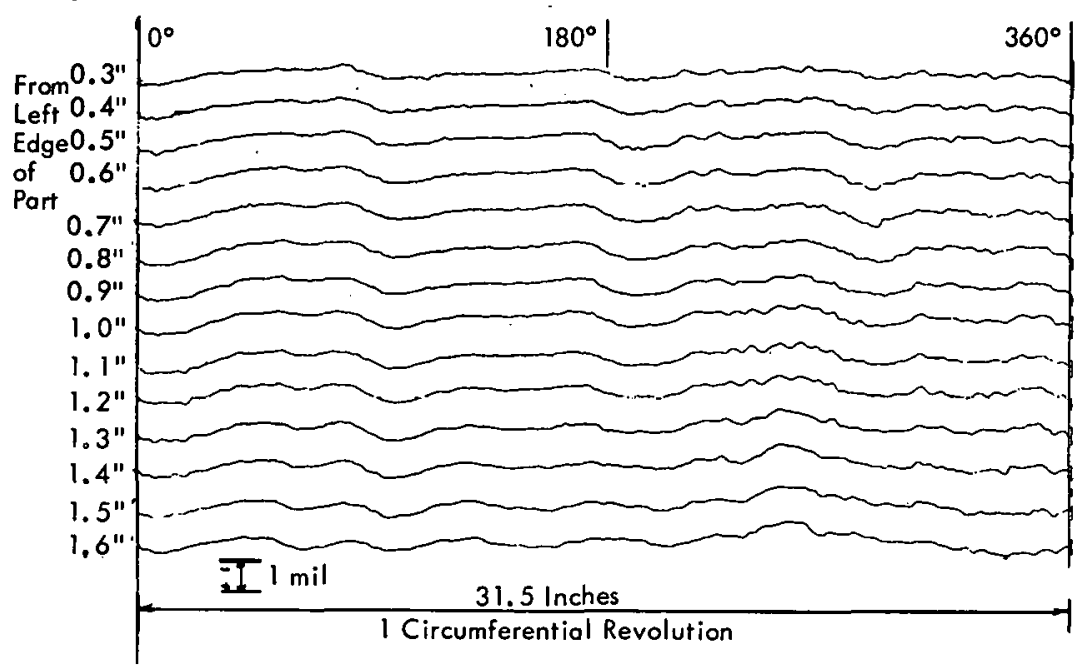

(a) Ultrosonic Profile.

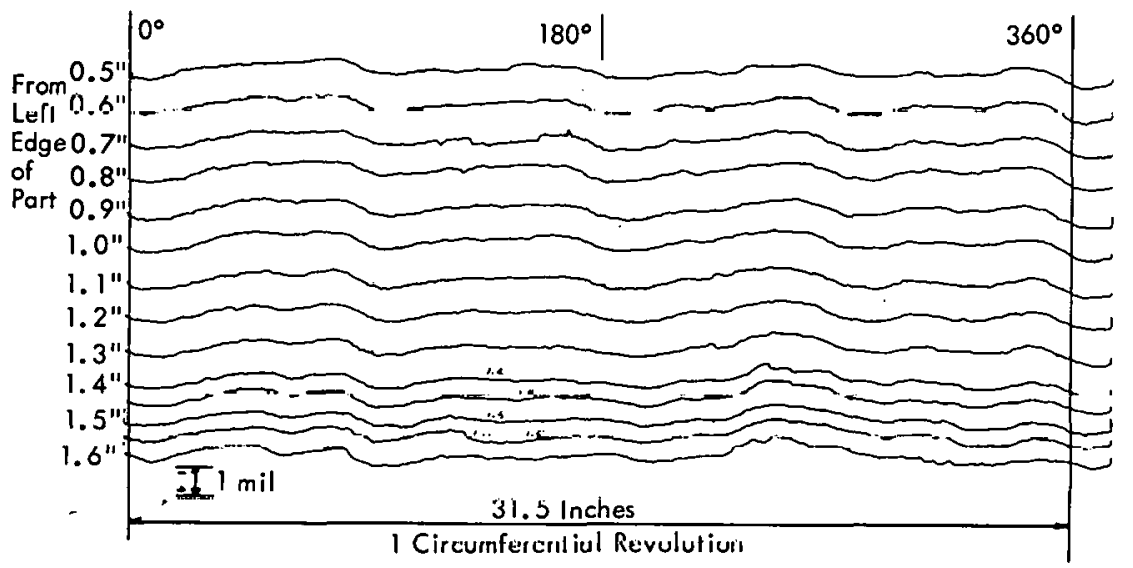

(b) Mechanical Profile.

Figure 29. WALL.THICKNESS PROFILES FOR A URANIUM ALLOY CYLINDER.

(Part 2; OD, 9.9 inches; Length, 1.7 inches; Wall Thickness, 0.167 inch; Chart Calibration. 4.1 units/0.001 inch)

cylinder is 5 revolutions per second (rps). From the experimentally determined transfer. function of the system, Figure 20, the phase lag angle is $6^{\circ}$ and the magnitude is $0 \mathrm{db}$ at $5 \mathrm{~Hz}$. Thus, $A=B, \phi=6^{\circ}$, and $w=10 \pi$.

So:

$$
\text { Error }=A(\sin w t-\sin (w t-60))
$$

Using the trigonometric identity:

$$
\sin A-\sin B=2 \cos \frac{(A+B)}{2} \sin \frac{(A-B)}{2},
$$


one obtains:

$$
\text { Error }=2 A \sin (\phi / 2) \cos (w t-\phi / 2) \text {. }
$$

Substituting appropriate values for $w$ and $\phi$, and $A=0.005$ inch:

$$
\begin{aligned}
& \text { Error }=(0.01 \mathrm{in}) \sin 3^{\circ} \cos \left(10 \mathrm{wt}-3^{\circ}\right), \text { or } \\
& \text { Error }(\text { peak to peak })=2(0.01 \mathrm{in}) \sin 3^{\circ} \text {, or } \\
& \text { Error (peak to peak })=0.001 \mathrm{in} .
\end{aligned}
$$

It is obvious that the following error of the servo system is a cosinusoidal signal whose amplitude is dependent upon $\phi$, the phase lag of the servo system. The following error is a measure of the thickness that the servo system is failing to machine from the part. The following error is machined into the part and is detected as a small-amplitude variation in the wall thickness of the part. In the preceding example, the wall-thickness variation was theoretically reduced from 0.01 to 0.001 inch. Because of the following error, the servo system is not capable of machining the part to any smaller wall-thickness tolerance.

Two methods may be utilized to reduce the magnitude of the following error: One method is to decrease the phase lag of the servo system at the lower frequencies of interest, the second is to compensate for the phase lag by placing the ultrasonic probe physically ahead of the cutting tool.

Both methods were utilized in the development of the wall-thickness machining system. One design criterion of the frequency-compensation network is to minimize the phase lag of the servo system. This minimization is accomplished by increasing the bandwidth of the system and increasing the DC system gain. But, a compromise must be reached in increasing the DC gain. As the DC gain is increased, the system becomes more oscillatory as it approaches instability. The DC gain is increased until the system has a $30 \%$ overshoot to a step response. This value is considered to be the optimum gain setting.

The second method was incorporated into the system by placing the ultrasonic probe $6^{\circ}$ ahead of the cutting tool, Figure 14. This tool-probe geometry actually cancels out $6^{\circ}$ of the system phase lag by adding $6^{\circ}$ of mechanical phase lead. The magnitude of the angle was determined primarily from the experimental closed-loop frequency response, Figure 20.

Analysis of the tool-probe fixture reveals that movement of the cutting tool in response to the servo system contributes a small machining error. The source of the error is the positioning of the ultrasonic probe above the tool in a plane tilted $6^{\circ}$ above the horizontal. The probe measures distance along a radial line passing through the center of the part. But, it is physically attached to the tool and is constrained to move in a horizontal plane.

Figure 30 shows the movement of the tool and probe in response to the inner surface of a cylinder moving from Arc TV to Arc WY. The arc actually moved the radial distance, $x$, but the tool and probe are constrained to move the horizontal distance, $a$. The probe moved along the line from Point $C$ to Point $B$ in order to reposition itself a fixed distance from the back surface of the cylinder. The tool moved from Point $E$ to Point $G$ and, in doing so, 

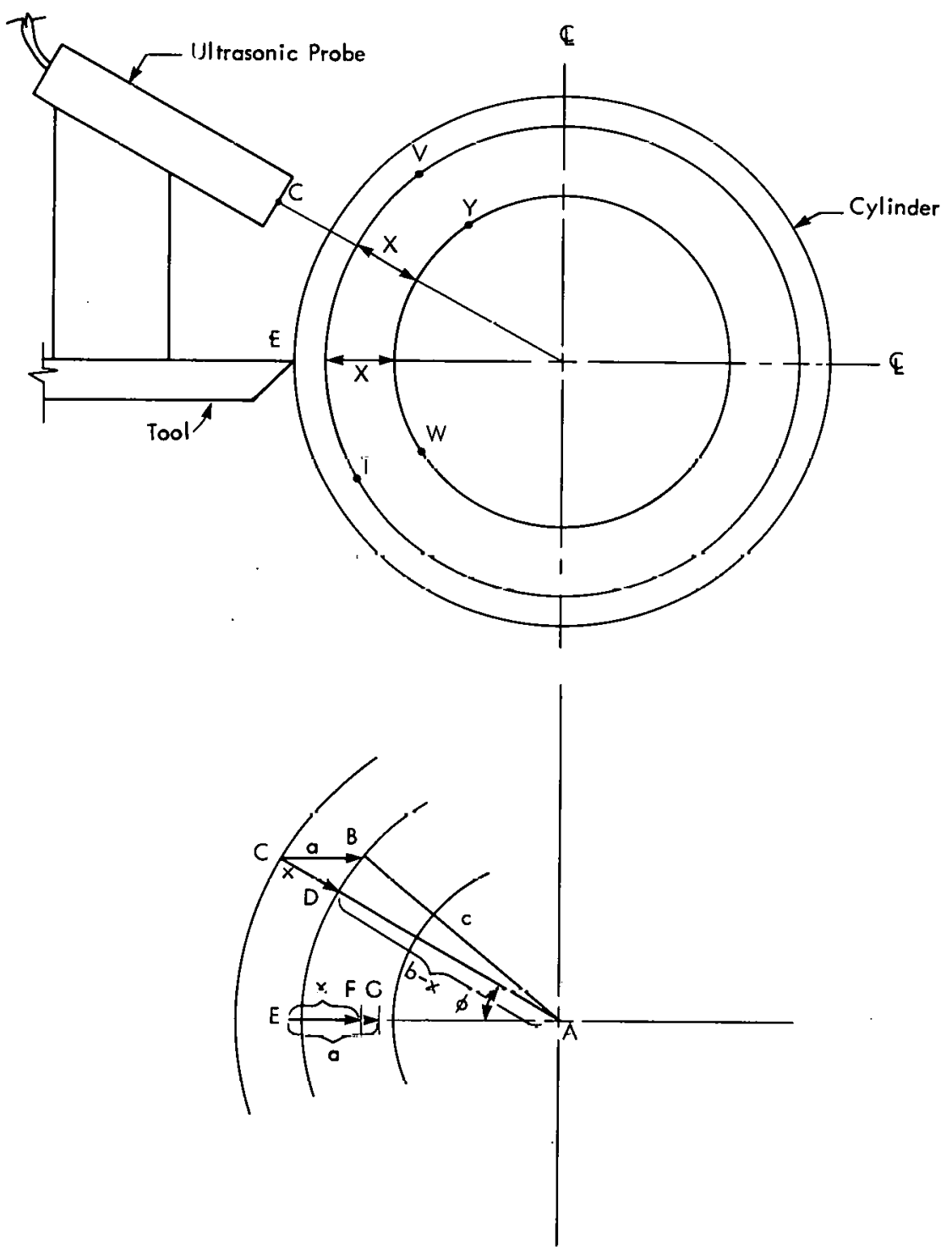

Figuro 30. ANALYEIG OT ERnON IN TOOL-rnODC MOVEMLNT.

actually moved farther than the radial movement of the inner wall. The error of movement is the difference detween Distance a and Distance $x$ :

$$
\text { Error } \equiv \mathbf{a}-\mathbf{x} \text {. }
$$

Using the mathematical equation to express the length of the side of an oblique triangle as a function of the other two sides and the enclosed angle, for Triangle ABC:

$$
\begin{aligned}
& c^{2}=a^{2}+b^{2}-2 a b \cos \phi, \text { or } \\
& a^{2}=2 a b \cos \phi-b^{2}+c^{2},
\end{aligned}
$$




$$
\begin{gathered}
a^{2}-2 a b \cos \phi=c^{2}-b^{2}, \text { or } \\
a^{2}-2 a b \cos \phi+b^{2} \cos ^{2} \phi=c^{2}-b^{2}+b^{2} \cos ^{2} \phi, \text { or } \\
a-b \cos \phi= \pm \sqrt{c^{2}-b^{2}+b^{2} \cos ^{2} \phi}, \text { or } \\
a-b \cos \phi= \pm \sqrt{c^{2}-b^{2} \sin ^{2} \phi}, \text { or } \\
a= \pm \sqrt{c^{2}-b^{2} \sin ^{2} \phi+b \cos \phi} .
\end{gathered}
$$

From Figure 30 , because all radii of a circle are equal:

$$
\begin{gathered}
b-x=c \text {, so } \\
a= \pm \sqrt{(b-x)^{2}-b^{2} \sin ^{2} \phi+b \cos \phi}, \text { or } \\
a= \pm \sqrt{b^{2} \cos ^{2} \phi+x(x-2 b)+b \cos \phi} .
\end{gathered}
$$

Thus:

$$
\text { Error }= \pm \sqrt{b^{2} \cos ^{2} \phi+x(x-2 b)+b \cos \phi-x} .
$$

Assuming a cylinder of 8 inches in diameter, a nominal wall thickness of 0.1 inch, a maximum inner surface movement of 0.010 inch, and $6^{\circ}$ between the probe and tool, the maximum error of tool movement is only $\mathbf{4 0}$ microinches. This amount of error is very small and does not significantly affect the accuracy of the machining system.

Figure 31 is a plot of the error of tool movement as a function of the probe radial movement and mechanical angle between tool and probe. It shows that the error of tool movement can become a significant error if the mechanical angle becomes large, along with large movement of the ultrasonic probe. Thus, as a design criterion, it is better to keep the mechanical angle small. If the mechanical angle is equal to or less than $8^{\circ}$, the error-of-tool movement will be equal to or less than one percent of the probe radial movement.

Horizontal offset between the ultrasonic probe and tool is another small source of error. This offset is necessary because the reflectoscope system cannot operate properly when the ultrasonic probe is looking at the surfaces cut by the tool. The probe must be positioned normal to the surfaces from which the ultrasonic sound is being reflected. This small offset of 0.1 inch probably adds a small error to the machining system because the ultrasonic probe is actually measuring wall thickness to one side of the position where the tool is cutting. But the error is not considered significant because experimental wall-thickness inspections show that the wall thickness changes very slowly along a line parallel to the axis of rotation of the cylinders.

A phenomenon which may cause an error in the water-path measurement is the change of the velocity of ultrasonic sound in water as a function of temperature. A secondary function of the reference surface is to reduce the magnitude of the water-path measurement error. The reference surface actually reduces the water path to be measured from 1.2 inches to approximately 0.1 inch. 


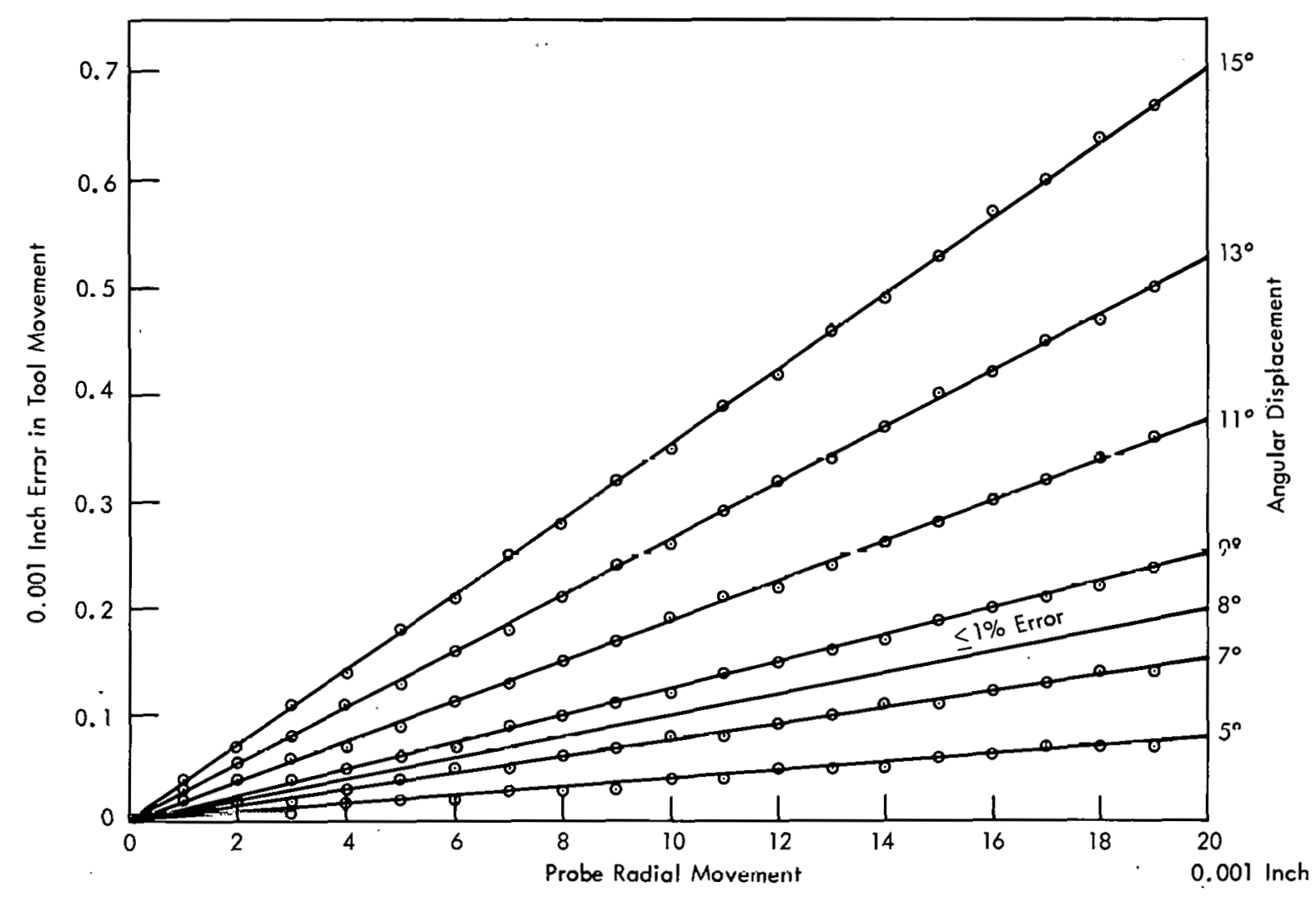

Figure 31. TOOL-MOVEMENT ERROR AS A FUNCTION OF THE PROBE RADIAL MOVEMENT. (Diameter of Part, 8 inches)

The thickness-readout module measures time which is directly proportional to the distance being measured. Assuming that the water-path time period remains constant, a mathematical expression can be obtained for the error-of-thickness measurement as a function of temperature. The velocity of sound in water at $13^{\circ} \mathrm{C}$ is $4728 \mathrm{ft} / \mathrm{sec}$; at $19^{\circ} \mathrm{C}$, it is 4794 $\mathrm{ft} / \mathrm{sec}$. Plotting a straight line through these two points, a value of $\mathrm{dV} / \mathrm{dT}=132 \mathrm{in} / \mathrm{sec}-0 \mathrm{C}$ or $73.3 \mathrm{in} / \mathrm{sec}{ }^{\circ} \mathrm{F}$ is obtained.

Equation 39 is the familiar equation for distance as a function of time and velnçity:

$$
D=t V
$$

where:
$t$ represents the time, in sec,
$V$ the velocity, in $\mathrm{ft} / \mathrm{sec}$, and
D the distance, in $\mathrm{ft}$.

The velocity of sound in water is a function of temperature: 


$$
D=t V(T)
$$

where:

$\mathrm{T}$ represents the temperature in ${ }^{\circ} \mathrm{F}$.

Therefore:

$$
\begin{gathered}
d D=(\partial D / \partial t) d t+(\partial D / \partial V) d V, \text { or } \\
d V=(\partial V / \partial T) d T, \text { or } \\
d D=(\partial D / \partial t) d t+(\partial D / \partial V)(\partial V / \partial T) d T, \text { or } \\
\partial D / \partial V=t,
\end{gathered}
$$

if $\mathrm{T}$ is constant.

Furthermore:

$$
d D=(\partial D / \partial t) d t+t(\partial V / \partial T) d T
$$

and $t$ is constant.

Also:

$$
d D=t(\partial V / \partial T) d T
$$

The time required for sound to travel through 0.1 inch of water at $13^{\circ} \mathrm{C}$ is $1.76 \times 10^{-6}$ sec, thus:

$$
\begin{gathered}
\mathrm{dD}=\left(1.76 \times 10^{-6} \mathrm{sec}\right)(73.3 \mathrm{in} / \mathrm{sec} \circ \mathrm{F}) \mathrm{dT}, \text { or } \\
\mathrm{d} \overline{\mathrm{D}}=0.129 \times 10^{-3} \mathrm{in} /{ }^{\circ} \mathrm{F} \mathrm{dt} .
\end{gathered}
$$

Thus, if the water path is only 0.1 inch, a measurement error of only 130 microinches is caused by a $10 \mathrm{~F}$ change in the temperature of the water path. If the water path is 1.2 inches, the error would be 12 times as large. Thus, addition of the reference surface close to the metal shim has significantly reduced the water path to be measured and also has reduced the measurement error of the water path caused by water temperature variations.

\section{Machining Tests to Evaluate the System Performance}

In preparation to machine two uranium alloy cylinders, a test was made to determine how accurately the reflectoscope system can measure the inner contour (IC) runout of one of the cylinders. The cylinder had been distorted in previous setups so that it was impossible to mount the part in the chuck of the lathe without IC runout. An LVDT probe positioned 
inside the cylinder and directly in line with the ultrasonic probe measured the IC runout of the part. The ultrasonic probe positioned outside the cylinder also measured the IC. The IC runout is the sum of the outer contour $(\mathrm{OC})$ runout and the wall thickness of the cylinder. The two probe systems were calibrated to each other and their measurements were electronically subtracted. The difference in the two measurements was the inaccuracy of the reflectoscope system. The test showed that the reflectoscope system measured the IC runout of the uranium alloy cylinder to within 500 microinches. The measurement contained small errors caused by the material structure of the uranium alloy and also any setup and calibration errors of the two probe systems.

Two uranium alloy cylinders were machined in order to test the ability of the ultrasonically controlled machining system to machine a constant-wall cylinder. Prior to machining, the back surface runout of each cylinder was approximately 8 mils, peak to peak. Inspection results after machining showed a wall variation of 1.7 and 1.5 mils, peak to peak, respectively, and a surface finish of 80 and 30 microinches $A A$, respectively, for the two cylinders. The 30-microinch AA finish was obtained after reducing both the control system gain and the dither signal amplitude on the second machined part. The machining results are presented in Table 4.

The first part machined had a poor surface finish. Chip weld back apparently due to a chatter-like motion between the tool and part caused this poor finish. To improve the surface finish on the second machined part, the dither signal to the servo valve and the system gain were reduced. The second machined part had an improved surface finish of 30 microinches $A A$ and a small wall-thickness variation.

Data in Table 4 show that the ultrasonically controlled wall-thickness machining system can give improvement over conventional methods in machining parts to a conștant wall

Table 4

MACHINING DATA FOR TWO IIRANIUM ALLOY PARTS

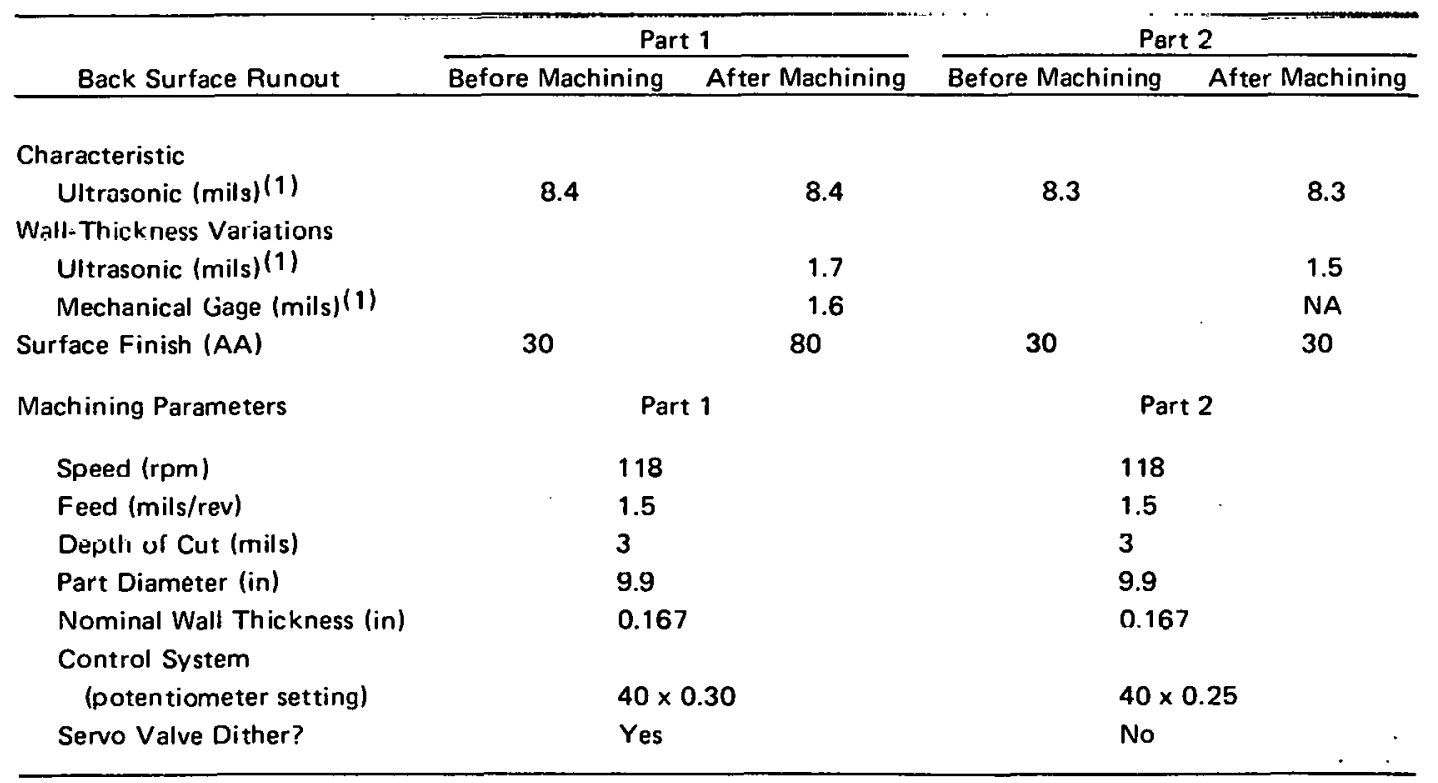

(1) Peak to peak. 
thickness. If the front surfaces of the two cylinders had been machined conventionally, the magnitude of the wall-thickness variations of the finish-machined cylinders would be equal to the IC runout. For example, Part 2 would have a wall thickness variation of 83 mils, peak to peak, if machined conventionally. But, the ultrasonically controlled machining system left a wall variation of only 15 mils, peak to peak, and $80 \%$ improvement over conventional methods.

During machining of the two parts, visual observation showed some random and uncontrolled movement of the tool into the workpiece. The movements were small in amplitude, short in time duration, and limited in the number of occurrences such that characterization was difficult. The effect of the uncontrolled movements was a poorer surface finish in the local area of the occurrences. Several different phenomena could be the probable cause of the random and uncontrolled movement. Fluid turbulence at the surface of the swiftly rotating cylinder could generate random ultrasonic reflections. Also, very small chips could accidently slip past the rubber tubing which successfully prevented large chips from getting in front of the ultrasonic probe.

The uncontrolled movements were random and infrequent and thus did not significantly affect the results of the machining tests. Even though the exact cause of the movements was not identified, any future development and application of the machining system will require elimination of this phenomenon. 


\section{SUMMARY AND CONCLUSIONS}

An electrohydraulic servo system utilizing a reflectoscope system containing two TRMs as the sensor in the feedback path was developed to machine the walls of cylinders to a constant wall thickness. Addition of a second receiver and another TRM enabled the reflectoscope system to make two different thickness measurements concurrently. A frequency compensation network widened the bandwidth of the system to $200 \mathrm{~Hz}$ and increased the DC system gain. The tool-probe assembly was developed to partially compensate the system phase lag at low frequencies with a mechanical phase lead. The machining system demonstrated its ability to machine the wall of an uranium alloy cylinder to within 1.5 mils of being a constant thickness. The machining system showed a definite advantage over conventional methods of machining constant-walled cylinders when the IC runout is several times larger than 15 mils.

One factor which limits the successful application of the ultrasonically controlled machining system "is the material structure of metals. Operation of the thickness-readout modules is dependent upon the principle that sound travels through a material at a constant velocity. Any phenomenon which affects the velocity of sound traveling through a material causes inaccuracies in the ultrasonic thickness measurements. Investigation into the material structure of Type 6061 aluminum metal revealed that variations in grain size, inclusions, and segregations of alloying metals affect the accuracy of the ultrasonic thickness measurements.

Comparison of ultrasonic and conventional wall-thickness measurements of cylinders made from different metals revealed that inaccuracies of varying magnitudes were present in the ultrasonic measurements. A uranium alloy metal was found which showed good agreement between the ultrasonic and conventional thickness measurements. This metal was used to test and evaluate the machining capabilities of the wall-thickness machining system. Thus, the number of metals which may be accurately machined on the machining system is probably small in number.

A second factor limiting the success of the machining system is the high rotational speeds required to machine the cylinders with a single-point tool. The required machining speeds for cylinders in the 8 to 12-inch-diameter range is typically from 100 to $500 \mathrm{rpm}$. Cylinders having previously been distorted by previous machining setups will typically have from two to four lobes of runout of from 2 to 10 -mil amplitude. The bandwidth of the system was increased to $200 \mathrm{~Hz}$ by using a small hydraulic cylinder, a fast-response servo valve, and by electronically compensating the frequency response. But, even with this large bandwidth and a high DC gain, the servo system is incapable of following closely enough the IC runout of fast rotating parts; but, at slow rotating speeds, the metal cutting process is seriously degraded. At higher rotational speeds, the following error is larger and the walls of the finished machined parts have small but undesired thickness variations.

An area that may be considered for future development efforts is the use of rotary tool cutters with the ultrasonically controlled wall-thickness machining system. The machining system may be applied to milling and grinding parts to a constant wall thickness or to a specific shape or other configuration. The need for a high-speed rotating part is eliminated, and the servo system is now capable of accurately following a slow-moving part. This method may be capable of machining parts to within the basic resolution of the ultrasonic sensor. The machining accuracy of the system is still dependent upon the material structure of the part, and only the metals demonstrating accurate ultrasonic thickness measurements should be used. 


\section{REFERENCES}

(1) "Measuring Thickness From One Surface", Measurement and Control, I, pp 410 - 416; September 1962.

(2) Goldman, R.; U/trasonic Technology, Reinhold Publishing Company, New York, New York (1962).

(3) Newman, D. R., Ryden, J., and Lamb, L. T.; Ultrasonic Thickness Measurement for Precision Control of Machine Tools, BNWL-1022 UC 37; Battelle Memorial Institute, Pacific Northwest Laboratory, Richland, Washington; July 1969.

(4) Type UM715 and UM721 Reflectoscope and Accessories Operating and Maintenance Manual; Automation Industries, Incorporated - Sperry Division, Danbury, Connecticut.

(5) McElroy, J. T.; Focused Ultrasonic Beams, TR66-40; Automation Industries, Inc, Research Division, Boulder, Colorado; September 1966.

(6) Saucedo, R. and Schiring, E. E.; Introduction to Continuous and Digital Control Systems, The Macmillan Company, New York, New York (1968).

(7) Dorf, R.; Modern Control Systems, Addison-Wesley Publishing Company, Reading, Massachusetts (1967). 


\section{APPENDIX}

\section{THE SPERRY REFLECTOSCOPE SYSTEM}

\section{Description}

The Sperry Reflectoscope ${ }^{(4)}$ shown in Figure 5, utilizes the pulse-echo method to measure thickness. The main chassis of the system houses the cathode-ray tube (CRT) display, a timing board, the main power supply, and two modules [the master pulser receiver (MPR) and the thickness-readout module (TRM)]. An auxiliary cabinet houses a second TRM, a slave receiver (SR), and two modules containing associated electronic circuits. The fundamental operation of a pulser receiver and a thickness-readout module are discussed in this section.

I he C'RT display shows the ultrasonic pulses that are transmitted and received by the ultrasonic probe. The main transmitted pulse, commonly called the main bang, and its retlections from the front and back surfaces of a 1/4-inch aluminum part are illustrated in Figure A-1. Any segment of the time scale may be displayed by adjusting the display controls.

Figure A-1 also shows the gate signal which is the drop in the horizontal trace of the display. The gate signal indicates that the TRM is measuring the time period between the front-surface and back-surface reflections. This time period is proportional to the thickness of the aluminum part.

The timing board of the reflectoscope system generates all the synchronization signals for the CRT display, the MPR, the SR, and the two TRMs. The frequency rate of the synchronization signals is variable from 400 to $2000 \mathrm{~Hz}$,

The main power supply provides the regulated high-voltage power for operation of the CRT. It also provides low-voltage power for the timing board and the modules in the main chassis.

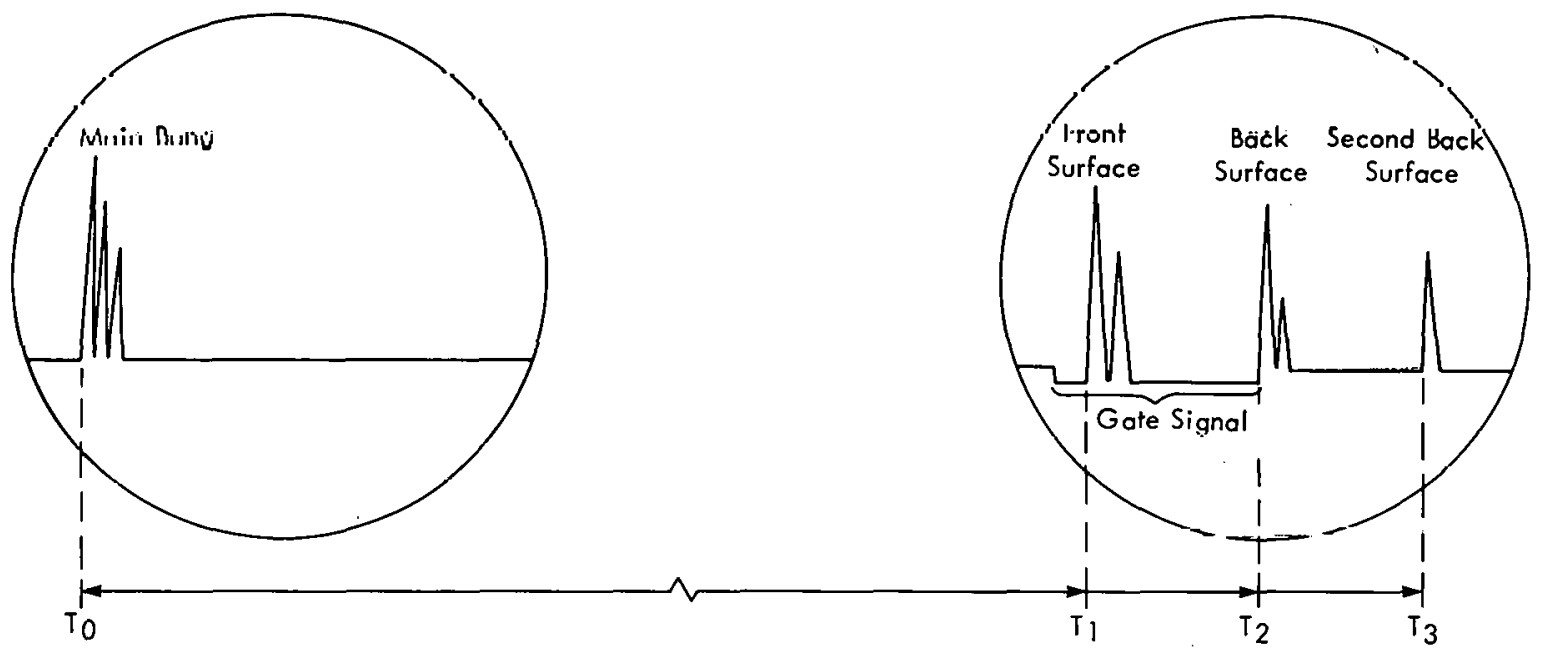

Figure A-1. TYPICAL SPERRY REFLECTOSCOPE CATHODE-RAY TUBE DISPLAYS. (Main Transmitted Pulse and Reflected Pulses from a 1/4-Inch-Thick Aluminum Plate) 
An auxiliary power supply provides low-voltage power to the modules in the bottom auxiliary cabinet.

\section{Pulser Receiver}

A block diagram of the basic pulser receiver is shown in Figure A-2. A high-voltage rectifier provides power to a pulse amplifier. The pulse amplifier receives a synchronization pulse from the main timing board and generates a 600-volt pulse. The pulse-length potentiometer adjusts the time duration of the pulse which is transmitted to the ultrasonic probe. The probe transforms the main-bang pulse into ultrasonic sound and also transforms the reflected ultrasonic pulses into electrical pulses. A four-stage wideband amplifier amplifies the main-bang pulse and the reflected pulses. The sensitivity potentiometer adjusts the gain of the amplifier. The output of the fourth stage of the amplifier is the input signal to the video detector. The ultrasonic pulses are detected by the video detector and are amplified by a two-stage video amplifier. The video pulses are amplified by a video-display driver amplifier and are displayed on the CRT display. The video pulses are also amplified by a thickness-readout-unit driver amplifier and then are applied to the input of the thickness-readout module.

\section{Thickness-Readout Module}

A block diagram of the thickness-readout module is shown in Figure A-3. The function of the module is to measure the time period between any two consecutive ultrasonic pulses which are displayed on the CRT. A meter displays the thickness of the part which is

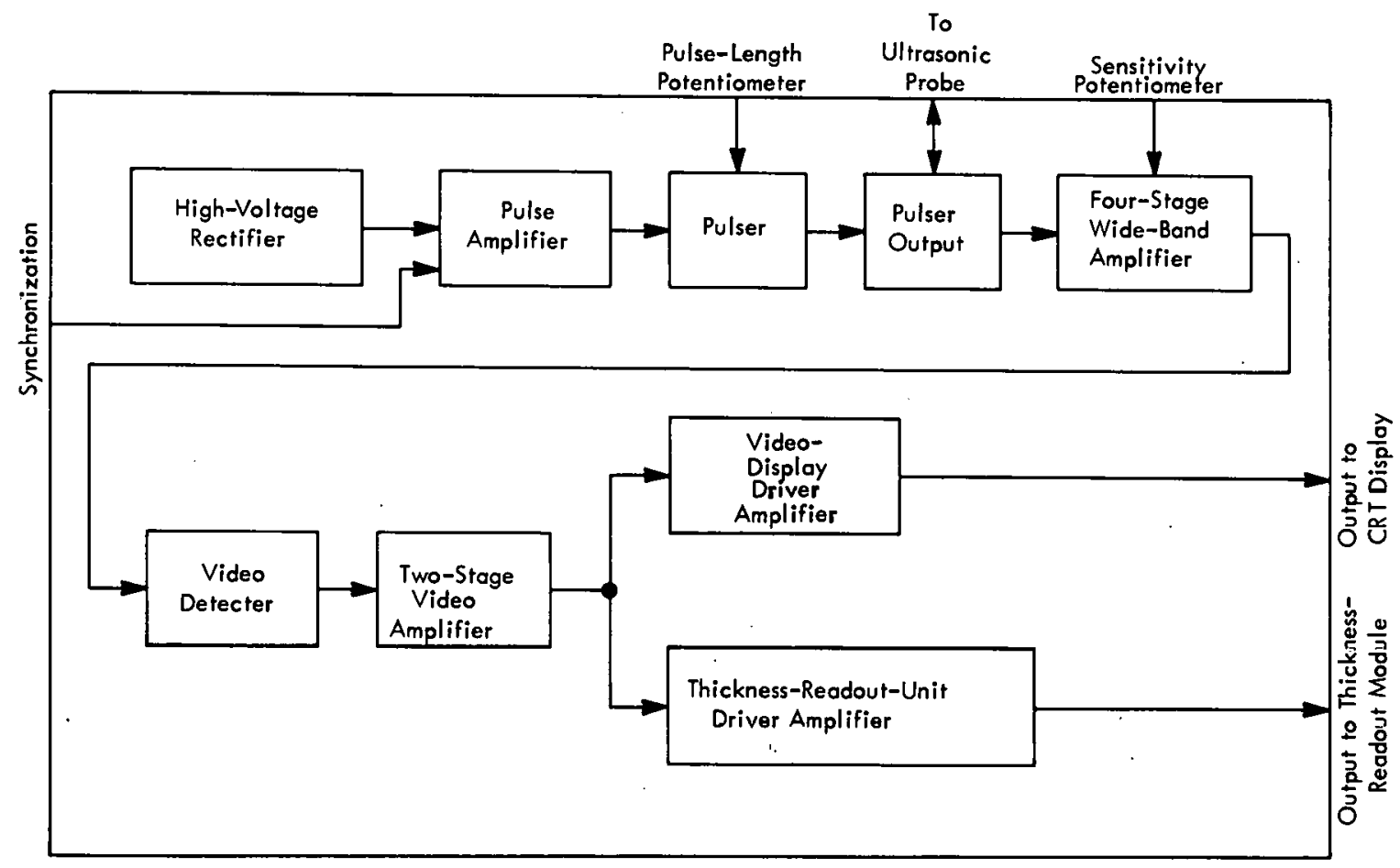

Figure A-2. PRINCIPAL COMPONENTS OF THE PULSER RECEIVER. 


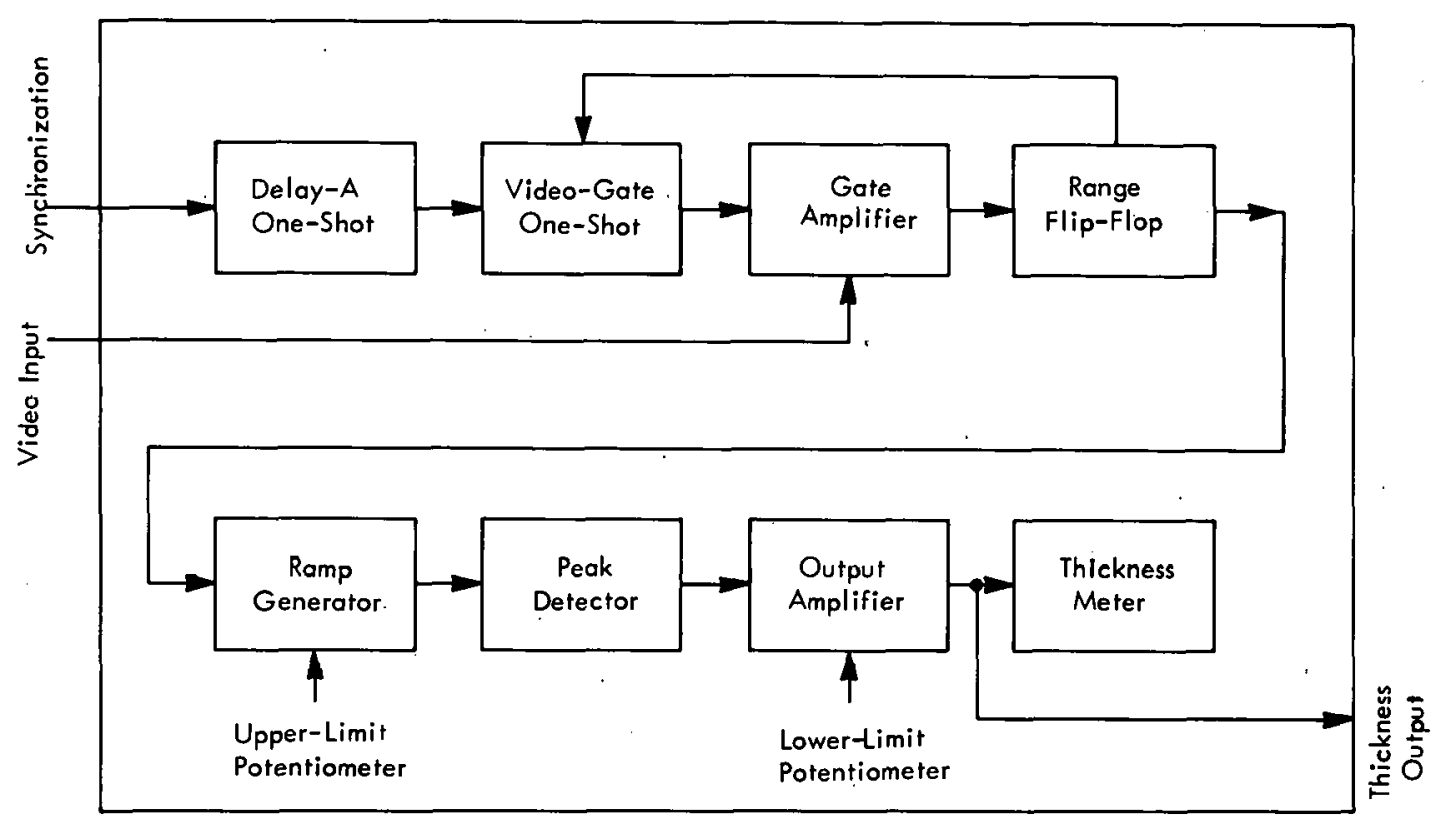

Figure A-3. PRINCIPAL COMPONENTS OF THE THICKNESS-READOUT MODULE.

proportional to the time period measured. Two potentiometers adjust the upper and the lower-limit thickness settings on the meter. The gate potentiometer adjusts the gate signal displayed on the CRT to the left of the first ultrasonic pulse that is to initiate the measurement. The gate signal automatically terminates on the second ultrasonic pulse, indicating completion of the measurement.

Figure A-4 shows the typical sequence of voltage waveforms as the TRM measures the thickness of a part. First, the module receives a synchronization pulse from the main timing board of the reflectoscope system. After a time delay, the video-gate flip-flop is set, and the gate amplifier is opened to allow the two video pulses to pass through to the range flip-flop. The gate signal is initiated on the display when the video-gate flip-flop is set. The two video pulses set and reset the range flip-flop which measures the actual time period between the two pulses. When the range flip-flop resets, the video-gate flip-flop resets, allowing no more video pulses to pass through the gate amplitier. Also, the gate signal is terminated on the CRT display, indicating completion of the measurement. The range flip-flop turns on a ramp generator when it sets and turns it off when it resets. The slope of the voltage ramp generated is adjusted by the upper-limit potentiometer which varies the sensitivity of the thickness measurement. The peak of the generated ramp is deterted by the peak detector which outputs a DC voltage equal to the measured peak. The DC voltage is amplified and then is read on the voltmeter which indicates the thickness.

The range of the TRM is adjusted and the module is calibrated prior to making a series of thickness measurements. For example, assume that the meter is to read thicknesses from 0.1 to 0.2 inch. To adjust the meter, two accurate metal shims, 0.1 and 0.2 inch thick, are measured. The upper-limit potentiometer is adjusted until the meter reads full scale when the thick shim is measured. Conversely, the lower-limit potentiometer is adjusted until the meter reads zero scale when the thin shim is measured. This setup operation is a repetitive 


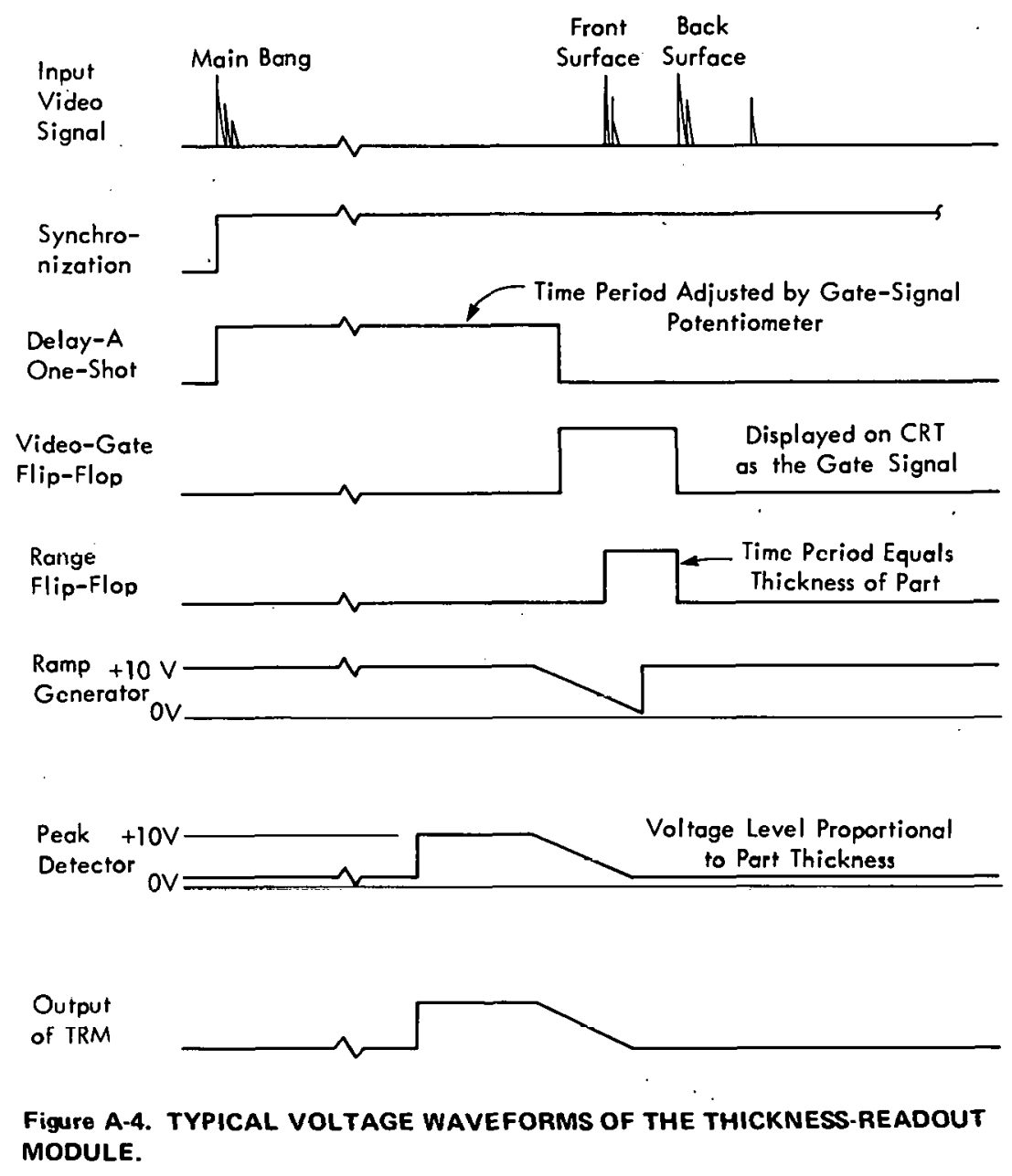

procedure and potentiometer adjustments are made until the meter reads full and zero scale accurately each time the measurements are made. Now, the meter range has been adjusted and the TRM can accurately measure any unknown thickness in the meter range.

After the range of the meter has been accurately adjusted, the module is to be calibrated. Calibration is accomplished by measuring the 0.1 and 0.2 -inch-thick shims again and recording the two respective output voltages. The calibration constant is the difference of the two voltages divided by the difference in the thickness of the two shims. The calibration constant is expressed as millivolts per 1 mil of material. Knowing the calibration constant, the thickness of a part can be accurately recorded on a strip-chart recorder or other similar recording devices. 


\section{ACKNOWLEDGEMENTS}

The author wishes to express his thanks to the Fabrication Development Department of the Oak Ridge Y-12 Plant for providing the opportunity to be involved in this development project.

A word of thanks also is expressed to L. A. Abbatiello and R. E. Hewgley for their assistance as group leaders on this project:

Finally, I wish to thank Dr. W. L. Green of the University of Tennessee for his contribution to the project as a consultant, co-worker, and arivisnr. 


\section{DISTRIBUTION}

Atomic Energy Commission - Oak Ridge

Hickman, H. D.

Zachry, D. S., Jr

Oak Ridge Gaseous Diffusion Plant

Bogdanowicz, W. A.

Carey, L. E.

Wilcox, W. J., Jr

Winkel, R. A.

Oak Ridge Y-12 Plant

Abbatiello, L. A.

Alvey, H. E.

Bernander, N. K.

Burditt, R. B.

Burkhart, L. E.

Denny, A.

Ellingson, R. D.

Foulk, D. L.

Fraser, R. J.

Gritzner, V. B.

Hensley, C. E.

Hewgley, R. E.

Jones, F. W.

Kahl, K. G.

Keith, A.

Kite, H. T.

Lundin, M. I.

Phillips, L. R.

Oliphant, G. W.

Perry, A. E.

Schreyer, J. M.

Smith, H. F., Jr

Smith, R. D.

Stoner, H. H.

Thompson, C. H.

Tilson, F. V.

Weathersby, W. E.

Whitson, W. K.

Yaggi, W. J./Googin, J. M.
Y-12 Central Files (5)

$Y-12$ Central Files (master copy)

$Y-12$ Central Files (route copy)

Y-12 Central Files (Y-12 RC)

\section{Paducah Gaseous Diffusion Plant}

Levin, R. W.

In addition, this report is distributed in accordance with the category UC-38, Engineering and Equipment, as given in the USAEC Standard Distribution Lists for Unclassified Scientific and Technical Reports, TID-4b00. 